\title{
An Optical Diagnostic for Instantaneous Measurements of Soot Volume Fraction, Primary Particle Diameter and Mean Aggregate Radius of Gyration in Large Turbulent Flames
}

\author{
By \\ David Sawires \\ A thesis submitted to The Faculty of Graduate Studies and Research \\ in partial fulfilment of the degree requirements of \\ Master of Applied Science in Mechanical Engineering \\ Ottawa-Carleton Institute for \\ Mechanical and Aerospace Engineering \\ Department of Mechanical and Aerospace Engineering \\ Carleton University \\ Ottawa, Ontario, Canada
}

Copyright $($ C 2017 - David Sawires 


\section{Abstract}

This thesis details the development of an optical diagnostic capable of making simultaneous, instantaneous measurements of the soot volume fraction, soot primary particle diameter, and soot mean aggregate radius of gyration in large, turbulent, nonpremixed flames. A combination of auto-compensating laser induced incandescence and elastic light scattering was used to make the measurements. The produced optical measurement system was validated by quantifying soot within a reference co-annular laminar diffusion flame. Results agreed with the published data at the same flame conditions within precisely calculated measurement uncertainties obtained with Monte Carlo analysis. This analysis revealed that with larger optical measurement volumes the overall uncertainties are dominated by uncertainties in the optical and fractal properties of soot which are common to all optical diagnostics. The results also showed that if the

optical and fractal properties are assumed to be constant, the relative uncertainties arising from measurement noise only are significantly lower. Finally, experiments were completed to investigate the minimum achievable optical measurement volume, where small volumes resulted in overall uncertainties being dominated by measurement noise. The results demonstrate that the developed soot measurement system is ready to be used to make measurements on large turbulent flames. 


\section{Acknowledgements}

First and foremost, I would like to take this opportunity to express my deep gratitude to my thesis supervisor Professor Matthew Johnson. Over the course of the past two years and a half I have learnt so much from Professor Johnson's love and dedication to his research. I consider myself lucky to have been given the chance to be part of his research group. If it was not for your continuous support and guidance both academically and personally during the difficult times I would not have been here today. I will forever be grateful to you for pushing me to finish my degree when nothing seemed to be working. Thank you.

I would also like to thank Dr. Brian Crosland for always being there with answers to my endless questions. Your wealth of knowledge has been of great help and you were always the number one resource that I relied on.

A special thanks also goes out to all the members of the Energy and Emissions Lab at Carleton University. Melina, Brad, Darcy, Jay, Dave, Steve, Nick, Nick, Scott and Carol: you have been like a family to me over the past two years. You guys made my time there an enjoyable one by providing constant support.

Dad, Mom, and Michael. I cannot begin to mention how much I owe you for bearing with me and bringing me here. I am very lucky to be part of our family.

Last but not least, Marina, my lovely fiancé. This degree belongs to you as much as it is to me. You have lived every single moment of it with me from the good ones when things were working to the bad ones where nothing was going right. You were always present and kept me going with your positivity and ambition. We finally made it! 


\section{Table of Contents}

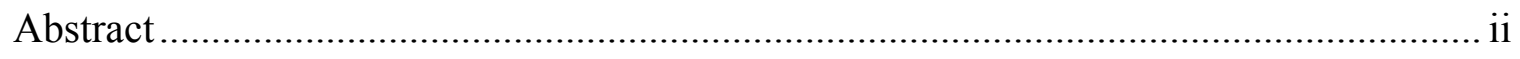

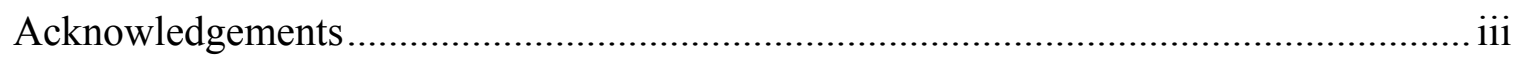

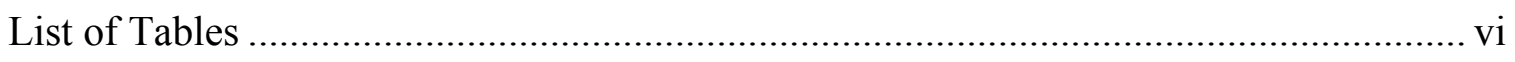

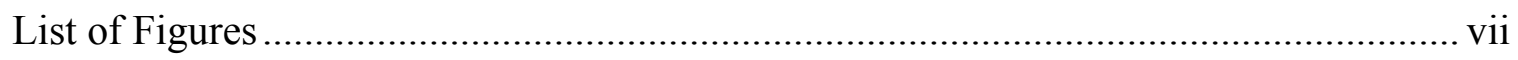

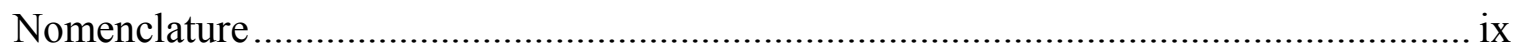

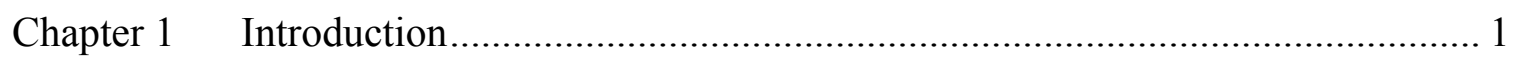

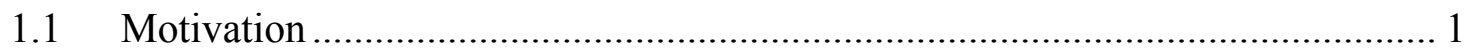

1.2 Current Measurement Techniques …………….......................................... 2

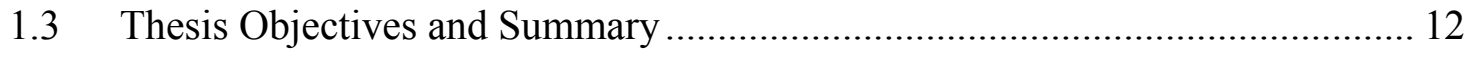

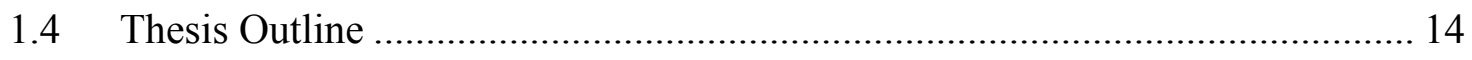

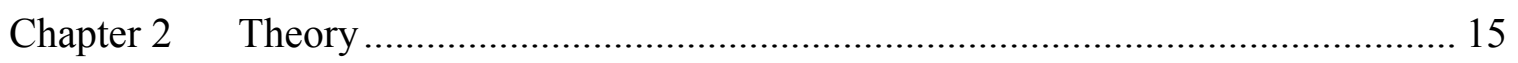

2.1 Soot Volume Fraction via LII Experiment................................................... 15

2.2 Mean Aggregate Radius of Gyration via ELS ............................................... 17

2.3 Primary Particle Diameter via ELS …………………............................... 21

Chapter 3 Experimental Setup and Procedure ………………………....................... 23

3.1 General Arrangement ......................................................................... 23

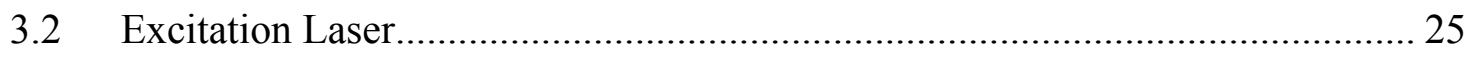

3.3 Collection and Detection Optics and Detectors ………................................. 28

3.3.1 Collection Optics Common to Forward and Backward Directions ............ 29

3.3.2 Backward Angle Detectors and Optics ...................................................... 31

3.3.3 Forward Angle Detectors and Optics........................................................ 32

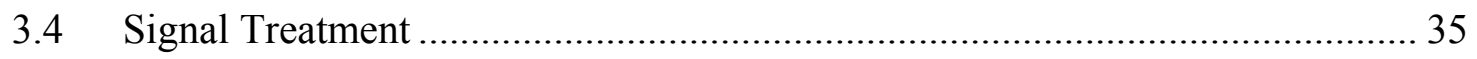




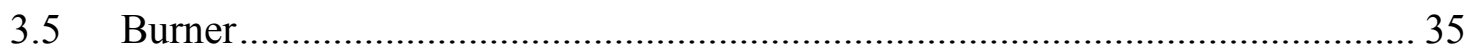

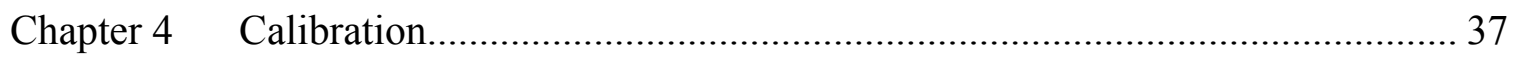

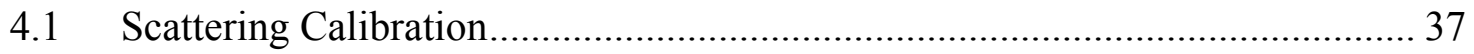

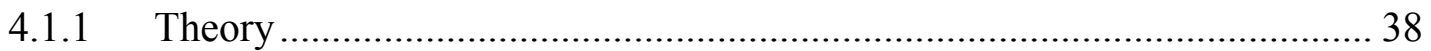

4.1.2 Scattering Calibration Implementation .................................................... 40

4.1.3 ELS Calibration Results with $500 \mu$ m pinhole ........................................... 43

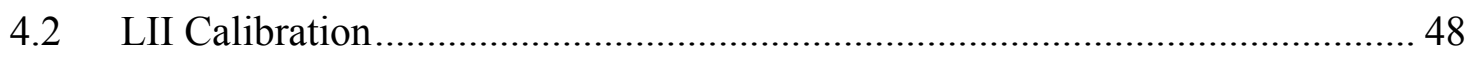

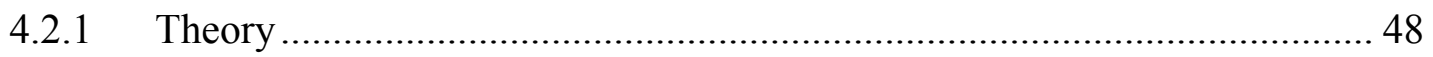

4.2.2 Implementation of the LII Calibration........................................................ 49

4.2.3 LII Calibration Results with $500 \mu \mathrm{m}$ pinhole ............................................ 50

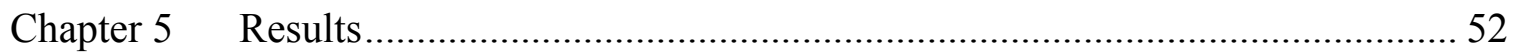

5.1 Soot Measurement Results using the $500 \mu \mathrm{m}$ Pinhole ………………………..... 52

5.2 Uncertainty Analysis with $500 \mu \mathrm{m}$ Pinhole ……............................................. 55

5.3 Measurement Uncertainty with Varying the Pinhole Size …………………...... 61

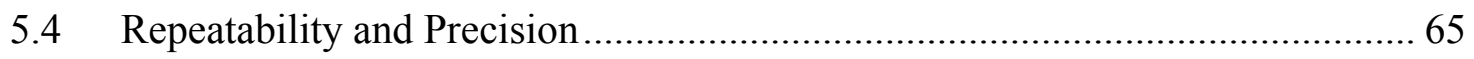

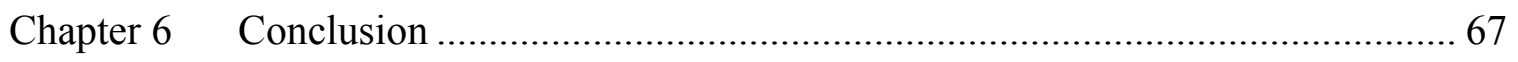

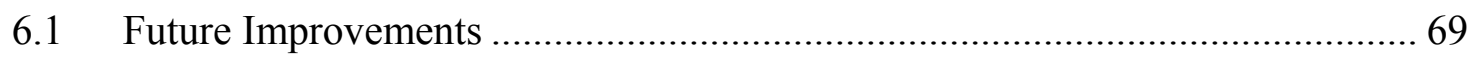

6.1.1 Varying the size of the measurement optics ............................................... 69

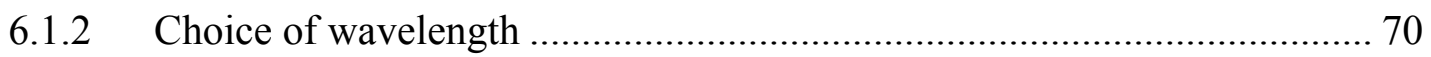

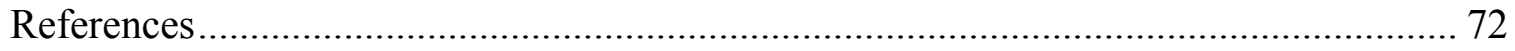




\section{List of Tables}

Table 1.1: Summary of the available relevant measurement techniques that look at soot

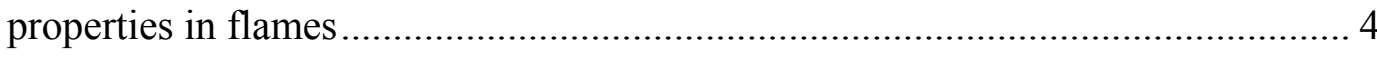

Table 3.1: Summary of the parts used to form the excitation laser sheet and focus it into

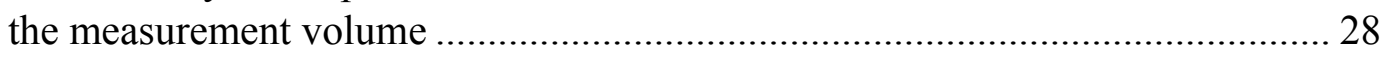

Table 3.2: Different pinhole sizes used and the corresponding measurement volume dimensions 29

Table 3.3: Summary of collection optics common to both sides ...................................... 31

Table 3.4: Summary of the detection optics used in the experiment ............................... 34

Table 4.1: Transmissivities of the filters used in the $500 \mu \mathrm{m}$ calibration process ............ 45

Table 4.2: Experimental data for the transfer of the calibration constant from the backward side to the forward side.

Table 4.3: Summary of all calibration constants obtained for the four scattering and LII measurement channels for all the pinhole sizes used in the experiment................51

Table 5.1: Input parameters to the Monto Carlo Distribution and their relative contribution to the uncertainties on the measured quantities. 56

Table 5.2: Comparison of the total uncertainties and the measurement noise uncertainties only 60 


\section{List of Figures}

Figure 1.1: Typical TEM image of soot (Coderre et al., 2011) ....................................... 2

Figure 3.1: A photograph of the invar hoop with the optics and the excitation laser mounted on it. The assembly is centered around the burner in the middle

Figure 3.2: General layout of the shaping and detection optics mouinted on the invar

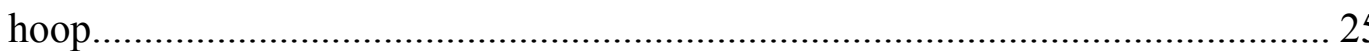

Figure 3.3: Laser fluence profiles at three different heights relative to the centre of the laser sheet taken inside the measurement volume. The mean fluence is approximately $1 \mathrm{~mJ} / \mathrm{mm}^{2}$ 26

Figure 3.4: Ray trace diagram for light travel through the collection optics..................... 31

Figure 3.5: Backward optics on the invar mount ........................................................... 32

Figure 3.6: Forward optics on the invar mount.............................................................. 33

Figure 4.1: Spectralon puck used to calibrate the backwards optics mounted on a custommade mount

Figure 4.2: Calibration of the backward scattering optics using a diffuse spectralon puck mounted on a traverse along the optical axis 42

Figure 4.3: Transfer of the calibration between (i) the backward scattering optics and (ii) the forward ones using an integrating sphere mounted inside the measurement volume by using the same pulsed Nd:YAG laser.

Figure 4.4: Measured backward scattering calibration signal voltage versus location inside the measurement volume.....

Figure 4.5: Measured voltage vs location inside the measurement volume for the 6 calibration runs

Figure 4.6: Box and whisker plot showing the spread of the calibration constant for 6 different measurements. The mean and $95 \%$ confidence intervals obtained through a t-test are also plotted (blue dashed)

Figure 4.7: Integrating sphere assembly used in the LII calibration. 50

Figure 5.1: (a) Scatter plot of instantaneous measurements of soot volume fraction and soot primary particle diameter with $95 \%$ confidence intervals as compared with 
data published for soot volume fraction by Snelling et al. (2005) and data published for primary particle diameter by Tian et al. (2004) and calculated from the results presented in Snelling et al. (2011) (Crosland, Thomson, et al., 2013). (b) Scatter plot of instantaneous measurements of soot primary particle diameter and soot mean aggregate radius of gyration with $95 \%$ confidence intervals as compared with data published for radius of gyration by Snelling et al. (2011) using TEM and scattering measurements from Snelling et al. (2011) and Link et al. (2011) plotted against primary particle diameter data by Tian et al. (2004) and Snelling et al. (2011). All measurements are taken at a height of $42 \mathrm{~mm}$ above the burner exit.

Figure 5.2: Effect of varying the measurement volume on the uncertainty in the soot volume fraction measurement. 95\% confidence intervals are plotted for both the total uncertainties (dotted lines) and measurement noise (bold lines)

Figure 5.3: Effect of varying the measurement volume on the uncertainty in the primary particle diameter measurement. $95 \%$ confidence intervals are plotted for both the total uncertainties (dotted lines) and measurement noise (bold lines)

Figure 5.4: Effect of varying the measurement volume on the uncertainty in the mean aggregate radius of gyration measurement. 95\% confidence intervals are plotted for both the total uncertainties (dotted lines) and measurement noise (bold lines)

Figure 5.5: Box and whisker plot showing the spread of the means for 8 different sets of measurements. The mean and $95 \%$ confidence intervals obtined through a t-test are also plotted (blue dashed). 66

Figure A.1: INVAR hoop engineering drawing 78 


\section{Nomenclature}

\begin{tabular}{|c|c|c|c|c|}
\hline $\begin{array}{l}\text { Latin } \\
\text { Symbol }\end{array}$ & Description & Units & $\begin{array}{l}\text { First } \\
\text { Eq. }\end{array}$ & $\begin{array}{l}\text { Use } \\
\text { Pg. }\end{array}$ \\
\hline$A$ & Irradiated area on detector & {$\left[\mathrm{m}^{2}\right]$} & $(4.2)$ & 39 \\
\hline$A_{A P}$ & Area of aperture & {$\left[\mathrm{m}^{2}\right]$} & $(4.5)$ & 49 \\
\hline$A_{L}$ & Area of lens & {$\left[\mathrm{m}^{2}\right]$} & $(4.5)$ & 49 \\
\hline$c$ & Speed of light & {$[\mathrm{m} / \mathrm{s}]$} & $(2.1)$ & 16 \\
\hline$C_{s}$ & Structure factor coefficients & - & $(2.4)$ & 18 \\
\hline$C_{D}$ & Scattering calibration constant & - & $(4.4)$ & 39 \\
\hline$D_{f}$ & Fractal dimension & - & $(2.3)$ & 19 \\
\hline$D_{\text {filt }}$ & $\begin{array}{l}\text { Change in filter arrangement between the calibration } \\
\text { and experiment }\end{array}$ & - & - & 40 \\
\hline$d_{p}$ & Soot primary particle diameter & {$[\mathrm{m}]$} & $(2.3)$ & 2 \\
\hline $\mathrm{E}$ & Energy collected at each plane & {$[\mathrm{J}]$} & $(4.1)$ & 39 \\
\hline ELS & Elastic light scattering & - & - & 10 \\
\hline$E\left(m_{\lambda}\right)$ & $\begin{array}{l}\text { Wavelength dependent soot refractive index } \\
\text { absorption function }\end{array}$ & - & $(2.1)$ & 8 \\
\hline$F\left(m_{\lambda}\right)$ & $\begin{array}{l}\text { Wavelength dependent soot refractive index } \\
\text { scattering function }\end{array}$ & - & $(2.9)$ & 21 \\
\hline$f_{v}$ & Soot volume fraction & {$[\mathrm{m}]$} & $(2.1)$ & 2 \\
\hline$f_{n}$ & $\begin{array}{l}\text { Ratio of the aggregate size first two moments of } \\
\text { distribution }\end{array}$ & {$[\mathrm{m}]$} & $(2.9)$ & 21 \\
\hline$G_{c a l}$ & Gain in LII calibration & - & $(4.5)$ & 49 \\
\hline$h$ & Planck's constant & {$\left[\mathrm{m}^{2} \mathrm{~kg} / \mathrm{s}\right]$} & $(2.1)$ & 16 \\
\hline ICCD & Intensified charge coupled device & - & - & 5 \\
\hline LIF & Laser induced florescence & - & - & 5 \\
\hline$k$ & Boltzmann's constant & {$[\mathrm{J} / \mathrm{K}]$} & $(2.1)$ & 16 \\
\hline$k_{f}$ & Fractal prefactor & - & $(2.1)$ & 18 \\
\hline$K_{a b s}$ & Absorption coefficient & {$\left[\mathrm{m}^{-1}\right]$} & $(2.9)$ & 21 \\
\hline$K_{v v}$ & Scattering coefficient for vertically polarized light & {$\left[\mathrm{m}^{-1}\right]$} & $(2.9)$ & 21 \\
\hline$\ell_{0}$ & Integral length scale & {$[\mathrm{m}]$} & - & 61 \\
\hline$\ell_{K}$ & Kolmogorov length scale & {$[\mathrm{m}]$} & - & 61 \\
\hline LII & Laser induced incandescence & - & - & 3 \\
\hline LOSA & Line of sight attenuation & - & - & 3 \\
\hline M & Magnification of the optics & - & $(4.5)$ & 49 \\
\hline$N$ & Number of primary particle per aggregate & - & $(2.3)$ & 17 \\
\hline $\bar{N}$ & $\begin{array}{l}\text { Arithmetic mean number of primary particle per } \\
\text { aggregate }\end{array}$ & - & $(2.5)$ & 19 \\
\hline$N_{m}$ & $\begin{array}{l}\text { Geometric mean number of primary particle per } \\
\text { aggregate }\end{array}$ & - & $(2.5)$ & 19 \\
\hline NTLAF & Non-linear regime two-line atomic fluorescence & - & - & 7 \\
\hline $\mathrm{PAH}$ & Polychromatic hydrocarbons & - & - & 5 \\
\hline
\end{tabular}




\begin{tabular}{lllll} 
Latin & & & First & Use \\
Symbol & Description & Units & Eq. & Pg. \\
\hline PIV & Particle image velocimetry & - & - & 5 \\
ppm & Parts per million & - & - & 52 \\
& & & & \\
$\boldsymbol{q}$ & Scattering wave vector & - & $(2.4)$ & 18 \\
RDG-FA & Rayleigh-Debye-Gans Fractal Aggregate Theory & - & - & 15 \\
$R e_{\ell_{0}}$ & Turbulence Reynolds number & - & - & 61 \\
$R_{i}$ & Irradiance of incident beam & {$\left[\mathrm{J} / \mathrm{m}^{2}\right]$} & $(4.2)$ & 39 \\
$R_{g}$ & Soot radius of gyration & {$[\mathrm{m}]$} & $(2.3)$ & 2 \\
$R_{g m 1}$ & Soot mean aggregate radius of gyration & {$[\mathrm{m}]$} & $(2.8)$ & 19 \\
$R_{v v}$ & Dissymmetry ratio & - & $(2.6)$ & 19 \\
$r_{s}$ & Reflectivity of spectralon & - & $(4.2)$ & 39 \\
$p$ & Log-normal probability density function & - & $(2.5)$ & 18 \\
$S$ & Structure factor & - & $(2.4)$ & 18 \\
slpm & Standard liter per minute & {$[1 / \mathrm{min}]$} & - & 35 \\
$S\left(\boldsymbol{q} R_{g}\right)$ & Effective polydisperse structure factor & - & $(2.7)$ & 18 \\
TiRe & Time resolved & - & - & 8 \\
TEM & Transfer electron microscopy & - & - & 4 \\
$T_{p e}$ & Equivalent temperature & {$[\mathrm{K}]$} & $(2.1)$ & 16 \\
$T_{g}$ & Initial gas temperature & {$[\mathrm{K}]$} & $(2.1)$ & 27 \\
$u$ & Distance between the measurement location and lens & {$[\mathrm{m}]$} & $(4.5)$ & 49 \\
$\mathrm{~V}$ & Voltage measured & {$[\mathrm{V}]$} & $(2.1)$ & 15 \\
$V_{m r}$ & Volume of measurement volume & {$\left[\mathrm{m}{ }^{3}\right]$} & $(4.3)$ & 39 \\
$w_{e}$ & Equivalent sheet thickness & {$[\mathrm{m}]$} & $(2.1)$ & 16 \\
$Z$ & Impedance of measurement device & {$[\Omega]$} & $(4.5)$ & 49
\end{tabular}

Greek Symbol Description

First Use Units Eq. Pg.

\begin{tabular}{|c|c|c|c|}
\hline$\alpha$ & Thermal accommodation coefficient & - & - \\
\hline$\beta$ & Angle between the calibration surface and optics & [rad] & $(4.2)$ \\
\hline$\Delta \varphi_{\text {cal }}$ & Calibration signal at each plane & {$[\mathrm{V}]$} & $(4.1)$ \\
\hline$\Delta\left(\lambda_{c}\right)$ & Width of bandpass filter in LII calibration & {$[\mathrm{m}]$} & $(4.5)$ \\
\hline$\eta_{1}$ & Calibration constant for LII-blue channel & {$\left[\mathrm{A} / \mathrm{m}^{3}\right]$} & $(2.1)$ \\
\hline$\theta$ & Scattering angle & [rad] & $(2.6)$ \\
\hline$\lambda$ & Wavelength of LII or scattering channel & {$[\mathrm{m}]$} & $(2.1)$ \\
\hline$\rho$ & Depolarization ratio of spectralon & - & $(4.2)$ \\
\hline$\sigma_{g}$ & $\begin{array}{l}\text { Standard deviation of the number of primary particles } \\
\text { per aggregate }\end{array}$ & - & $(2.5)$ \\
\hline$\Omega_{\text {det }}$ & Solid angle of detection optics & {$[\mathrm{sr}]$} & $(4.2)$ \\
\hline$\Omega\left(\lambda_{c}\right)$ & $\begin{array}{l}\text { Combined response of PMT tubes and filters at the } \\
\text { centre wavelength }\end{array}$ & {$[\mathrm{A} / \mathrm{W}]$} & $(4.5)$ \\
\hline
\end{tabular}




\section{Chapter 1}

\section{Introduction}

\subsection{Motivation}

Exposure to particulate matter (PM) emissions is well proven to be directly linked to various human health effects such as cardiovascular and lung diseases as well as mortality (U.S. EPA, 2010). Combustion of fossil-fuels generates PM emission in the form of soot, which is comprised mostly of black carbon (Eklund et al., 2014). A recent study has suggested that reductions of black carbon emissions are even more strongly correlated with increases in human life expectancy than reductions in PM emissions (Grahame et al., 2014). In addition, black carbon is potentially second to only $\mathrm{CO}_{2}$ in terms of its climate forcing effects (Bond et al., 2013; Jacobson, 2010) and black carbon is one of the main sources of glacier melting in the Arctic (Ramanathan and Carmichael, 2008).

Flaring, i.e. the combustion of unwanted gases in an open turbulent diffusion flame, is an important source of black carbon emissions (Conrad and Johnson, 2017). Flaring is prevalent in the oil and gas industry, where it is estimated that approximately 135 billion $\mathrm{m}^{3}$ of gas are flared globally each year (Elvidge et al., 2009). Stohl et al. (2013) have suggested that $42 \%$ of black carbon surface deposition in the Arctic is due to flaring activities. However there is significant uncertainty on the amounts of black carbon emitted by flares and how this changes under different 
conditions (McEwen and Johnson, 2012; U.S. EPA, 2012). Accurately measuring soot within turbulent flames typical of flares is essential for being able to understand and model soot formation, to predict emissions under varying conditions, and to inform effective operating procedures and regulations to minimize emissions.

\subsection{Current Measurement Techniques}

Soot forms inside a flame as collections of small (generally 20 to $50 \mathrm{~nm}$ diameter) spherical particles that are often lumped together to form mass fractal aggregates. Figure 1.1 below shows a typical image of soot inside flames. Soot formation inside flames begins as chemical reactions rapidly change fuel molecules into soot precursors such as acetylene, which further react to start forming benzene rings. These benzene rings combine and evolve into soot nuclei which grow into the soot spherules that combine to form the soot aggregates (Santoro and Miller, 1987).

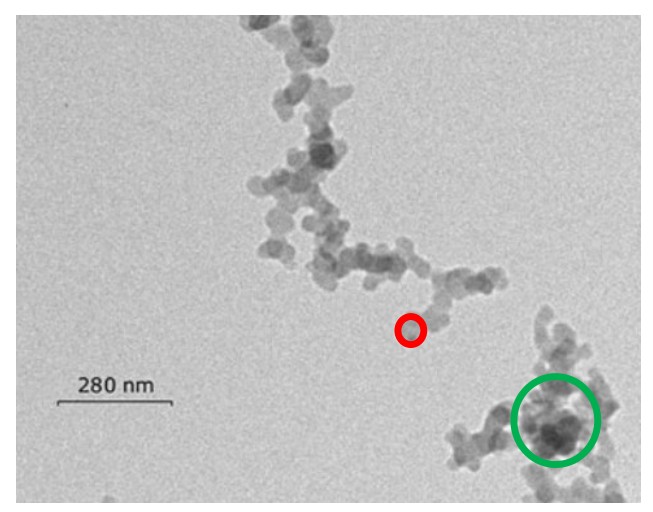

Figure 1.1: Typical TEM image of soot (Coderre et al., 2011)

Soot may be characterized in terms of the primary particle diameter of each spherule $\left(d_{\mathrm{p}}\right)$ (circled in red on Figure 1.1), the radius of gyration of the aggregated spherules $\left(R_{g}\right)$ which is a measure of the size of the aggregates (approximated by the green circle), and 
the volume fraction $\left(f_{v}\right)$ of the spherules in the surrounding gas which is the ratio of the volume occupied by the spherules to the total volume.

When developing measurement techniques that will help enhance the understanding of soot formation, it is important to be able to make measurements that are accurate enough to be able to detect the changes of the soot properties in different regions of the flame. Techniques such as line-of-sight attenuation (LOSA) have often been used to measure the soot volume fraction inside flames (Snelling et al., 1999; Arana et al., 2004; Greenberg and $\mathrm{Ku}, 1997)$. However, measurements inside turbulent flames are problematic due to the dependence of the LOSA technique on symmetry (Thomson et al., 2008). Laser induced incandescence (LII) is arguably the benchmark approach for making spatially resolved soot volume fraction measurements within flames (Lee et al., 2009; Qamar, 2009; Bladh et al., 2011). However, LII alone cannot provide information on the aggregate properties of the soot inside the flame and often needs to be combined with other measurement techniques (Olofsson et al., 2013; Snelling et al., 2011; Reimann et al., 2009; Crosland, Thomson, et al., 2013).

A literature review of current techniques for making measurements of $f_{v}, d_{p}$ and $R_{g}$ within turbulent flames is summarized in Table 1.1. Columns within the table detail the measured quantities in each study, the measurement technique(s) used, the type of flame considered, and comments on the suitability of the approach for simultaneous and instantaneous measurements of soot parameters within turbulent flames. 
Table 1.1: Summary of the available relevant measurement techniques that look at soot properties in flames

\begin{tabular}{|c|c|c|c|c|c|c|}
\hline Author & Flame & Measurements & Method & $\begin{array}{l}\text { Instantaneous/ } \\
\text { time } \\
\text { resolved/averaged }\end{array}$ & Goals and results & Relevant Comments \\
\hline $\begin{array}{l}\text { Quay, Lee, Ni, \& } \\
\text { Santoro, } 1994\end{array}$ & Laminar & $f_{v}$ & LII & Time resolved & $\begin{array}{l}\text { Successfully obtained } \\
\text { spatially resolved } \\
\text { measurements using LII }\end{array}$ & $\begin{array}{l}\text { - Deduced that LII is suitable for } \\
\text { instantaneous measurements. } \\
\text { - Concluded that combined LII and } 2 \\
\text { angle ELS would be a good step, } \\
\text { never went into depth }\end{array}$ \\
\hline $\begin{array}{l}\text { De luliis et al., } \\
1998\end{array}$ & Laminar & $f_{v}, d_{p}$ and $R_{g}$ & $\begin{array}{l}\text { Extinction and } \\
\text { scattering }\end{array}$ & Time averaged & $\begin{array}{l}\text { Introduced modified } \\
\text { structure factor, } \\
\text { compared well with } \\
\text { previous literature }\end{array}$ & $\begin{array}{l}\text { - Found that multi angle scattering } \\
\text { gave good agreement with literature }\end{array}$ \\
\hline $\begin{array}{l}\text { Hu, Yang, \& } \\
\text { Köylü, } 2003\end{array}$ & Turbulent & $f_{v}, d_{p}$ and $R_{g}$ & $\begin{array}{l}\text { Probe, TEM } \\
\text { and extinction }\end{array}$ & Time averaged & $\begin{array}{l}\text { Evolution of soot } \\
\text { particles inisde the the } \\
\text { flame length }\end{array}$ & $\begin{array}{l}\text { - } 0.5 \mathrm{~mm} \text { spatial accuracy } \\
\text { - Experiments are not simultaneous } \\
\text { and intrusive. } \\
\text { - Only obtains time averaged results }\end{array}$ \\
\hline $\begin{array}{l}\text { Yang \& Köylü, } \\
\text { 2005a }\end{array}$ & Turbulent & $f_{v} d_{p}$ and $R_{g}$ & $\begin{array}{l}\text { Scattering and } \\
\text { extinction }\end{array}$ & Time averaged & $\begin{array}{l}\text { Measured trends for all } \\
\text { three quantities with } \\
40 \% \text { uncertainty }\end{array}$ & $\begin{array}{l}\text { - Time averaged measurements only. } \\
\text { - Measurements not simultaneous }\end{array}$ \\
\hline $\begin{array}{l}\text { Yang \& Köylü, } \\
\text { 2005b }\end{array}$ & Turbulent & $f_{v}, d_{p}$ and $R_{g}$ & $\begin{array}{l}\text { Scattering and } \\
\text { extinction }\end{array}$ & Time averaged & $\begin{array}{l}\text { Developed theory for } \\
\text { combined measurement } \\
\text { technique }\end{array}$ & $\begin{array}{l}\text { - Time averaged measurements only. } \\
\text { - Measurements not simultaneous }\end{array}$ \\
\hline Xin \& Gore, 2005 & Turbulent & $f_{v}$ & LII & $\begin{array}{l}\text { Instantaneous } \\
\text { and time averaged }\end{array}$ & $\begin{array}{l}\text { Instantaneous and time } \\
\text { averaged results do not } \\
\text { match }\end{array}$ & $\begin{array}{l}\text { - Demonstrated suitability of LII to do } \\
\text { measurements in turbulent flames }\end{array}$ \\
\hline $\begin{array}{l}\text { Teng \& Köylü, } \\
2006\end{array}$ & N/A & N/A & $\begin{array}{l}\text { Numerical } \\
\text { simulation }\end{array}$ & - & $\begin{array}{l}\text { Suggest } 30 \text { and } 150 \\
\text { degrees }\end{array}$ & $\begin{array}{l}\text { - Important findings regarding the } \\
\text { scattering theory }\end{array}$ \\
\hline
\end{tabular}


Table 1.1: Summary of the available relevant measurement techniques that look at soot properties in flames (continued)

\begin{tabular}{|c|c|c|c|c|c|c|}
\hline Author & Flame & Measurements & Method & $\begin{array}{l}\text { Instantaneous/ time } \\
\text { resolved/averaged }\end{array}$ & Goals and results & Relevant Comments \\
\hline Qamar, 2009 & Turbulent & $f_{v}$ & LII & $\begin{array}{l}\text { Time averaged and } \\
\text { instantaneous }\end{array}$ & $\begin{array}{l}\text { Soot intermittency } \\
\text { typically exceeded } \\
97 \% . \text { Studied the } \\
\text { evolution of soot } \\
\text { inside the flame }\end{array}$ & $\begin{array}{l}\text { - Demonstrated instantaneous LII } \\
\text { measurements in flame. } \\
\text { - Only fv measurements. }\end{array}$ \\
\hline $\begin{array}{l}\text { Lee et al., } \\
2009\end{array}$ & Turbulent & $f_{v}, \mathrm{OH}$ and $\mathrm{PAH}$ & LII and LIF & Instantaneous & $\begin{array}{l}18 \% \text { uncertainty for } \\
f_{v} . \text { Studied effects } \\
\text { of position/velocity } \\
\text { on } f_{v} \text {. }\end{array}$ & $\begin{array}{l}\text { - No measurements for } R_{g} \text { or } d_{p} \text {. } \\
\text { - Study focuses on identifying different } \\
\text { sooting regions in the flame. } \\
\text { - Used ICCD camera, which are slow } \\
\text { - high spatial resolution }\end{array}$ \\
\hline $\begin{array}{l}\text { Reimann et } \\
\text { al., } 2009\end{array}$ & Laminar & $f_{v}, d_{p}$ and $R g$ & LII/ELS & Time Averaged & $\begin{array}{l}\text { Demonstrates } \\
\text { suitability of } \\
\text { method by } \\
\text { comparison to TEM } \\
\text { data. Recommends } \\
\text { taking } \\
\text { polydispersity into } \\
\text { account }\end{array}$ & $\begin{array}{l}\text { - Approximated structural factor as } \\
\text { monodisperse. } \\
\text { - Measurements not taken simultaneously }\end{array}$ \\
\hline $\begin{array}{l}\text { Narayanan } \\
\text { \& Trouvé, } \\
2009\end{array}$ & Turbulent & $f_{v}$ & LII & Instantaneous & $\begin{array}{l}\text { Understand effect } \\
\text { of turbulence on } \\
\text { soot characteristics }\end{array}$ & - Only measured $f_{v}$ through ICCD images \\
\hline $\begin{array}{l}\text { Hergen } \\
\text { Oltmann, } \\
\text { Reimann, \& } \\
\text { Will, } 2010\end{array}$ & Laminar & Aggregates & $\begin{array}{l}\text { Wide angle } \\
\text { scattering }\end{array}$ & time averaged & $\begin{array}{l}\text { Demonstrated ELS } \\
\text { technique works }\end{array}$ & - No quantitative data for $f_{v}$ or $d_{p}$ \\
\hline $\begin{array}{l}\text { Markus } \\
\text { Köhler et al., } \\
2011\end{array}$ & Turbulent & $\begin{array}{l}f_{v}, \text { temperature } \\
\text { and velocity }\end{array}$ & PIV/LII & $\begin{array}{l}\text { Instantaneous and } \\
\text { time averaged }\end{array}$ & $\begin{array}{l}\text { Recommends } \\
1064 \mathrm{~nm} \text { laser to be } \\
\text { used. }\end{array}$ & $\begin{array}{l}\text { - No } R_{g} \text { and } d_{p} \text { measurements. } \\
\text { - Methodology geared towards catering for } \\
\text { CFD modellers }\end{array}$ \\
\hline
\end{tabular}


Table 1.1: Summary of the available relevant measurement techniques that look at soot properties in flames (continued)

\begin{tabular}{|c|c|c|c|c|c|c|}
\hline Author & Flame & Measurements & Method & $\begin{array}{l}\text { Instantaneous/ } \\
\text { time } \\
\text { resolved/averaged }\end{array}$ & Goals and results & Relevant Comments \\
\hline Yon et al., 2011 & Laminar & $\begin{array}{l}\text { Soot optical } \\
\text { properties of } \\
\text { soot for diesel } \\
\text { engines }\end{array}$ & $\begin{array}{l}\text { LII and } \\
\text { extinction }\end{array}$ & Instantaneous & $\begin{array}{l}\text { No Quantitative } \\
\text { measurements on soot } \\
\text { formulation }\end{array}$ & $\begin{array}{l}\text { - Not presented as a measurement } \\
\text { technique } \\
\text { - Demonstrated feasibility of making } \\
\text { instantaneous LII measurements }\end{array}$ \\
\hline $\begin{array}{l}\text { Snelling et al., } \\
2011\end{array}$ & Laminar & $f_{v}, d_{p}$ and $R_{g}$ & LII/ELS & Instantaneous & $\begin{array}{l}\text { Showed that LII+ELS is } \\
\text { in agreement with } \\
\text { previous results }\end{array}$ & $\begin{array}{l}\text { - Used } 532 \text { laser but concluded that } \\
1064 \text { better avoids fluorescence } \\
\text { - Needed an external input from } 2 \\
\text { angle scattering experiment to get } \\
\text { aggregate size distribution. }\end{array}$ \\
\hline $\begin{array}{l}\text { Köhler, Boxx, } \\
\text { Geigle, \& Meier, } \\
2011\end{array}$ & Turbulent & $\begin{array}{l}\text { Velocity and } \\
\text { soot formation }\end{array}$ & LII/PIV & Instantaneous & $\begin{array}{l}\text { Series of images that } \\
\text { show soot propagation } \\
\text { through turbulent flame }\end{array}$ & - No quantitative results for $f_{v}, R_{g}$ or $d_{p}$ \\
\hline $\begin{array}{l}\text { Bladh et al., } \\
2011\end{array}$ & Laminar & $\begin{array}{l}d_{p} \text { and } \\
\text { temperature }\end{array}$ & LII & $\begin{array}{l}\text { Time resolved } \\
\text { /time averaged }\end{array}$ & $\begin{array}{l}\text { Studied trends in soot } \\
\text { particles and } \\
\text { temperatures at } \\
\text { different flame heights }\end{array}$ & $\begin{array}{l}\text { - Time resolved LII not suitable for } \\
\text { turbulent flames }\end{array}$ \\
\hline $\begin{array}{l}\text { H. Oltmann, } \\
\text { Reimann, \& Will, } \\
2012\end{array}$ & $\begin{array}{l}\text { Laminar } \\
\text { with } \\
\text { application } \\
\text { on } \\
\text { turbulent }\end{array}$ & $R_{g}$ & $\begin{array}{l}\text { Wide angle } \\
\text { scattering }\end{array}$ & Instantaneous & $\begin{array}{l}\text { Demonstrated } \\
\text { technique works for } \\
\text { turbulent }\end{array}$ & $\begin{array}{l}\text { - No results for } d_{p} \text { or } f_{v} \text { however } \\
\text { demonstrated that multi angle } \\
\text { scattering is successful in making } \\
\text { aggregate size measurements in } \\
\text { turbulent flames }\end{array}$ \\
\hline $\begin{array}{l}\text { Hadef, Geigle, } \\
\text { Zerbs, Sawchuk, } \\
\text { \& Snelling, } 2013\end{array}$ & Laminar & $f_{v}$ and $d_{p}$ & LII & Time resolved & $\begin{array}{l}\text { Underestimation } \\
\text { compared to TEM } \\
\text { results at } 42 \mathrm{~mm}\end{array}$ & $\begin{array}{l}\text { - Gulder flame comparison. } \\
\text { - No } R_{g} \text { measurement. } \\
\text { - Ignored aggregation. } \\
\text { - Time resolved LII not suitable for } \\
\text { turbulence because of difficulty to } \\
\text { make temperature estimates }\end{array}$ \\
\hline
\end{tabular}


Table 1.1: Summary of the available relevant measurement techniques that look at soot properties in flames (continued)

\begin{tabular}{|c|c|c|c|c|c|c|}
\hline Author & Flame & Measurements & Method & $\begin{array}{l}\text { Instantaneous/ } \\
\text { time } \\
\text { resolved/averaged }\end{array}$ & Goals and results & Relevant Comments \\
\hline Olofsson et al., 2013 & $\begin{array}{l}\text { laminar } \\
\text { premixed }\end{array}$ & $f_{v}$ & LII & Time resolved & $\begin{array}{l}\text { Sublimation takes } \\
\text { place between } 3500 \mathrm{k} \\
\text { and } 3700 \mathrm{k}\end{array}$ & $\begin{array}{l}\text { - Studied effect of sublimation on } \\
\text { uncertainties in } E(m)\end{array}$ \\
\hline $\begin{array}{l}\text { Crosland, Thomson, \& } \\
\text { Johnson, } 2013\end{array}$ & Laminar & $f_{v}, d_{p}$ and $R_{g}$ & LII/ELS & Instantaneous & $\begin{array}{l}\text { Performed } \\
\text { instantaneous and } \\
\text { simultaneous } \\
\text { measurements of } f_{v,} \\
d_{p} \text { and } R_{g .} \text { Provided } a \\
\text { detailed uncertainty } \\
\text { analysis }\end{array}$ & $\begin{array}{l}\text { - Basis of current work } \\
\text { - Demonstrated technique works } \\
\text { on small scale flames. } \\
\text { - Need to build on technique and } \\
\text { expand for large scare flares }\end{array}$ \\
\hline Ma \& Long, 2014 & Laminar & Aggregate sizes & $\begin{array}{l}\text { scattering } \\
\text { plus } \\
\text { extinction }\end{array}$ & Time averaged & $\begin{array}{l}\text { Spectrally and } \\
\text { spatially resolved } \\
\text { measurements }\end{array}$ & $\begin{array}{l}\text { - Needed input from previous LII } \\
\text { measurements of } d_{p} \text {. } \\
\text { - Experiments not done } \\
\text { simultaneously. }\end{array}$ \\
\hline $\begin{array}{l}\text { Cenker, Bruneaux, } \\
\text { Dreier, \& Schulz, } 2014\end{array}$ & Turbulent & $f_{v}$ & LII & Numerical & $\begin{array}{l}\text { Studied applicability } \\
\text { of time resolved LII in } \\
\text { turbulent flames }\end{array}$ & $\begin{array}{l}\text { - Uncertainties very high for small } \\
\text { particle sizes. } \\
\text { - Time resolved LII is only used for } \\
d_{p} \text { measurements. } \\
\text { - Recommends using two color } \\
\text { pyrometry. }\end{array}$ \\
\hline $\begin{array}{l}\text { Mahmoud, Nathan, } \\
\text { Medwell, Dally, \& } \\
\text { Alwahabi, } 2015\end{array}$ & Turbulent & $f_{v}$ & LII+NTLAF & Instantaneous & $\begin{array}{l}\text { Studied soot } \\
\text { temperature } \\
\text { interaction in } \\
\text { turbulent flames }\end{array}$ & $\begin{array}{l}\text { - Used ICCD cameras and made } \\
\text { measurements of } f_{v} \text { only. } \\
\text { ICCD cameras are slow and hard } \\
\text { to align from different angles } \\
\text { making it not suitable for } \\
\text { scattering }\end{array}$ \\
\hline
\end{tabular}


Table 1.1: Summary of the available relevant measurement techniques that look at soot properties in flames (continued)

\begin{tabular}{|c|c|c|c|c|c|c|}
\hline Author & Flame & Measurements & Method & $\begin{array}{l}\text { Instantaneous/ } \\
\text { time } \\
\text { resolved/averaged }\end{array}$ & Goals and results & Relevant Comments \\
\hline $\begin{array}{l}\text { Erik, Johan, } \\
\text { Sandra, Bladh, \& } \\
\text { Erik, } 2015\end{array}$ & Laminar & $\begin{array}{l}E(m) \text { and } \\
\text { temperature }\end{array}$ & LII/ELS & Time averaged & $\begin{array}{l}0.14 \mathrm{~J} / \mathrm{cm}^{2} \text { as threshold } \\
\text { for sublimation for } 1064 \\
\mathrm{~nm} \text { and } 3400 \mathrm{k}\end{array}$ & $\begin{array}{l}\text { - Aimed at estimating the sublimation } \\
\text { temperature and threshold fluence. } \\
\text { - Successfully used one angle } \\
\text { scattering. } \\
\text { - Studied evolution of soot } \\
\text { - Demonstrated suitability of LII+ELS } \\
\text { to make measurements but no } \\
\text { quantitative results. }\end{array}$ \\
\hline $\begin{array}{l}\text { Crosland, } \\
\text { Thomson, \& } \\
\text { Johnson, } 2015\end{array}$ & Turbulent & $f_{v}, d_{p}$ and $R_{g}$ & LII/ELS & Instantaneous & $\begin{array}{l}\text { Studied soot formation } \\
\text { along the axis of } \\
\text { turbulent diffusion } \\
\text { flames }\end{array}$ & $\begin{array}{l}\text { - Demonstrated the success of the } \\
\text { proposed LII and ELS technique of } \\
\text { measuring soot parameters inside } \\
\text { turbulent diffusion flames }\end{array}$ \\
\hline $\begin{array}{l}\text { Leschowski, } \\
\text { Thomson, } \\
\text { Snelling, Schulz, } \\
\text { \& Smallwood, } \\
2015\end{array}$ & Laminar & $f_{v}$ & $\begin{array}{l}\text { LII and } \\
\text { extinction }\end{array}$ & Time resolved & $\begin{array}{l}\text { Study effect of soot } \\
\text { precursors on } f_{v} \\
\text { measurements }\end{array}$ & $\begin{array}{l}\text { Recommended that LII with high } \\
\text { spatial resolution is necessary to } \\
\text { adequately resolve the steep } \\
\text { gradients in soot concentration in } \\
\text { the non-premixed flame. } \\
\text { - Time resolved LII not suitable for } \\
\text { turbulent flames }\end{array}$ \\
\hline $\begin{array}{l}\text { Kempema \& } \\
\text { Long, } 2016\end{array}$ & Laminar & Aggregates & 2 angle ELS & Time averaged & $\begin{array}{l}\text { Demonstrates suitability } \\
\text { of multi angle scattering } \\
\text { to perform } \\
\text { instantaneous } \\
\text { measurements }\end{array}$ & $\begin{array}{l}\text { - No measurement of } f_{v} \text { and } d p \text { but } \\
\text { shows feasibility of two angle } \\
\text { scattering for LII measurements }\end{array}$ \\
\hline $\begin{array}{l}\text { Huber, } \\
\text { Altenhoff, \& } \\
\text { Will, } 2016\end{array}$ & $\begin{array}{l}\text { Soot } \\
\text { generator }\end{array}$ & $f_{v}, d_{p}$ and $R_{g}$ & $\begin{array}{l}\text { TiRe LII + } \\
\text { Wide angle } \\
\text { scattering }\end{array}$ & Time resolved & $\begin{array}{l}\text { Showed suitability of } \\
\text { combined ELS+LII for } \\
\text { doing nanoparticle } \\
\text { measurements }\end{array}$ & $\begin{array}{l}\text { - Used } 532 \mathrm{~nm} \text {. } \\
\text { - Measurements not done } \\
\text { simultaneously }\end{array}$ \\
\hline
\end{tabular}


As can be gleaned from Table 1.1, LII has been extensively used in making in-flame measurements. While LII is not capable of making measurements of aggregates, it has often been used to measure soot volume fraction and primary particle diameter. Different variants of LII have been developed, the most common of which are Time-Resolved LII (TiRe-LII) and Auto Compensating LII (AC-LII). In time-resolved LII measurements, soot particles are rapidly heated and the subsequent heat transfer from the particles to the surrounding region is studied by looking at the decay of the LII signal as a means to measuring primary particle diameter (Bladh et al., 2011; Huber et al., 2016; Hadef et al., 2013). To apply this method, the temperature of the surrounding regions inside the flame need to be known and the time decay of the LII signal needs to be measured to determine the cooling rate. While this technique proves to be very effective in laminar flames, it is not suitable for making instantaneous measurements in turbulent flames due to the intermittent nature of the flames which makes the determination of the cooling rate inaccurate (Charwath et al., 2011). In AC-LII (or 'two color LII), the LII signal is instantaneously sampled at two different wavelengths. This gives the advantage of instantaneously calculating the heated soot temperature at the measurement volume through pyrometry which is then used to calculate the soot volume fraction. This LII variant could also be considered to be minimally intrusive (M. Köhler et al., 2011), as the heated soot temperature is below the sublimation limits. While the effect of the soot heating might alter some of the properties of soot, staying below the sublimation limit preserves the mass of soot inside the flame (Snelling et al., 2005). AC-LII has been used to make instantaneous soot volume fraction measurements inside turbulent flames since the cooling rate of the particles does not need to be known (Xin and Gore, 2005; Qamar 
et al., 2009; Lee et al., 2009; Narayanan and Trouvé, 2009; M. Köhler et al., 2011; Markus Köhler et al., 2011; Mahmoud et al., 2015; Crosland et al., 2015). Building directly on the work of Crosland et al. $(2013 ; 2015)$, AC-LII will be used in the current work to make instantaneous soot volume fraction measurements.

Simultaneous measurements of $d_{p}$ and $R_{g}$ with $f_{v}$, require another technique in combination with AC-LII. As shown in Table 1.1, other techniques such as transmission electron microscopy (TEM), extinction, and elastic light scattering (ELS) have frequently been employed (Hu et al., 2003; Yang and Köylü, 2005b; Yang and Köylü, 2005a; Ma and Long, 2014; Leschowski et al., 2015; Oltmann et al., 2010; Oltmann et al., 2012; Crosland et al., 2015; Crosland, Thomson, et al., 2013). However, the intrusive nature of TEM is not favorable and extinction measurements are more suited for axisymmetric flames (i.e. laminar flames) due to the need to spatially resolve the absorption coefficients (De Iuliis et al., 1998; Sorensen et al., 1992; Dasch, 1992). Yang \& Köylü (2005a; 2005b) attempted to use extinction in turbulent flames by using a probe that was used to transmit the light into the measurement volume such that the extinction measurement was limited to within the length of the measurement probe. While this was successful in providing measurements of $f_{v}, d_{p}$ and $R_{g}$, the intrusive measurement technique meant that the measurements were time averaged and not synchronous.

Elastic scattering of incident light by the soot particles inside the flame can be used to make inferences about primary particle diameter and aggregate size. Hergen Oltmann et al. (2010) demonstrated the use of wide angle scattering to make measurements of aggregates and were successful in producing time-averaged results. 
More attempts have been made to use scattering and several research articles show the suitability of using multiple angle measurements to make instantaneous soot particle diameter and radius of gyration measurements inside turbulent flames (e.g. Oltmann et al., 2010; Kempema and Long, 2016). In a numerical simulation, Teng \& Köylü (2006) concluded that due to the scattering profile of soot particles, it is favorable to perform the multi-angle scattering measurements at 30 and 150 degrees relative to the direction of the incident light. Crosland et al. $(2013 ; 2015)$ demonstrated the success of ELS in making instantaneous and simultaneous measurements of $d_{p}$ and $R_{g}$ in both laminar and turbulent flames. In their approach, a combination of LII and ELS was used to obtain simultaneous measurements of the primary particle diameter, mean aggregate radius of gyration, and the soot volume fraction.

Consistent with the work of Crosland et al. $(2013 ; 2015)$, the preceding discussion suggests that using AC-LII to measure the soot volume fraction combined with ELS to measure the particle diameter and the mean aggregate radius of gyration provides the best solution to making simultaneously measurements within turbulent non-premixed flames. In addition to Crosland's work, a few articles have presented a combination of the aforementioned methods to perform in-flame measurements (Erik et al., 2015; Reimann et al., 2009; Snelling et al., 2011). Reimann et al. (2009) studied the suitability of a combined LII/ELS method and demonstrated this by making comparisons with TEM data. However, the measurements were not taken simultaneously. Snelling et al. (2011) also demonstrated the promise of combined LII/ELS experiments but only made measurements at one scattering angle. In their analysis, external input from another two angle scattering experiment was required to get the aggregate size distribution needed for 
the calculations. This means that this value was not obtained simultaneously, which is one of the main goals of the current research. Erik et al. (2015) used the combined LII and ELS to obtain time-averaged results. They presented important results regarding the limiting threshold for the fluence and temperature to avoid sublimation when using $1064 \mathrm{~nm}$ laser that are useful to this research; however, they did not publish quantitative data detailing measurements of the soot volume fraction, primary particle diameter, or the mean aggregate radius of gyration which are a primary goal of this research.

To the knowledge of the author, only Crosland et al. $(2013 ; 2015)$ have performed and published a technique for simultaneous and instantaneous measurements of soot volume fraction, primary particle diameter, and mean aggregate radius of gyration of soot that is applicable to turbulent flames. The work presented in this thesis is a continuation of Crosland's research by adapting his technique to be applicable for large scale turbulent flames. A new (larger) optical setup has been implemented and quantitatively investigated to fit the end goal of the research - making instantaneous measurements on a lab scale flare at the Carleton University flare facility.

\subsection{Thesis Objectives and Summary}

The objective of this thesis is to develop and validate a combined LII/ELS experiment capable of simultaneously measuring the volume fraction, primary particle diameter, and mean aggregate radius of gyration inside a large, turbulent non-premixed flame. While other parameters such as the optical and morphological properties of soot as well as the soot composition are also important parameters to study, the choice of focusing on $f_{v}, d_{p}$, 
and $R_{g}$ stems from the fact that the combination of those three parameters allows for studying the soot formation and evolution as it happens inside flames.

Building on the work presented in Crosland et al. (2013), a single $1064 \mathrm{~nm}$ laser operated at $15 \mathrm{~Hz}$ was used to provide the scattering signal and induce incandescence. Key adaptations to their technique that were implemented include increasing the geometrical size of the apparatus to make it suitable for use with large-scale flames, the use of collection optics with larger solid angles in combination with better responsivity detectors to capture more signal, and configuring the optics to achieve a smaller measurement volume to improve the spatial resolution of the system.

The results obtained from test measurements show that the new system is capable of making instantaneous and simultaneous measurements of the soot volume fraction, primary particle diameter, and the mean aggregate radius of gyration that match published results within rigorously calculated measurement uncertainties. A study of the effect of varying the measurement volume on the signal noise and by association the total uncertainties has also been conducted. The results of this study highlight that while smaller measurement volumes are preferable in turbulent flames to reduce the effect of mixing and improve the spatial resolution, the uncertainties at smaller measurement volumes become dominated by the signal noise as opposed to the soot properties for the larger volumes. The results of this section provide a guide for future research when making measurements in turbulent flames. 


\subsection{Thesis Outline}

Chapter 2 presents a discussion of the theory behind AC-LII and ELS and its application to making measurements of $f_{v}, d_{p}$, and $R_{g}$. The equations used as well as the soot modelling parameters are shown. Chapter 3 details the experimental setup of the apparatus and provides the procedure undertaken in the experiment. Chapter 4 describes the calibration of the equipment. A detailed discussion of the theory, procedure and the results of the calibration are provided. In Chapter 5, the results of experiment are displayed. Comparisons to published data are made as well as a detailed discussion of the uncertainty and errors is presented. Chapter 6 summarizes the conclusions of the thesis and provides recommendations for future work. 


\section{Chapter 2}

\section{Theory}

\subsection{Soot Volume Fraction via LII Experiment}

The theory presented for measuring soot volume fraction $\left(f_{v}\right)$ via the LII technique is based on that described in Snelling et al. (2005). In accordance with Rayleigh-DebyeGans Fractal Aggregate Theory (RDG-FA) (Julien and Botet, 1987; Martin and Hurd, 1987; Dobbins and Megaridis, 1991), the soot volume fraction can be calculated using the following equation (Snelling et al., 2005) by measuring the light intensity that is emitted from a soot particle that undergoes heating:

$$
f_{v}=\frac{V_{1}}{\eta_{1} \frac{12 \pi c^{2} h}{\lambda_{1}^{6}} E\left(m_{\lambda_{1}}\right) w_{e}\left[\exp \left(\frac{h c}{k \lambda_{1} T_{p e}}\right)-1\right]^{-1}}
$$

where $\lambda_{1}$ is the equivalent centre wavelength for the measurement channel. This is

defined as the wavelength value where $\int_{-\infty}^{\lambda_{1}} \tau(\lambda) \Theta(\lambda) d(\lambda)=\int_{\lambda_{1}}^{\infty} \tau(\lambda) \Theta(\lambda) d(\lambda)$ holds true. In this integral, $\tau(\lambda)$ is the detector response while $\Theta(\lambda)$ is the product of the light transmission properties of the all the filters and optics placed in between the measurement volume and the detector (Snelling et al., 2005) (the specific apparatus used will be detailed in Chapter 3 of this paper). $E\left(m_{\lambda}\right)$ is the soot refractive index light absorption function evaluated at $\lambda_{1} ; V_{l}$ is the experimentally measured voltage for the channel; $\eta_{1}$ is the calibration constant derived from the calibration procedure described 
later in Chapter 4; $c$ is the speed of light; $h$ is the Planck constant; $w_{e}$ is the equivalent laser sheet thickness which is described in more detail below; $k$ is the Boltzmann constant; and $T_{p e}$ is the equivalent heated particle temperature. $T_{p e}$ is referred to as the equivalent temperature because it is a single value defined so as to take into account the non-uniform distribution of temperature inside the measurement volume. The mean value of $E\left(m_{\lambda}\right)$ is taken to be 0.348 at a $\lambda_{1}$ of $447 \mathrm{~nm}$ (Crosland, Thomson, et al., 2013). This value was determined in Crosland, Thomson, et al., (2013) by taking the mean of values of $E\left(m_{\lambda}\right)$ that are presented in the literature (Dobbins et al., 1994; Snelling et al., 2004; Coderre et al., 2011; Köylü and Faeth, 1996; Krishnan et al., 2000; Schnaiter et al., 2003; Bond et al., 2006). $E\left(m_{\lambda}\right)$ is assumed to vary in a linear fashion with wavelength such that the ratio of the refractive index of light at the lower and upper wavelengths $\left(E\left(m_{\lambda_{1}}\right) / E\left(m_{\lambda_{2}}\right)\right)$ is taken to be equal to 1.15 (Crosland, Thomson, et al., 2013), where $\lambda_{2}=775 \mathrm{~nm}$. The application of Equation (2.1) is based on the absolute voltage output from a detector that is calibrated to measure the power emitted from an incandescing particle.

The value of $T_{p e}$ used to calculate the soot volume fraction is determined from the incandescence signal when it is captured at the two different wavelengths used in the LII experiment by using the following equation (Snelling et al., 2005):

$$
T_{p e}=-h c \frac{\left(\lambda_{2}-\lambda_{1}\right)}{\ln \left(\frac{V_{1}}{V_{2}} \frac{\eta_{2}}{\eta_{1}} \frac{\lambda_{1}^{6}}{\lambda_{2}^{6}} \frac{E\left(m_{\lambda_{1}}\right)}{E\left(m_{\lambda_{2}}\right)}\right) k \lambda_{1} \lambda_{2}}
$$

The equivalent sheet thickness $\left(w_{e}\right)$ was calculated numerically using an LII simulation code first presented in Snelling (1997), Smallwood et al. (2001) and Snelling et al. 
(2000) and modified to produce output distributions for uncertainty analysis by Crosland et al. (2011) (Refer to Chapter 3 for details).

According to Snelling et al. (2005), the centre wavelength approximation as described in Equation (2.1) introduces a 1\% error in the calculation of $T_{p e}$ for typical inflame heated soot. As described in Crosland, Thomson, et al. (2013), this is included in the uncertainty analysis (see Section 5.2) by introducing a multiplier on the $T_{p e}$ value with a mean of 1 and a standard deviation of $0.5 \%$.

Another error to be accounted for in the soot volume fraction measurement is that due to the absorption of the LII signal inside the flame. For the flame conditions used in this experiment, this is approximated to introduce an error of around 5\% in the soot volume fraction calculation (Liu and Snelling, 2008). Therefore as described in Crosland, Thomson, et al. (2013), in the uncertainty analysis, an error multiplier with a standard deviation of $2.5 \%$ is added on the value of the soot volume fraction that is calculated from the LII signal in the experiment.

\subsection{Mean Aggregate Radius of Gyration via ELS}

The mean aggregate radius of gyration $\left(R_{g m l}\right)$ is derived from the measured forward and backward scattering signals based on the mass fractal aggregate theory of a polydisperse distribution of aggregates. Application of the theory to determine $R_{g m l}$ is described in detail in Crosland, Thomson, et al. (2013) and references therein, and is summarized again here for completeness. The number of primary particles in an aggregate $(N)$ is defined by Julien and Botet (1987) and Dobbins and Megaridis (1991) as follows: 


$$
N=k_{f}\left(\frac{2 R_{g}}{d_{p}}\right)^{D_{f}}
$$

where $k_{f}$ is the fractal prefactor taken to be 1.7 (Köylü, Xing, et al., 1995), $D_{f}$ is the fractal dimension with a mean value of 1.7 (Sorensen, 2011), and $R_{g}$ is the soot aggregate radius of gyration.

In polydisperse aggregates, the scattering is dependent on the scattering angle $(\theta)$ through the structure factor $(S)$ (Dobbins and Megaridis, 1991). The structure factor employed in the current work is based on the analysis presented by Lin et al. (1990) and is given by:

$$
S\left(\boldsymbol{q} R_{g}\right)=\left(1+\sum_{s=1}^{4} C_{s}\left(\boldsymbol{q} R_{g}\right)^{2 s}\right)^{-D_{f} / 8}
$$

where $q$ is defined as the scattering wave vector and calculated as $\boldsymbol{q}=\sin \left(\frac{\theta}{2}\right) 4 \pi / \lambda$, $C_{1}=8 /\left(3 D_{f}\right), C_{2}=2.5, C_{3}=-1.52$ and $C_{4}=1.02$. A good review of different forms of structure factors is provided in Sorensen (2001).

A $\log$ normal probability density function was chosen to account for the polydispersity by modeling the number of primary particles. The mathematical representation of the distribution of particle sizes is defined using the following equation:

$$
p\left(N, N_{m}, \sigma\right)=\frac{\exp \left(-\frac{1}{2}\left(\frac{\ln N / N_{m}}{\ln \sigma_{g}}\right)^{2}\right)}{\sqrt{2 \pi} N \ln \left(\sigma_{g}\right)}
$$


where $N_{m}$ and $\sigma$ are the geometric mean and the width used to describe the shape and size of the log normal distribution. In addition, an effective polydisperse structure factor needs to be defined as follows:

$$
\overline{S\left(\boldsymbol{q} R_{g}\right)}=\frac{\int_{0}^{\infty} N^{2} S\left(\boldsymbol{q}(\theta) R_{g}\right) p\left(N, N_{m}, \sigma_{g}\right) d N}{\int_{0}^{\infty} N^{2} p\left(N, N_{m}, \sigma_{g}\right) d N}
$$

The dissymmetry ratio $\left(R_{v v}\right)$ which in the experiment would be the ratio of the forward to backward scattering signals can then be defined as the ratio of the effective structure factors at angles $\theta$ and $180-\theta$ (Snelling et al., 2011) (subscript $v v$ denotes that the incident and scattered light are both vertically polarized):

$$
R_{v v}=\frac{\int_{0}^{\infty} N^{2} S\left(\boldsymbol{q}\left(\theta_{1}\right) R_{g}\right) p\left(N, N_{m}, \sigma\right) d N}{\int_{0}^{\infty} N^{2} S\left(\boldsymbol{q}\left(\theta_{2}\right) R_{g}\right) p\left(N, N_{m}, \sigma\right) d N}
$$

Finally, $R_{g m l}$ (where the subscript $m 1$ denotes the dependence on the first moment of the distribution) can be calculated based on the following formula given in De Iuliis et al. (1998):

$$
R_{g m 1}=\frac{d_{p}}{2}\left(\frac{\bar{N}}{k_{f}}\right)^{1 / D_{f}}
$$

where $\bar{N}$ is defined as the mean of the distribution $N$ and is given by $\bar{N}=N_{m} e^{\frac{\ln (\sigma)^{2}}{2}}$ for the log normal distribution described in Equation (2.6).

When performing the calculations, the width of the log normal distribution $\left(\sigma_{g}\right)$, as well as $k_{f}$ and $D_{f}$ are known from the literature. Hence, if the value of the primary 
particle diameter is assumed, Equation (2.7) can be solved to form a lookup table for $R_{v v}$ vs $N_{m}$. A value for $N_{m}$ can then be found when $R_{v v}$ is measured from the experiment. The value of $N_{m}$ is then used to calculate the mean aggregate radius of gyration using Equation (2.8). It is important to note that while this procedure assumes a value of $d_{p}$ to create the lookup table, it can be shown that any value chosen for the particle diameter will not affect the result (Crosland, Thomson, et al., 2013).

Based on the discussion presented in Crosland, Johnson, et al. (2013) the choice of the form of the structure factor has an effect on the value of the radius of gyration that is calculated. Crosland, Thomson, et al. (2013) analyzed six different structure factors for their effect on the value of the radius of gyration. They found that the lesscomputationally expensive structure factor proposed by Lin et al. (1990) (and employed in the current work) introduced an error of less than or equal to $6 \%$ for mean aggregate radius of gyration values of up to $300 \mathrm{~nm}$ when compared to a Gaussian cutoff structure factor. Hence as described in Crosland, Johnson, et al. (2013) a multiplier in the uncertainty analysis with a standard deviation of $3 \%$ was employed.

In addition to the choice of the structure factor, the distribution of the structure factor also introduces some variance in the value of $R_{g m l}$. The choice of a lognormal distribution over the preferred self-preserving distribution (Sorensen, 2001) adds a 2-4\% difference in the soot mean aggregate radius of gyration (Snelling et al., 2011; Crosland, Johnson, et al., 2013). Therefore, an error term with a $2 \%$ standard deviation is added to the uncertainty analysis for the $R_{g m l}$ calculations. 


\subsection{Primary Particle Diameter via ELS}

Once the mean aggregate radius of gyration is determined, the primary particle diameter can then be calculated using the following equation presented by De Iuliis et al. (1998) as follows:

$$
d_{p}=\left(\frac{\lambda_{s}{ }^{3}}{\pi^{3}} \frac{4 \pi E\left(m_{\lambda_{s}}\right) K_{v v}\left(\theta_{2}\right)}{F\left(m_{\lambda_{s}}\right) f_{n} \overline{S\left(q \cdot R_{g}\right)} K_{a b s, \lambda_{s}}} \frac{1}{k_{f}\left(2 R_{g m 1}\right)^{D_{f}}}\right)^{\frac{1}{3-D_{f}}}
$$

where $\lambda_{s}$ is the wavelength of the incident scattering laser $(1064 \mathrm{~nm})$ and $K_{v v}$ is the scattering coefficient for vertically polarized light at the backward scattering angle. In the experiment this is defined as measured voltage divided by the calibration constant. $F\left(m_{\lambda_{s}}\right)$ is the scattering function of the soot refractive index (measured as 0.31 (Yon et al., 2011)). $f_{n}$ is the ratio of the first two moments of the distribution of aggregate sizes and is given by:

$$
f_{n}=\frac{\int_{0}^{\infty} N^{2} p(N) d N}{\left(\int_{0}^{\infty} N p(N) d N\right)^{2}}
$$

The absorption coefficient $\mathrm{K}_{a b s}$ is dependent on the soot volume fraction obtained from the LII experiment as described earlier in Section 2.2 and is calculated as follows (Crosland, Thomson, et al., 2013):

$$
K_{a b s, \lambda_{s}}=\frac{6 \pi E\left(m_{\lambda_{s}}\right) f_{v}}{\lambda_{s}}
$$

Similar to the modelling errors discussed for the radius of gyration, choices made in the calculation of the particle diameter also introduce uncertainties in the calculations 
(Crosland, Thomson, et al., 2013). Tian et al. (2004) demonstrated that the assumption of monodisperse primary particle diameter implied by Equation (2.9) coupled with the flame conditions in this work will overestimate the primary particle diameter by approximately 20\%. Unfortunately, as discussed in Snelling et al. (2011), it is not appropriate to just apply a correction after $d_{p}$ has been calculated because the assumption that the particles are monodisperse factors into the historical measurements and calculations of the ratio $E(m) / F(m)$. Instead, the up to $20 \%$ overestimation is accounted for in the uncertainty analysis by introducing an error term with a standard deviation of $10 \%$ on the primary particle diameter calculations.

Based on the discussion presented in Sorensen (2001), intra-aggregate multiple scattering of soot particles should enhance the ELS signal by approximately $10 \%$ in all directions. Therefore, an error term with a standard deviation of 5\% is also included in the uncertainty analysis. Finally, Crosland, Thomson, et al. (2013) suggested that the absorption of the ELS signal by soot in the specific flame being studied here will introduce around $6.6 \%$ uncertainty in the calculations of $K_{v v}$. To account for this, an error term with a standard deviation of $3.3 \%$ is included in the uncertainty analysis for $K_{v v}$. 


\section{Chapter 3}

\section{Experimental Setup and Procedure}

\subsection{General Arrangement}

Due to the potential for significant radiation heat transfer from the target large flames to be measured, the laser head as well as all the optics were mounted on an invar hoop and could be shielded from the flame to reduce the exposure to heat. A detailed, dimensioned engineering drawing is provided in Appendix A. Invar is a nickel-iron alloy with a very low coefficient of thermal expansion of less than $1.3 \times 10^{-6 \circ} \mathrm{C}^{-1}$. Hence, it would remain stable when exposed to the heat from the flame, preserving the alignment of the optics. The hoop was designed while taking into consideration the mechanical loads that were going to be applied on the hoop and the anticipated heating from the flame to ensure the bending and warping of the arms was minimized. The design had to meet the ultimate goals of the project, which are to perform instantaneous measurements on large scale lab flares. The Carleton flaring facility has the capability of burning up to $4001 / \mathrm{min}$ of methane-based hydrocarbon fuel producing flames of up to $3 \mathrm{~m}$ in height. Therefore, the hoop was designed to have a radius of $750 \mathrm{~mm}$ to accommodate measurements on these larger flares. Invar platforms were welded to the hoop to provide support for the optics. A photograph of the hoop is shown in Figure 3.1, whereas Figure 3.2 shows a schematic of the general layout of the apparatus. 


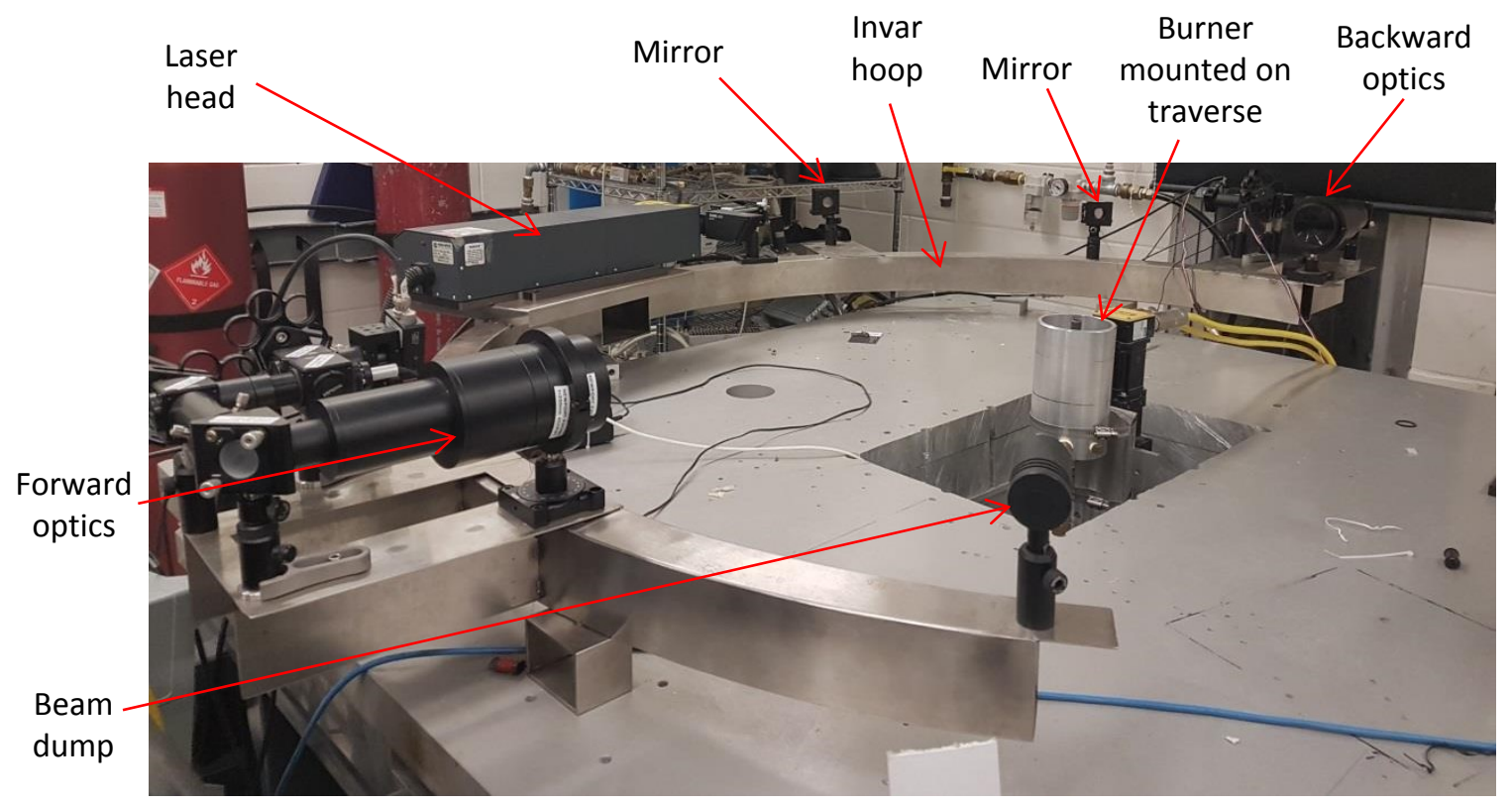

Figure 3.1: A photograph of the invar hoop with the optics and the excitation laser mounted on it. The assembly is centered around the burner in the middle

The general procedure followed in this experiment was to direct the $1064 \mathrm{~nm} \mathrm{Nd:YAG}$ laser into the measurement volume after being formed into a sheet. The laser induced scattering and incandescence as it illuminated soot particles present inside the flame. These signals were collected using the collection optics which were placed at a forward angle $\left(\theta_{1}\right)$ of $30^{\circ}$ and a backward angle $\left(\theta_{2}\right)$ of $150^{\circ}$. The optics were aligned so that the measurement volume of both sets of optics coincided inside the flame. The signals were then spectrally filtered and directed onto detectors that sensed the scattering at $1064 \mathrm{~nm}$, and incandescence signals at $775 \mathrm{~nm}$ and $447 \mathrm{~nm}$. The detector signals were then passed through gated integrators to be gated in time before being digitized and stored in the computer for processing and analysis. 


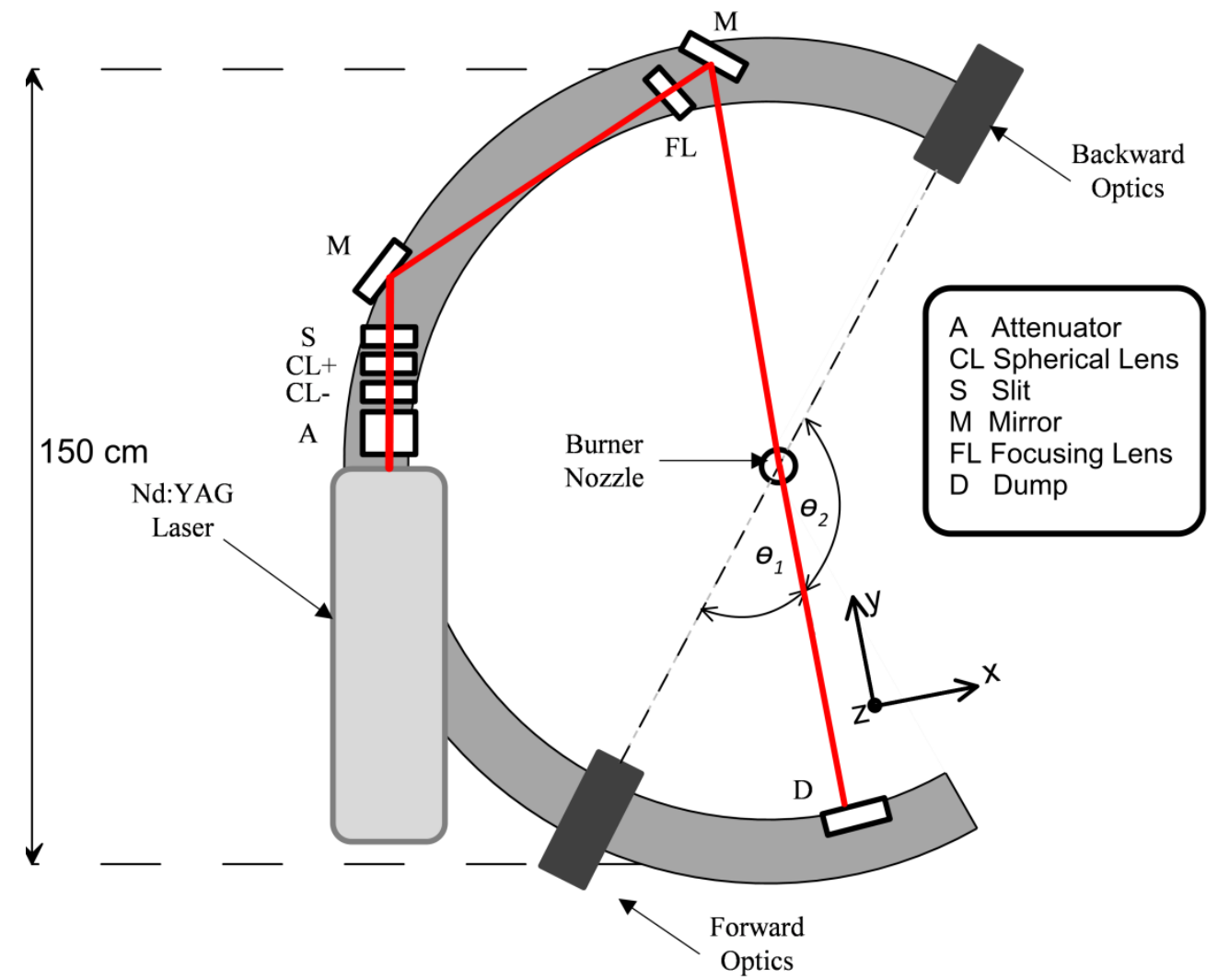

Figure 3.2: General layout of the shaping and detection optics mouinted on the invar hoop

\subsection{Excitation Laser}

A New Wave Research, SOLO 120 pulsed Nd:YAG laser operating at $1064 \mathrm{~nm}$ and $15 \mathrm{~Hz}$ was used to provide the scattering as well as induce the incandescence. The laser pulse was triggered externally through a Berkeley Nucleonics BNC pulse generator to ensure that the laser was firing in sync with the rest of the apparatus. The laser beam was first passed through a variable beam attenuator (Thorlabs VBA05-1064) to control the power of the laser and to ensure that the mean fluence of the laser sheet was high enough to maximize the LII signal but not too high to cause sublimation of the soot particles.

A set of cylindrical lenses (Thorlabs LK1336RM-C and LK1419RM-C) with focal lengths of $-50 \mathrm{~mm}$ and $150 \mathrm{~mm}$ were used to expand the laser beam into a vertical 
fan. The laser beam was then passed into a $3 \times 0.2 \mathrm{~mm}$ slit to produce a uniform laser sheet with a mean fluence of $1.0 \mathrm{~mJ} / \mathrm{mm}^{2}$. The laser profiles plotted in Figure 3.3 were measured with a Coherent LaserCam-HR camera by capturing images of the laser sheet as it passed through the measurement volume. The power was measured using an Ophir laser power meter. The images were then processed, and when combined with the measurement of the laser power, the laser fluence was calculated.

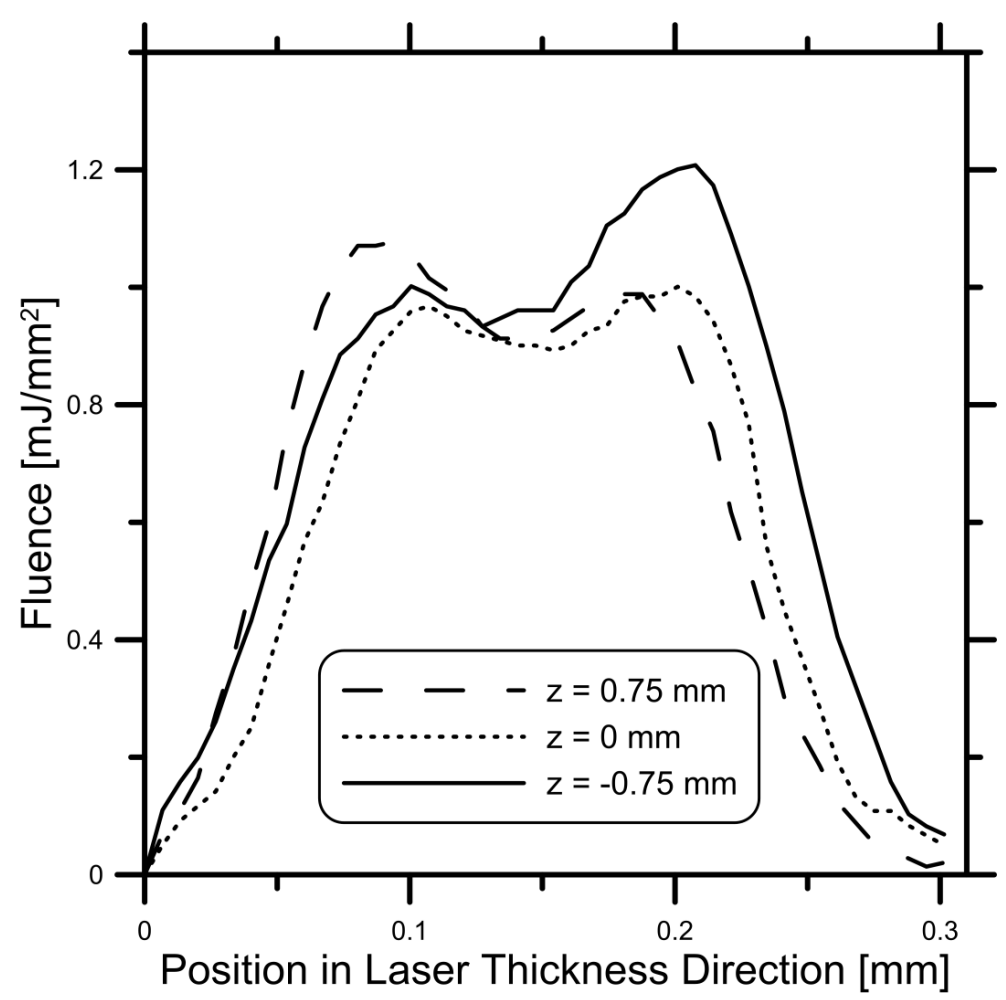

Figure 3.3: Laser fluence profiles at three different heights relative to the centre of the laser sheet taken inside the measurement volume. The mean fluence is approximately $1 \mathrm{~mJ} / \mathrm{mm}^{2}$

As shown in Figure 3.3, regardless of the height inside the sheet the mean laser fluence is approximately $1.0 \mathrm{~mJ} / \mathrm{mm}^{2}$. The measured laser profiles served as inputs to the LII simulations that were used to calculate the equivalent sheet thickness $\left(w_{e}\right)$. Doing so allowed the shape of the laser profiles to be taken into account when making the calculations of $w_{e}$. The parameters used as the input function for the simulation were the 
soot index of refraction absorption function $\left(0.21<E\left(m_{\lambda_{1}}\right)<0.41\right.$ and $\left.0.8<E\left(m_{\lambda_{1}}\right) / E\left(m_{\lambda_{2}}\right)<1.2\right)$, the thermal accommodation coefficient $(0.2<\alpha<0.5)$, the initial gas temperature $\left(1500 \mathrm{~K}<T_{g}<2100 \mathrm{~K}\right)$, and the primary particle diameter $(15 \mathrm{~nm}$ $<d_{p}<60 \mathrm{~nm}$ ) (Crosland, Thomson, et al., 2013). The resulting distribution of equivalent sheet thicknesses exhibited a normal distribution with a mean of $0.17 \mathrm{~mm}$ and a standard deviation of $0.1 \mathrm{~mm}$. The calculations were repeated for multiple planes inside the measurement volume and the results showed that the resulting equivalent sheet thickness was independent of the location within the measurement volume.

The laser sheet was then directed into the measurement volume using a pair of Thorlabs NK1K14 Nd:YAG laser mirrors. A Thorlabs LB1475-C 400 mm lens with an N-BK7 coating was used to project the image of the aperture into the measurement volume by refocusing the rays that have been diffracted after the laser passed through the slit aperture. At the opposing end of the hoop, a beam dump was used to collect the remainder of excitation laser light that has passed through the flame without being absorbed or scattered. Table 3.1 summarizes the optics that were used to produce the excitation laser sheet and direct it into the measurement volume. A description of each part is given along with the corresponding part number and vendor. 
Table 3.1: Summary of the parts used to form the excitation laser sheet and focus it into the measurement volume

\begin{tabular}{|c|c|c|c|}
\hline $\begin{array}{l}\text { Part (symbol in } \\
\text { Figure 3.2: General } \\
\text { layout of the } \\
\text { shaping and } \\
\text { detection optics } \\
\text { mouinted on the } \\
\text { invar hoop }\end{array}$ & Part Number & Vendor & Description \\
\hline Beam attenuator (A) & VBA05-1064 & Thorlabs & $\begin{array}{c}\text { A combination of a } \lambda / 2 \\
\text { waveplate and thin-film } \\
\text { polarizer used to adjust laser } \\
\text { output }\end{array}$ \\
\hline $\begin{array}{l}-50 \text { mm cylindrical } \\
\text { lens (CL-) }\end{array}$ & LK1336RM-C & Thorlabs & $\begin{array}{l}\text { Expands the laser beam into a } \\
\text { vertical fan }\end{array}$ \\
\hline $\begin{array}{l}150 \text { mm cylindrical } \\
\text { lens (CL-) }\end{array}$ & LK1419RM-C & Thorlabs & $\begin{array}{l}\text { Expands the laser beam into a } \\
\text { vertical fan }\end{array}$ \\
\hline $\begin{array}{l}200 \mu \mathrm{m} \text { slit aperture } \\
\text { (S) }\end{array}$ & S200R & Thorlabs & $\begin{array}{l}\text { Slit aperture used to form the } \\
\text { laser sheet. }\end{array}$ \\
\hline $\begin{array}{l}\text { Nd:YAG laser mirror } \\
\text { (M) }\end{array}$ & NK1-K14 & Thorlabs & $\begin{array}{l}\text { Used to turn the beam toward } \\
\text { the measurement volume }\end{array}$ \\
\hline $\begin{array}{l}\text { Nd:YAG laser mirror } \\
\text { (M) }\end{array}$ & NK1-K14 & Thorlabs & $\begin{array}{l}\text { Used to turn the beam toward } \\
\text { the measurement volume. }\end{array}$ \\
\hline $\begin{array}{l}400 \mathrm{~mm} \text { spherical } \\
\text { focusing lens ( } F L \text { ) }\end{array}$ & LB1475-C & Thorlabs & $\begin{array}{l}\text { Used to project the image of the } \\
\text { aperture into the measurement } \\
\text { volume by re-focusing the } \\
\text { diffracted rays }\end{array}$ \\
\hline Beam dump (D) & ABD-0.75NP & Kentek laser store & $\begin{array}{c}\text { Collects remainder of excitation } \\
\text { beam for safety }\end{array}$ \\
\hline
\end{tabular}

\subsection{Collection and Detection Optics and Detectors}

Both the forward and backward optics (as defined in Figure 3.2) consisted of a set of collection optics and detection optics. The collection optics were used to collect the scattering and LII signal from the measurement volume $750 \mathrm{~mm}$ away and focus it onto a 
pinhole aperture. The detection optics then filtered the signal spectrally and focused it onto the respective detectors. The collection optics for the forward and backward directions were identical, while the detectors and associated optics were different.

\subsubsection{Collection Optics Common to Forward and Backward Directions}

Two 3 inch achromatic doublets (Newport PAC097 and PAC095) with focal lengths of $750 \mathrm{~mm}$ and $250 \mathrm{~mm}$ were used to collect the signals from the measurement volume $750 \mathrm{~mm}$ away and project it onto a pinhole aperture located $250 \mathrm{~mm}$ further away along the optical path. The pinhole aperture was used to define the measurement volume. Table 3.2 below presents the different dimensions for the pinholes used in the experiment along with the corresponding dimensions of the ellipses defining the measurement volume and the total volume.

Table 3.2: Different pinhole sizes used and the corresponding measurement volume dimensions

\begin{tabular}{|c|c|c|}
\hline $\begin{array}{c}\text { Pinhole Size } \\
{[\mu \mathrm{m}]}\end{array}$ & $\begin{array}{c}\text { Measurement Volume Dimensions } \\
{[\mathrm{mm}]}\end{array}$ & $\begin{array}{c}\text { Measurement Volume } \\
{\left[\mathrm{mm}^{3}\right]}\end{array}$ \\
\hline $\mathbf{5 0 0} \boldsymbol{\mu \mathrm { m }}$ & $3 \times 1.5 \times 0.2$ & 0.709 \\
\hline $\mathbf{3 0 0} \boldsymbol{\mu \mathrm { m }}$ & $1.8 \times 0.9 \times 0.2$ & 0.254 \\
\hline $\mathbf{2 0 0} \boldsymbol{\mu \mathrm { m }}$ & $1.2 \times 0.6 \times 0.2$ & 0.113 \\
\hline $\mathbf{1 5 0} \boldsymbol{\mu m}$ & $0.9 \times 0.45 \times 0.2$ & 0.064 \\
\hline
\end{tabular}

A silver-coated Thorlabs PF10-03-P01 mirror was used to turn the signal $90^{\circ}$ onto the axis of the detectors. The signal was collimated using a $50 \mathrm{~mm}$ spherical lens (ThorLabs $32-323)$ 
Due to the spatial variations of the soot inside the flame, it is important to ensure that the detection optics are aligned to the same point inside the flame. A bias would be introduced if the forward and the backward collection optics do not sample the same measurement volume (Oltmann et al., 2012). To avoid this, the backward and forward collection optics were aligned at $150^{\circ}$ and $30^{\circ}$ relative to the direction of laser sheet propagation, such that the measurement volume locations of both angles were coincident along the same optical axis and occurred at the common focal length of both sets of optics. Since both the ELS and LII detectors were incorporated into the same setup, the measurement volume remained the same across all instantaneous measurements of the scattering signal (both forward and backward) as well as the LII signal at both the blue and red wavelengths. Due to the differences in the arrangement of the filters on either side (to be discussed below), a different wavelength alignment laser was implemented on each side. The alignment laser was shone back through the optical system to check the alignment of the pinhole and to make sure that the measurement volumes of both sets of optics coincided. A $633 \mathrm{~nm}$ laser was used on the forward side, while a $532 \mathrm{~nm}$ laser was used for the backward side. Table 3.3 summarizes the optics used for both the forward and backward angles. 
Table 3.3: Summary of collection optics common to both sides

\begin{tabular}{|c|c|c|c|}
\hline Part & Part Number & Vendor & Description \\
\hline $\begin{array}{l}3 \text { " diameter } \mathrm{f}=750 \mathrm{~mm} \\
\text { achromatic doublet }\end{array}$ & PAC097 & Newport & $\begin{array}{l}\text { Used to collect light from measurement } \\
\text { volume } 750 \mathrm{~mm} \text { away }\end{array}$ \\
\hline $\begin{array}{l}3 \text { " diameter } \mathrm{f}=250 \mathrm{~mm} \\
\text { achromatic doublet }\end{array}$ & PAC095 & Newport & $\begin{array}{l}\text { Used to focus collected light onto } \\
\text { aperture } 250 \mathrm{~mm} \text { away }\end{array}$ \\
\hline $\begin{array}{l}\text { 1" diameter silver coated } \\
\text { mirror }\end{array}$ & PF10-03-P01 & Thorlabs & Used to turn the signal $90^{\circ}$ to save space \\
\hline $500 \mu \mathrm{m}$ precision pinhole & P100S & Thorlabs & Defines the measurement volume \\
\hline $\begin{array}{l}\text { 1" diameter, } f=50 \mathrm{~mm} \\
\text { spherical lens }\end{array}$ & $32-323$ & $\begin{array}{l}\text { Edmund } \\
\text { Optics }\end{array}$ & Used to collimate the signal beam \\
\hline
\end{tabular}

Figure 3.4 is a simplified ray trace diagram that illustrates the light travel through the collection optics

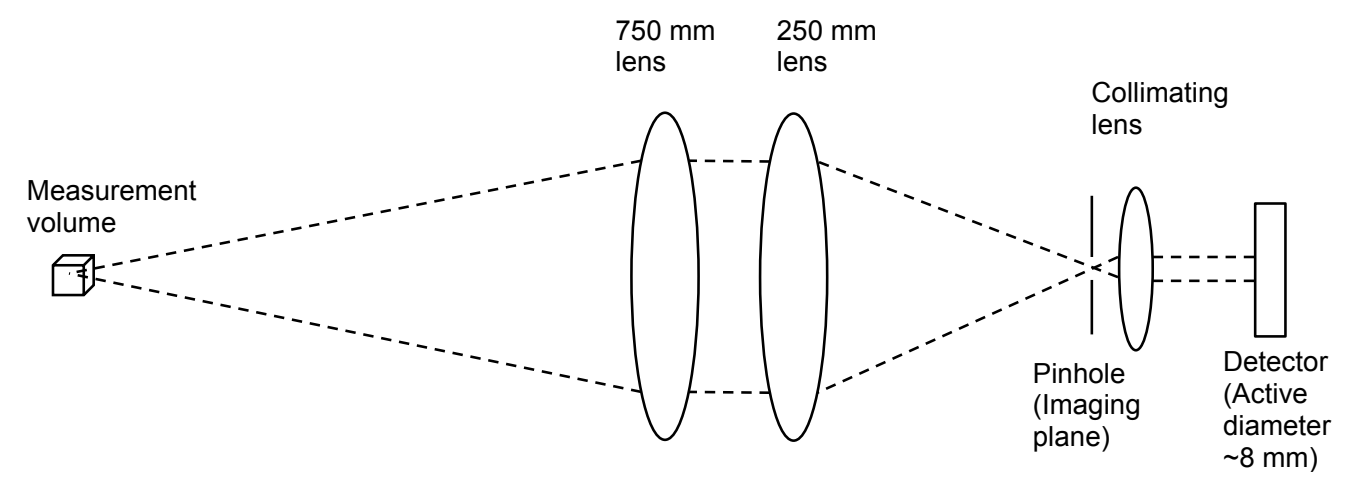

Figure 3.4: Ray trace diagram for light travel through the collection optics

\subsubsection{Backward Angle Detectors and Optics}

The backward side detector setup is shown in Figure 3.5. A combination of cage cube connectors with shortpass filters was used to spectrally filter the collimated signal. Three shortpass filters with wavelength upper limits of (i) $500 \mathrm{~nm}$ (ii) $600 \mathrm{~nm}$ and (iii) $850 \mathrm{~nm}$ 
were used to spectrally split the signal. The signal line was then filtered at $447 \mathrm{~nm}$ and $775 \mathrm{~nm}$ for the LII experiment and the remaining $1064 \mathrm{~nm}$ signal was used for the ELS experiment. A Thorlabs DET-10C was used to detect the ELS signal while PMT tubes were used to measure the incandescence signal. A Hamamtsu Multiakali PMT (H1072120) was used for the red signal while a Hamamatsu Biakali PMT (H1072-110) was used for the blue signal. Neutral density filters were used in front of all the detectors and PMT tubes during calibration to avoid the detector saturation.

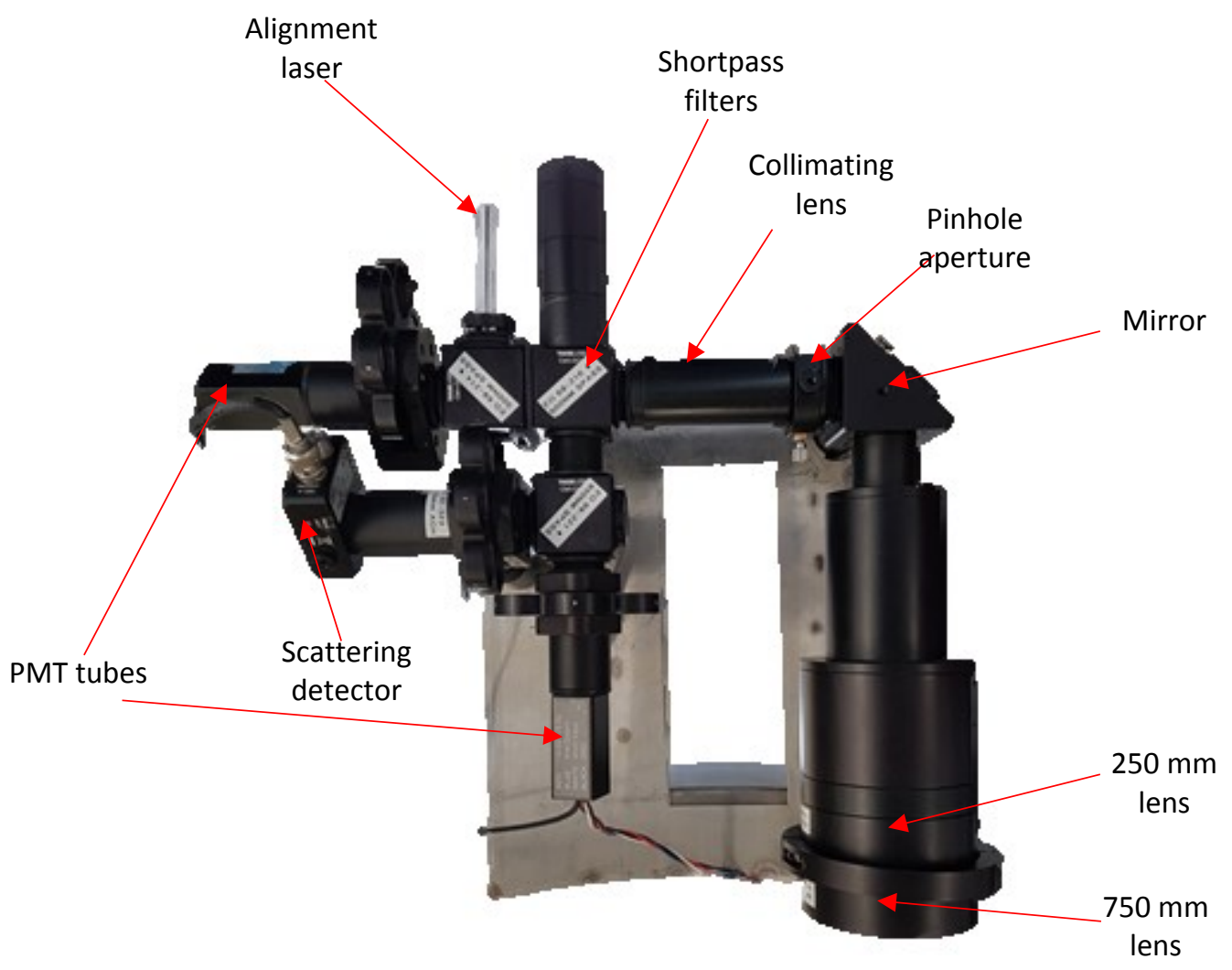

Figure 3.5: Backward optics on the invar mount

\subsubsection{Forward Angle Detectors and Optics}

Figure 3.6 shows the forward detector setup that was used in the experiment. Similar to the arrangement on the backward side, the signal on the forward side was also spectrally 
filtered onto their respective detectors. An identical Thorlabs DET-10C was used to measure the ELS signal, while Avalanche Si photodiodes (APD120A2) were used for the $447 \mathrm{~nm}$ and $775 \mathrm{~nm}$ LII signals. It is important to note that the different LII detectors on the front side were intended to capture any spikes in the LII signal that the PMT tubes were not capable of measuring. However, since the current work only performed the measurements in a steady laminar flame, the signals from those detectors were not used. Nevertheless, they will be of use when measurements are performed on turbulent flames.

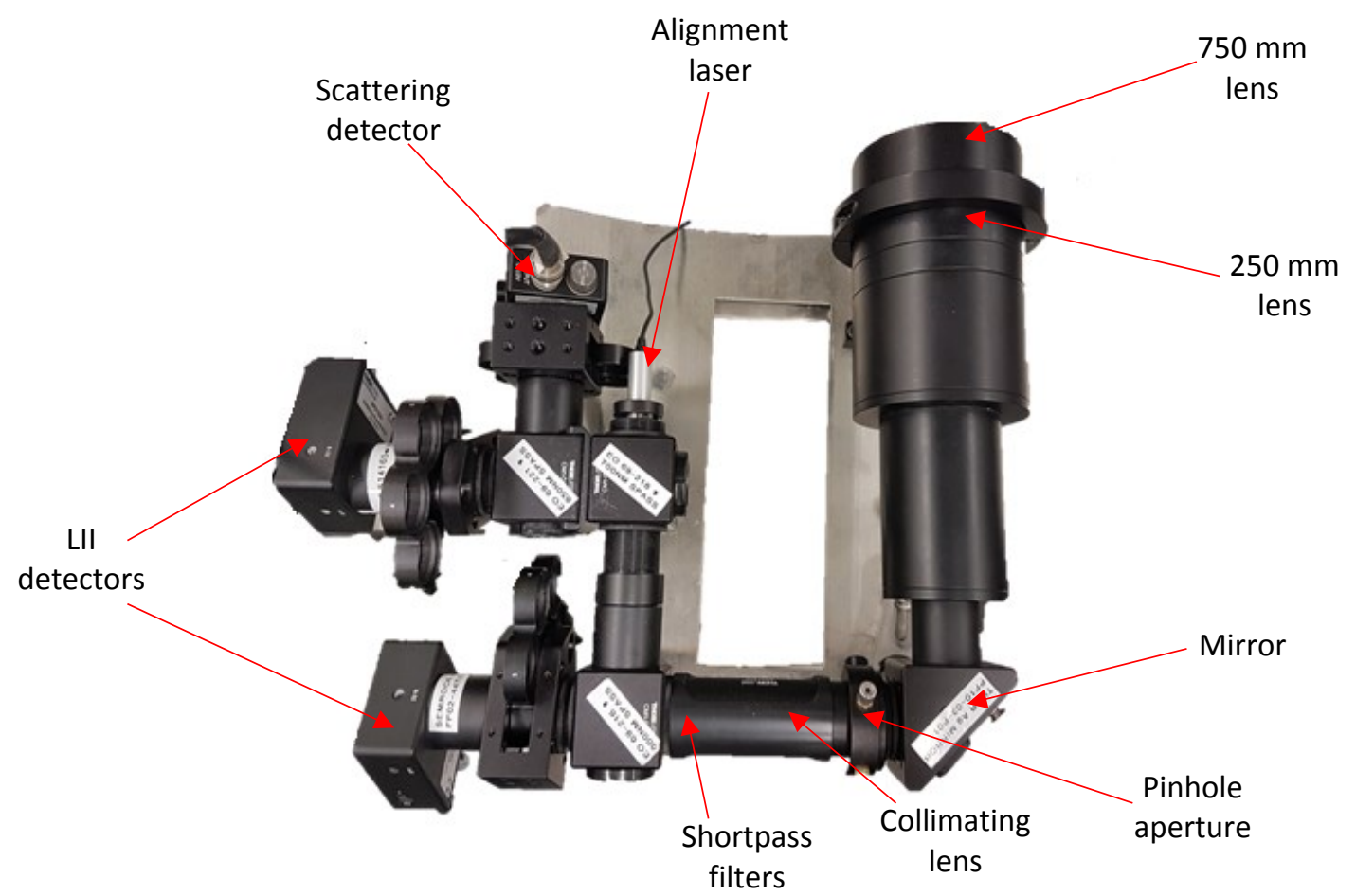

Figure 3.6: Forward optics on the invar mount

Table 3.4 shows the components used to filter and detect the signal on both the front and backward directions. The part numbers as well as a description of the parts are provided. 
Table 3.4: Summary of the detection optics used in the experiment

\begin{tabular}{|c|c|c|c|c|}
\hline & Part & Part Number & Vendor & Description \\
\hline \multirow{9}{*}{ 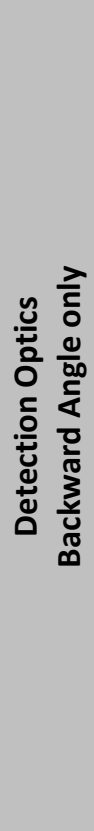 } & $\begin{array}{c}400 \mathrm{~nm} \\
\text { shortpass filter }\end{array}$ & $69-216$ & $\begin{array}{l}\text { Edmund } \\
\text { Optics }\end{array}$ & $\begin{array}{c}\text { Allows LII-blue and } 532 \mathrm{~nm} \text { alignment laser } \\
\text { beams through, reflects all else }\end{array}$ \\
\hline & $\begin{array}{l}500 \mathrm{~nm} \\
\text { shortpass filter }\end{array}$ & $69-214$ & $\begin{array}{l}\text { Edmund } \\
\text { Optics }\end{array}$ & $\begin{array}{l}\text { Allows LII-blue beam through and reflects } \\
\text { 532nm alignment beam }\end{array}$ \\
\hline & $\begin{array}{c}447 / 60 \\
\text { bandpass filter }\end{array}$ & $\begin{array}{l}\text { FF01-447/60- } \\
25\end{array}$ & Semrock & Used to select wavelength for LII \\
\hline & Bialkali PMT & $\mathrm{H} 1072-110$ & Hamamatsu & Detects LII-Blue signal on BS side \\
\hline & $\begin{array}{l}532 \mathrm{~nm} \\
\text { alignment laser }\end{array}$ & CPS532 & Thorlabs & $\begin{array}{c}\text { Used to send laser beam backward } \\
\text { through optics to allow meas volume } \\
\text { alignment }\end{array}$ \\
\hline & $\begin{array}{c}850 \mathrm{~nm} \\
\text { shortpass filter }\end{array}$ & $69-221$ & $\begin{array}{l}\text { Edmund } \\
\text { Optics }\end{array}$ & $\begin{array}{l}\text { Allows LII-Red beam through and reflects } \\
\qquad 1064 \mathrm{~nm} \text { ELS beam }\end{array}$ \\
\hline & $\begin{array}{l}\text { 785/62 } \\
\text { bandpass filter }\end{array}$ & $\begin{array}{l}\text { FF01-785/62- } \\
25\end{array}$ & Semrock & Used to select wavelength for LII \\
\hline & Multialkali PMT & H10721-20 & Hamamatsu & Detects LII-Red signal on BS side \\
\hline & $\begin{array}{c}\text { Biased Si } \\
\text { photodiode }\end{array}$ & DET10C & Thorlabs & Detects ELS \\
\hline \multirow{9}{*}{ 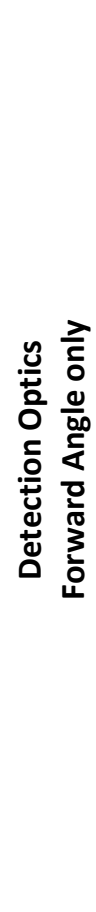 } & $\begin{array}{c}400-600 \mathrm{~nm} \\
\text { shortpass filter }\end{array}$ & $69-216$ & $\begin{array}{l}\text { Edmund } \\
\text { Optics }\end{array}$ & $\begin{array}{c}\text { Allows LII-blue and } 532 \mathrm{~nm} \text { alignment laser } \\
\text { beams through, reflects all else }\end{array}$ \\
\hline & $\begin{array}{c}\text { 700nm } \\
\text { shortpass filter }\end{array}$ & $69-218$ & $\begin{array}{l}\text { Edmund } \\
\text { Optics }\end{array}$ & $\begin{array}{l}\text { Allows LII-blue beam through and reflects } \\
532 \mathrm{~nm} \text { alignment beam }\end{array}$ \\
\hline & $\begin{array}{c}447 / 60 \\
\text { bandpass filter }\end{array}$ & $\begin{array}{c}\text { FF01-447/60- } \\
25\end{array}$ & Semrock & Used to select wavelength for LII \\
\hline & $\begin{array}{l}\text { Avalanche } \mathrm{Si} \\
\text { photodiode }\end{array}$ & APD120A2 & Thorlabs & Detects LII-Blue signal on FS side \\
\hline & $\begin{array}{l}633 \mathrm{~nm} \\
\text { alignment laser }\end{array}$ & CPS182 & Thorlabs & $\begin{array}{l}\text { Used to send laser beam backward } \\
\text { through optics to allow meas volume } \\
\text { alignment }\end{array}$ \\
\hline & $\begin{array}{c}850 \mathrm{~nm} \\
\text { shortpass filter }\end{array}$ & $69-221$ & $\begin{array}{l}\text { Edmund } \\
\text { Optics }\end{array}$ & $\begin{array}{l}\text { Allows LII-Red beam through and reflects } \\
\qquad 1064 \mathrm{~nm} \text { ELS beam }\end{array}$ \\
\hline & $\begin{array}{c}\text { 785/62 } \\
\text { bandpass filter }\end{array}$ & $\begin{array}{l}\text { FF01-785/62- } \\
25\end{array}$ & Semrock & Used to select wavelength for LII \\
\hline & $\begin{array}{l}\text { Avalanche Si } \\
\text { photodiode }\end{array}$ & APD120A2 & Thorlabs & Detects LII-Red signal on FS side \\
\hline & $\begin{array}{c}\text { Biased } \mathrm{Si} \\
\text { photodiode }\end{array}$ & DET10C & Thorlabs & Detects ELS \\
\hline
\end{tabular}




\subsection{Signal Treatment}

The signal from all the detectors and PMTs were carried via BNC cables to gated integrators (Stanford Research SR250) to be time-averaged during the period of the gate. A $10 \mathrm{~ns}$ averaging gate was initiated $30 \mathrm{~ns}$ after the onset of a PMT response for the LII signals while $30 \mathrm{~ns}$ gates were used for the scattering signals. The gates were chosen in accordance with the work done by Crosland (2013) as an optimization between the signal strength and the uncertainties in the equivalent sheet thickness calculations. The integrated signals were then passed through BNC cables to a National Instruments NI cDAQ-9188xt data acquisition system. The signals were then digitized and stored for further processing. A Labview software program was used to compute live results and control the different instruments. The gated integrators and data acquisition system were both triggered externally at $15 \mathrm{~Hz}$ using the same pulse generator that was used to trigger the firing of the laser.

\subsection{Burner}

The burner used in the experiment was a standard co-annular, laminar diffusion flame burner (Gülder and Snelling, 1993). Ethylene flowed through the $10.9 \mathrm{~mm}$ diameter, steel central fuel tube at a rate of $0.24 \mathrm{~g} / \mathrm{min}$ (mean velocity of $0.034 \mathrm{~m} / \mathrm{s}$ ), while an air co-flow at $367 \mathrm{~g} / \mathrm{min}$ (mean velocity of $0.695 \mathrm{~m} / \mathrm{s}$ ) flowed through the $90 \mathrm{~mm}$ diameter annulus. These flow conditions result in a laminar flame with a fuel flow Reynolds number of approximately 50 and an air to ethylene velocity ratio of approximately 20 . Comparing the gate widths of a few nanoseconds to the flow velocity of air confirms that the measurements are effectively the instantaneous relative to the flow. All experiments were performed at laboratory conditions with nominal temperature of $21^{\circ} \mathrm{C}$ and pressure 
of $1 \mathrm{~atm}$. This produced a steady, unbroken laminar flame with an approximate visible height of $65 \mathrm{~mm}$. This burner was chosen because of the well-studied soot formation properties of these standard flames at a flame height of $42 \mathrm{~mm}$. This allowed direct comparison to published results at this same flow condition for validation of the setup and evaluation of the uncertainties of the proposed measuring technique. The burner was mounted on a Parker Automation traverse system to allow three degrees of freedom movement in the $x, y$ and $z$ directions. This traverse system was used to provide the spatial accuracy needed when identifying the measurement location.

The burner was connected to two SLA 5800 series Brooks Mass flow controllers that controlled the flow rates of the ethylene and the co-flowing air. A compressed cylinder provided the ethylene while the air was taken from the compressed air lines running through the building. In each case the gasses were regulated down in pressure before the mass flow controller inlets. The air mass flow controller was calibrated using a Siemens Coriolis flow meter. A Sensidyne Gilibrator-2 was used to calibrate the ethylene mass flow controller. The calibration of the mass flow controller was important as high accuracy on the flowrates was required to ensure that the Gülder conditions were replicated. 


\section{Chapter 4}

\section{Calibration}

This chapter highlights the theory and procedures for calibrating the detectors used to measure scattering and LII signals. The calibration of the detectors enables the conversion of the voltages registered by the detectors to light intensity measurements, which can then be used to make measurements of the incandescence and scattering of the soot particles. Example calibration results with the $500 \mu \mathrm{m}$ pinhole are presented in detail, while a summary of the calibration constants for all the pinholes used in the experiment is presented at the end of the chapter.

\subsection{Scattering Calibration}

The method for calibrating the elastic light scattering detectors was based on the diffusesurface method first proposed in Crosland et al. (2013). The more common calibration method based on the Rayleigh scattering from pure gasses such as nitrogen or propane with known scattering cross-section (Sorensen, 2001) was rejected due to several inherent limitations. These include: 1) Scattering from ambient sources adds background interference that is too significant to be ignored. 2) The scattering signal obtained from the small gas molecules is very weak compared to that from particles during the actual experiment, such that additional signal filtering or change of gain settings is generally required during the experiment to avoid detector saturation (which introduces a bias error). 3) The weak signal during calibration also means that the standard calibration 
approach is not suitable for less sensitive detectors and photodiodes, and therefore stronger detectors such as PMTs have to be used and this brings along a deterioration of the signal to noise ratio and increases the photon shot noise. 4) Uncertainties of the scattering cross section of the small molecules used in the calibration contribute directly to the uncertainty of the measurement.

Crosland, Johnson, et al. (2013) instead proposed the use of a Lambertian surface during the scattering calibration procedure, which produces calibration signals that are up to 7 orders of magnitude larger than that achievable from gas molecules. This improves the accuracy by increasing the signal to noise ratio and decreasing the photon shot noise. This also allows for the use of less sensitive photodiodes that capture a larger number of photons before saturation and possess better performance characteristics at $1064 \mathrm{~nm}$ relative to the PMTs that are more commonly used. Crosland et al. (2013) provided a comparison of both methods and showed that the Lambertian scattering method provided comparable scattering coefficients while reducing the uncertainties in the measurements.

\subsubsection{Theory}

Because the diffuse surface used for the absolute calibration of the detectors was opaque, it was only possible to do the calibration of one plane at a time. Consistent with the method proposed by Crosland et al. (2013), the surface was traversed along the optical axis to capture the entire measurement volume. The calibration was then expressed through the following integral: 


$$
\int_{Z} \Delta \varphi_{c a l}(z) d z=\eta \int_{z} E d z
$$

where $\Delta \varphi_{\text {cal }}$ is the calibration signal obtained at each plane (measured in $\mathrm{V}$ ) and $\eta$ is the optical calibration constant $[\mathrm{V} / \mathrm{J}] . \quad E$ is the energy collected at each plane $[\mathrm{J}]$ and is calculated according to the following formula if the surface is considered to be Lambertian:

$$
E_{D}=R_{i} r_{S} \frac{(1-\rho) \cos [\beta(z)]}{\pi} \Omega_{\operatorname{det}}(z) A(z)
$$

where $R_{i}$ is the irradiance of the incident beam $\left[\mathrm{J} / \mathrm{m}^{2}\right], r_{s}$ and $\rho$ are the reflectivity and depolarization ratios of the surface used in calibration [-], $\beta(z)$ is the angle [rad] between the surface and the location of the optics. $\Omega_{\text {det }}$ is the solid angle [sr] of detection and $A(z)$ is the irradiated area $\left[\mathrm{m}^{2}\right]$ on the detector surface. The depolarization ratio in this instance is defined as the ratio of the depolarized scattered light to the total scattered light by the diffuse surface which is important as the experiment is set up for vertically polarized light.

Combining Equations (4.1) and (4.2) and isolating the terms which are common to both the calibration and actual experiment allows a relative calibration constant, $C_{D}$, to be defined as a function of the known properties of the surface:

$$
\eta_{D} R_{i} \Omega_{d e t} V_{m r}=C_{D}=\frac{\int \Delta \varphi_{\text {meas }}(z) d z}{r_{s} \frac{(1-\rho) \cos \beta}{\pi}}
$$

where $V_{m r}$ is the size of the measurement volume $\left[\mathrm{m}^{3}\right]$. 
The use of different neutral density filters that are either added or removed between the calibration procedure and the actual experiment to prevent detector saturation needs to be considered. Hence, the scattering coefficient for vertically polarized light (which is used in this experiment), $K_{v v}$, can be defined as follows:

$$
K_{v v}\left(\theta_{\text {exp }}\right)=\frac{\Delta \varphi_{\text {exp }}}{D_{\text {filt }} C_{D}}
$$

where $\Delta \varphi_{\exp }$ is the voltage signal that is measured during the scattering experiment and $D_{\text {filt }}$ is the product of all the filters that are added or removed in the experiment.

The method described above is only suitable for calibration of backward scattering optics as the scattering signal becomes weaker when the angle between the incident ray and the normal of the scattering surface increases. To transfer the calibration to the forward scattering optics, an integrating sphere was used and the ratio of the measured signal from the output of the sphere detected at the forward and the backward angles provided the scattering coefficient for the forward angle. Details of the procedure are provided below.

\subsubsection{Scattering Calibration Implementation}

Figure 4.1 shows a photo of the piece of $1.5-\mathrm{cm}$ diameter spectralon puck placed within the measurement volume was used to scatter the light for calibration. At $1064 \mathrm{~nm}$, spectralon has a reflectivity, $r_{s}$, of over $99 \%$ and a depolarization ratio, $\sigma$, of 0.48 . The spectralon disk was mounted on a Parker Automotive traverse and directed toward the backward scattering $\left(\theta=150^{\circ}\right)$ optics forming an angle $\beta$ between the normal of the spectralon surface and the axis of detection (See Figure 4.2), where $\beta$ was approximately $0^{\circ}$ during the calibration. 


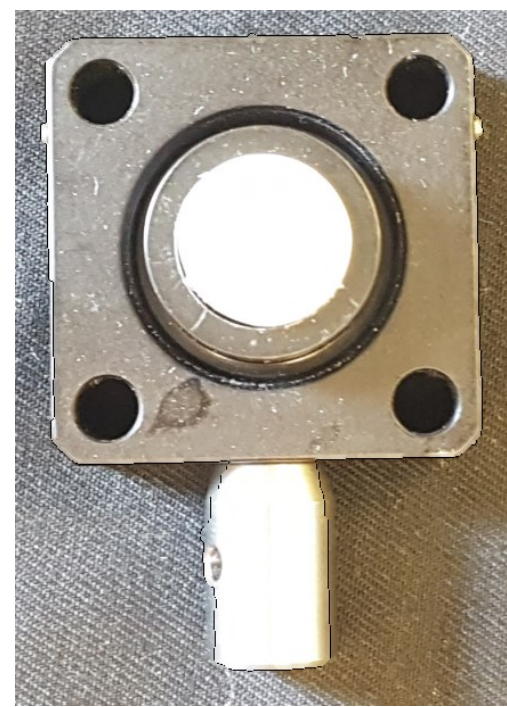

Figure 4.1: Spectralon puck used to calibrate the backwards optics mounted on a custommade mount

As illustrated in the schematic shown in Figure 4.2, the same Solo120 pulsed $\mathrm{Nd}$ :YAG laser that was used for the experiment was used to perform the scattering calibration. The laser was formed into a $3 \mathrm{~mm}$ tall by $0.2 \mathrm{~mm}$ thick sheet and directed onto the spectralon puck. The optics arrangement remained unchanged from the experiment as described in Section 3.3 with the exception of the neutral density filters that were added to ensure that the photodetectors were not saturated by the signal scattered from the puck. The scattering signal was recorded at each location as the puck was traversed along the axis of the detection optics (refer to Figure 4.2 below) in $0.5 \mathrm{~mm}$ increments to capture the signal throughout the entire measurement volume. The resulting signals were integrated in space according to Equation (4.3) to obtain the calibration constant. 


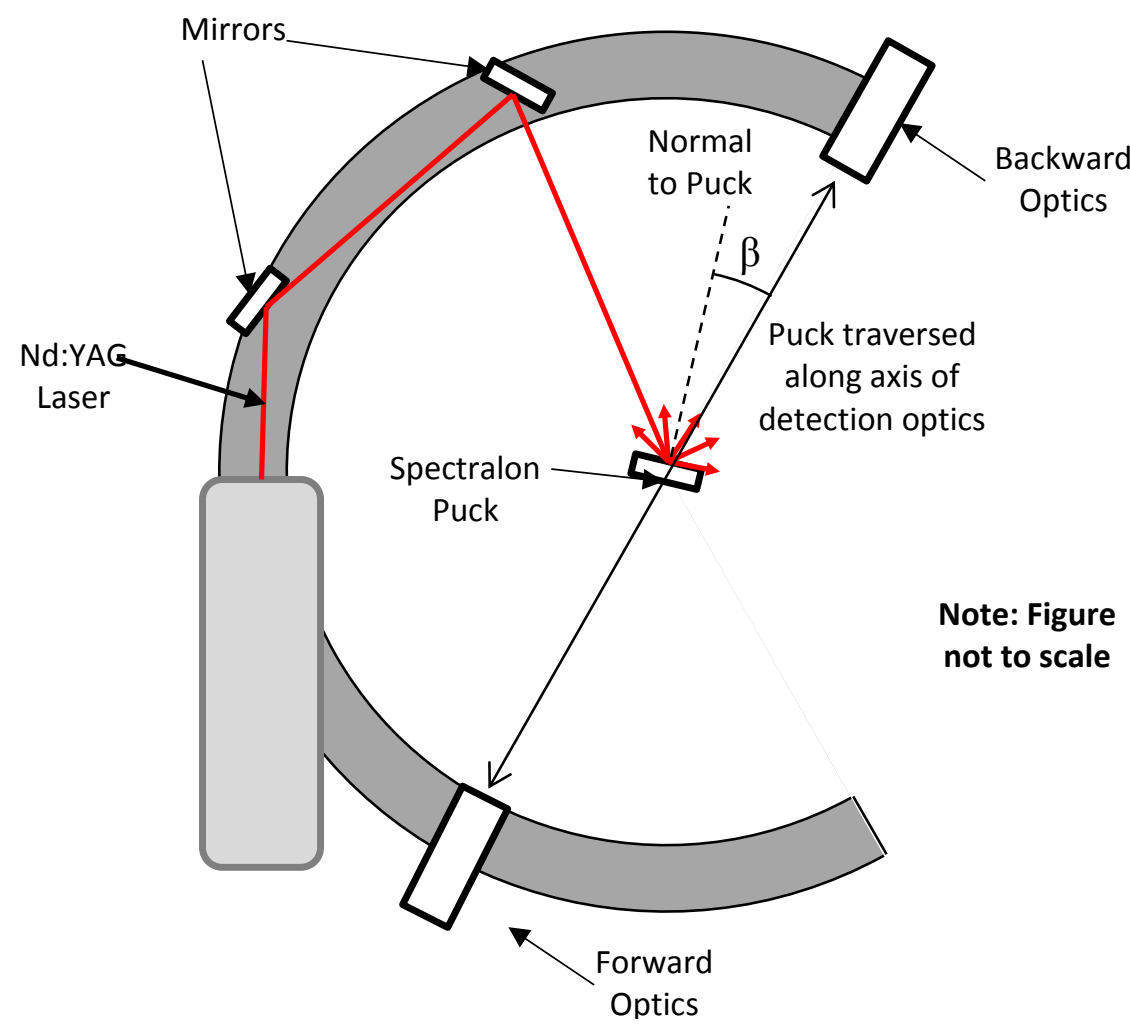

Figure 4.2: Calibration of the backward scattering optics using a diffuse spectralon puck mounted on a traverse along the optical axis

To transfer the calibration from the backward scattering optics to the forward scattering optics $\left(\theta=-30^{\circ}\right)$, a Labsphere spectralon integrating sphere with a 2.5 in port was used. As shown schematically in Figure 4.3, the laser was directed into the sphere while it faced the backward scattering optics to capture the output signal. The sphere was then rotated so that an equivalent signal could be measured with the forward scattering optics. The ratio between the two signals provided a means to transfer the calibration between the two sets of optics. The signal registered by the detectors was insensitive to the angle of the sphere output. 


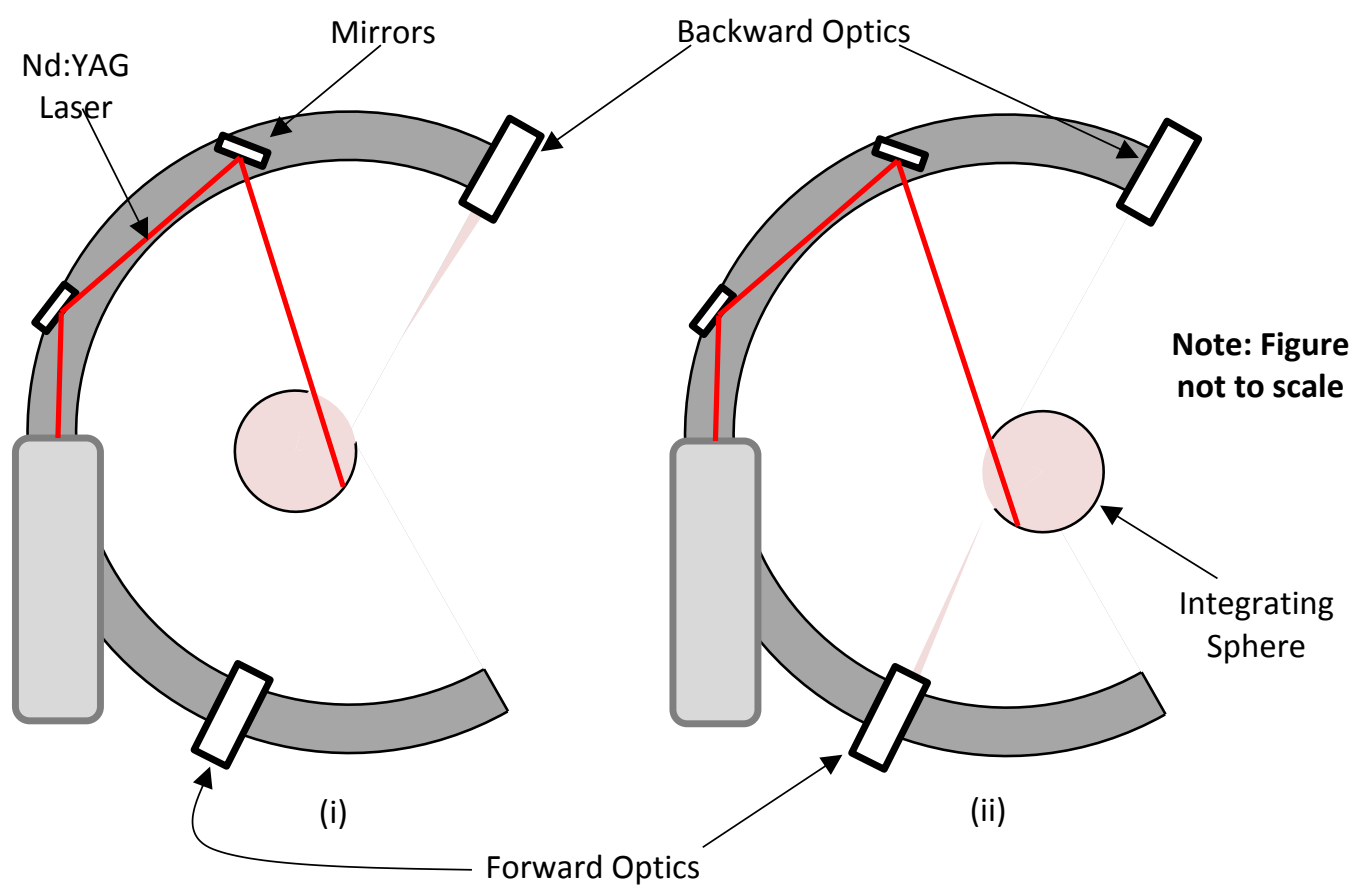

Figure 4.3: Transfer of the calibration between (i) the backward scattering optics and (ii) the forward ones using an integrating sphere mounted inside the measurement volume by using the same pulsed Nd:YAG laser

\subsubsection{ELS Calibration Results with $500 \mu \mathrm{m}$ pinhole}

\subsubsection{Backward calibration results}

Based on the procedure described in Section 4.1.2, Figure 4.4 shows a plot of the measured voltage during the backward calibration versus the location within the measurement volume as the spectralon puck was being traversed. 


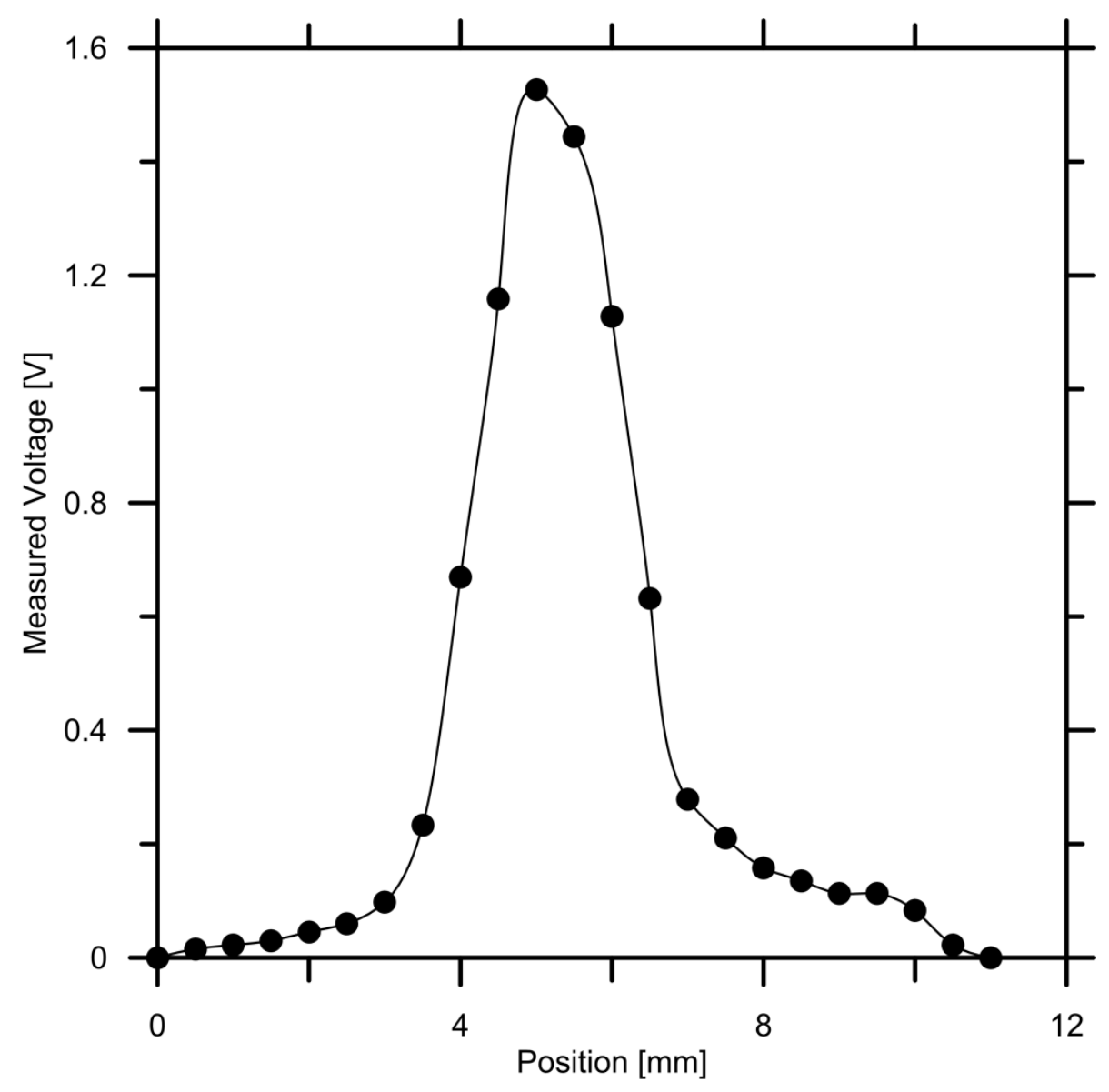

Figure 4.4: Measured backward scattering calibration signal voltage versus location inside the measurement volume

The captured signal was numerically integrated via Equation (4.3) using a trapezoidal integration. As described above, in this calibration procedure, it was important to ensure that the detectors were not saturated and hence a number of Thorlabs filters were used. Table 4.1 shows the combination of the neutral density filters that were used in the calibration of the detectors with the $500 \mu \mathrm{m}$ pinhole in place. The calibrated transmissivities of each filter at $1064 \mathrm{~nm}$ are also provided. The filters were calibrated by Maier Photonics to obtain accurate spectral transmissivities. 
Table 4.1: Transmissivities of the filters used in the $500 \mu \mathrm{m}$ calibration process

\begin{tabular}{|c|c|}
\hline $\begin{array}{c}\text { Thorlabs } \\
\text { Filter }\end{array}$ & $\begin{array}{c}\text { Transmissivity at } \\
\mathbf{1 0 6 4} \mathbf{~ n m}\end{array}$ \\
\hline NENIR06 & 0.2074 \\
\hline NENIR02 & 0.5272 \\
\hline NRNIR02 & 0.5306 \\
\hline NEN02B & 0.4915 \\
\hline NEN03B & 0.3408 \\
\hline NEN04B & 0.3657 \\
\hline NEN06B & 0.1955 \\
\hline
\end{tabular}

To obtain the absolute calibration constant, the transmissivities of the filters were divided out of the calibration constant and this gave a calibration constant of $0.42 \mathrm{Vm}$ for the backward scattering channel when using the $500 \mu \mathrm{m}$ pinhole.

\subsubsection{Forward calibration results}

The backward calibration constant obtained above was then transferred to the forward optics using the integrating sphere as described in Section 4.1.2. Since the signal output when the sphere is used is weaker than when the laser light scattered from the spectralon puck, fewer neutral density filters were used. Table 4.2 below provides the details of the calibration transfer results. 
Table 4.2: Experimental data for the transfer of the calibration constant from the backward side to the forward side.

\begin{tabular}{|c|c|c|c|c|}
\hline Side & $\begin{array}{c}\text { Measured } \\
\text { Voltage [V] }\end{array}$ & Filters & $\begin{array}{c}\text { Transmissivity at } \\
1064 \mathrm{~nm}\end{array}$ & $\begin{array}{c}\text { Ratio of forward calibration } \\
\text { constant to backward } \\
\text { calibration constant }\end{array}$ \\
\hline \multirow{2}{*}{ Backward } & 3.95 & NENIR06 & 0.2074 & \multirow{2}{*}{0.6} \\
\hline \multirow{2}{*}{ Forward } & 1.25 & NENIR06 & 0.2704 & \\
\cline { 2 - 4 } & NENIR02 & 0.5272 & \\
\hline
\end{tabular}

The ratio of the scattering signal that was registered from the sphere at both locations allowed for the forward absolute calibration constant to be measured as $0.25 \mathrm{Vm}$ when using the $500 \mu \mathrm{m}$ pinhole.

\subsubsection{Repeatability analysis (Shown using the $150 \mu \mathrm{m}$ pinhole)}

To assess the repeatability of the calibration, the smallest pinhole size was used since this had the highest noise to signal ratio and thus provided the most conservative (highest) estimation of the repeatability uncertainty. The full calibration procedure was repeated six times and the spread of the data was examined. For each run, the backward calibration constant was obtained and a respective forward calibration constant was calculated.

For the backward calibration runs, Figure 4.5 shows the measured signals obtained during the six repeated calibrations. 


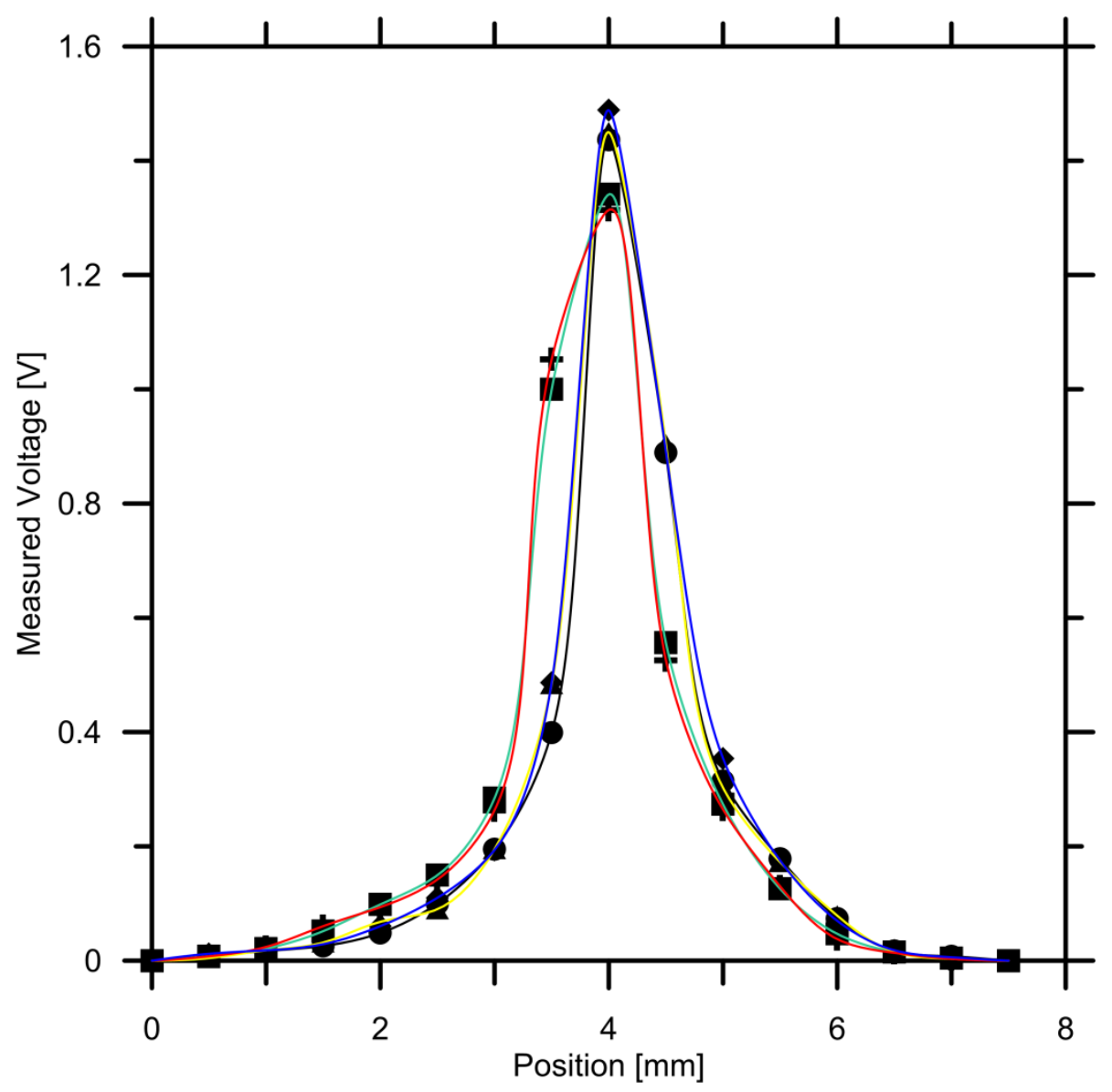

Figure 4.5: Measured voltage vs location inside the measurement volume for the 6 calibration runs

Figure 4.6 shows the spread of the backward calibration constants and their respective forward scattering calibration constants that were obtained from each of the runs. The box and scatter plot represents the $25^{\text {th }}, 50^{\text {th }}$ and $75^{\text {th }}$ percentiles. The mean and the $95 \%$ confidence interval obtained through a t-statistic test are also plotted. 


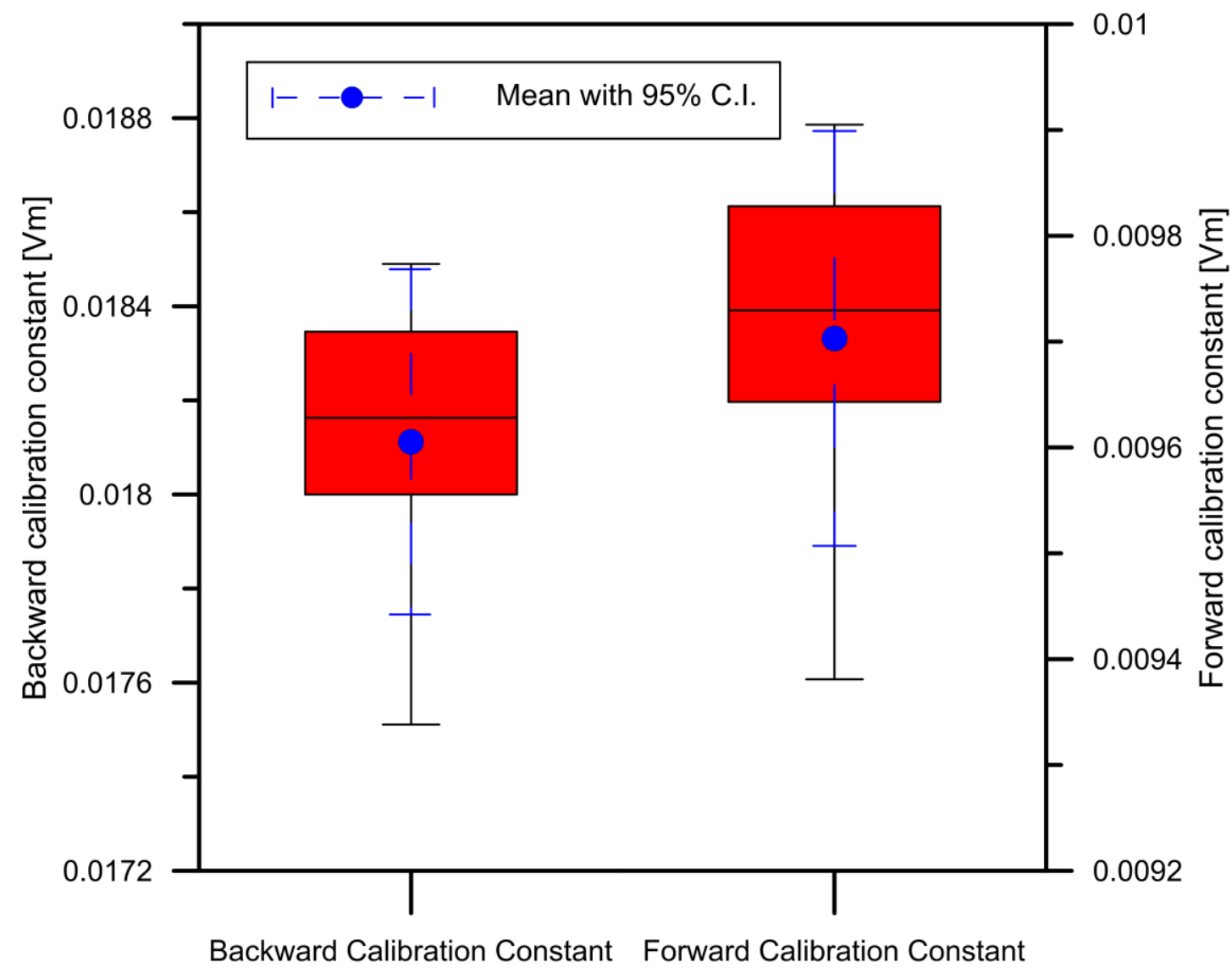

Figure 4.6: Box and whisker plot showing the spread of the calibration constant for 6 different measurements. The mean and $95 \%$ confidence intervals obtained through a t-test are also plotted (blue dashed)

These results show that the scattering procedure gives a calibration constant that is repeatable within a precision error of $3 \%$ at $95 \%$ confidence.

\subsection{Calibration}

\subsubsection{Theory}

The calibration of the LII detectors was based on the procedure described in Snelling et al. (2005). A $100 \mathrm{~W}$ Rhodium calibration light source of known radiance was used to provide the calibrating signal. For a known radiance, $R_{S}$, the voltage registered on the detector can be calculated as: 


$$
\mathrm{V}_{\mathrm{cal}}=G_{c a l} Z M^{2} A_{A P} \frac{A_{L}}{u^{2}} R_{S}\left(\lambda_{c}\right) \Omega\left(\lambda_{c}\right) \Delta\left(\lambda_{c}\right)
$$

where $G_{c a l}$ is the gain on the PMT detectors used in the calibration, $Z$ is the impedance of the measuring device in $\Omega, M$ is the magnification of the optics, $A_{A P}$ is the area of the aperture in $\mathrm{m}^{2}, A_{L}$ is area of the lens in $\mathrm{m}^{2}, u$ is the distance from the measurement location to the lens in $\mathrm{m}, \Omega\left(\lambda_{c}\right)$ is the combined response of the PMT tubes along with the filter transmission in $\mathrm{A} / \mathrm{W}$ and $\Delta\left(\lambda_{c}\right)$ is the width of the bandpass filter in $\mathrm{m}$.

Similar to the scattering calibration, Equation (4.5) can be arranged to combine all the terms that are common between the calibration and the experiment to define a calibration constant, $\eta$, as follows:

$$
Z M^{2} A_{A P} \frac{A_{L}}{u^{2}} \Omega\left(\lambda_{c}\right) \Delta\left(\lambda_{c}\right)=\eta=\frac{\mathrm{V}_{\mathrm{cal}}}{R_{S}\left(\lambda_{c}\right) G_{c a l}}
$$

\subsubsection{Implementation of the LII Calibration}

The $100 \mathrm{~W}$ calibrated Rhodium light source assembly with known spectral radiance properties attached to the same integrating sphere described in Section 4.1.2 was used to provide the constant light source for the calibration. Figure 4.7 shows the light source and integrating sphere assembly used. 


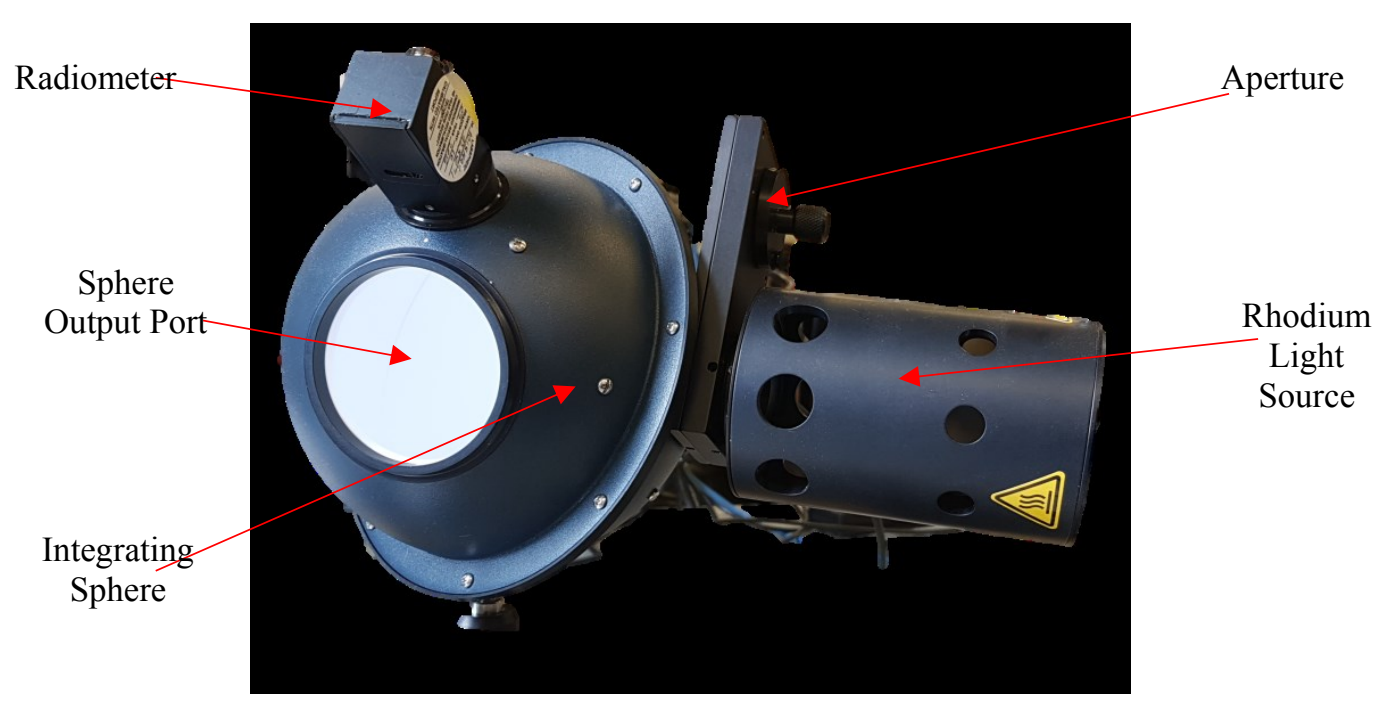

Figure 4.7: Integrating sphere assembly used in the LII calibration

The optics arrangement remained the same as described in Section 3.3. The spectral radiance of the sphere at the center wavelengths of $447 \mathrm{~nm}$ and $775 \mathrm{~nm}$ was provided from the calibration curves. It is important to note that during the calibration, it was critical to keep the PMT response within the specified range of $0.01 \mathrm{~A}$ to ensure linearity of the PMTs. The voltages on all the LII channels were recorded and Equation (4.6) was used to obtain the calibration constants.

\subsubsection{Calibration Results with $500 \mu \mathrm{m}$ pinhole}

The output of the integrating sphere was measured using the radiometer attached to one of the ports on the integrating sphere (refer to Figure 4.7). The radiometer current output was measured to be $6.3 \times 10^{-8} \mathrm{~A}$. Based on the calibration curves provided by the manufacturer, the sphere radiance at the wavelengths of $445 \mathrm{~nm}$ and $784 \mathrm{~nm}$ was thus $40.3 \mathrm{~mW} / \mathrm{cm}^{2}-\mathrm{sr}-\mu \mathrm{m}$ and $2.45 \mathrm{~mW} / \mathrm{cm}^{2}-\mathrm{sr}-\mu \mathrm{m}$ respectively.

The voltages on the blue PMT channel and the red PMT channels were measured using a $50 \mathrm{k} \Omega$ terminating resistance and were found to be $4.2 \mathrm{~V}$ and $6.7 \mathrm{~V}$ respectively. 
Based on this, the calibration constants were calculated to be $1.66 \times 10^{-11} \mathrm{~m}^{3} / \mathrm{A}$ for the blue PMT channel and $1.09 \times 10^{-12} \mathrm{~m}^{3} / \mathrm{A}$ for the red PMT channel. The calibration procedure was also repeated five times to assess the precision error. Due to the fact that the calibration was performed using a constant output filament lamp, the voltage drops registered on the PMT tubes were unaltered and the same calibration constants were obtained.

\subsection{Summary of the Calibration Results for all Pinhole Sizes}

Based on the work and results described in this chapter, all the measurement channels were calibrated and their respective calibration constants were obtained. The voltages that were measured during the experiments were then divided by the absolute calibration constants before being implemented in the calculation of the soot volume fraction, primary particle diameter, and mean radius of gyration according to the equations and principles that are discussed in Chapter 2. Table 4.3 summarizes the calibration constants found for all the scattering and LII channels, for all of the pinholes used in the experiment.

Table 4.3: Summary of all calibration constants obtained for the four scattering and LII measurement channels for all the pinhole sizes used in the experiment

\begin{tabular}{|c|c|c|c|c|}
\hline Channel & $\begin{array}{c}\text { Calibration } \\
\text { constant with } \\
\mathbf{5 0 0} \boldsymbol{\mu m} \text { pinhole }\end{array}$ & $\begin{array}{c}\text { Calibration } \\
\text { constant with } \\
\mathbf{3 0 0} \boldsymbol{\mu m} \text { pinhole }\end{array}$ & $\begin{array}{c}\text { Calibration } \\
\text { constant with } \\
\mathbf{2 0 0} \boldsymbol{\mu m} \text { pinhole }\end{array}$ & $\begin{array}{c}\text { Calibration } \\
\text { constant with } \\
\mathbf{1 5 0} \boldsymbol{\mu m} \text { pinhole }\end{array}$ \\
\hline $\begin{array}{c}\text { Back } \\
\text { Scattering }\end{array}$ & $0.42 \mathrm{Vm}$ & $0.1 \mathrm{Vm}$ & $0.03 \mathrm{Vm}$ & $0.018 \mathrm{Vm}$ \\
\hline $\begin{array}{c}\text { Front } \\
\text { Scattering }\end{array}$ & $0.25 \mathrm{Vm}$ & $0.06 \mathrm{Vm}$ & $0.018 \mathrm{Vm}$ & $0.0094 \mathrm{Vm}$ \\
\hline LII Blue & $1.66 \times 10^{-11} \mathrm{~m}^{3} / \mathrm{A}$ & $9.7 \times 10^{-12} \mathrm{~m}^{3} / \mathrm{A}$ & $1.41 \times 10^{-12} \mathrm{~m}^{3} / \mathrm{A}$ & $2.43 \times 10^{-12} \mathrm{~m}^{3} / \mathrm{A}$ \\
\hline LII Red & $1.09 \times 10^{-12} \mathrm{~m}^{3} / \mathrm{A}$ & $3.7 \times 10^{-13} \mathrm{~m}^{3} / \mathrm{A}$ & $8.47 \times 10^{-13} \mathrm{~m}^{3} / \mathrm{A}$ & $2.48 \times 10^{-13} \mathrm{~m}^{3} / \mathrm{A}$ \\
\hline
\end{tabular}




\section{Chapter 5}

\section{Results}

\subsection{Soot Measurement Results using the $500 \mu \mathrm{m}$ Pinhole}

The experiment was first run with the $500 \mu \mathrm{m}$ pinhole installed. This produced a measurement volume with the dimensions of a $3 \mathrm{~mm}$ by $1 \mathrm{~mm}$ vertical ellipse with a thickness of $0.2 \mathrm{~mm}$ and a total volume of $0.709 \mathrm{~mm}^{3}$. The acquisition was done over a period of 2 minutes, obtaining a set of 1800 instantaneous measurements of $f_{v}, R_{g m l}$, and $d_{p}$ in the reference co-annular diffusion flame. The calculated mean values of the soot volume fraction, primary particle diameter, and mean aggregate radius of gyration for this data set were $5.01 \mathrm{ppm}, 29.2 \mathrm{~nm}$, and $76.9 \mathrm{~nm}$ respectively.

Figure 5.1 plots the instantaneous measurements from this data set along with the mean values of all the instantaneous measurements within their $95 \%$ confidence interval bounds obtained from the uncertainty analysis (to be further discussed in Section 5.2). Data from (i) LII measurements by Snelling et al. (2005), (ii) transmission electron microscopy (TEM) measurements by Tian et al. (2004) and Snelling et al. (2011) as well as (iii) scattering measurement done by Snelling et al. (2011) and Link et al. (2011) are also plotted on the same graph for comparison. 


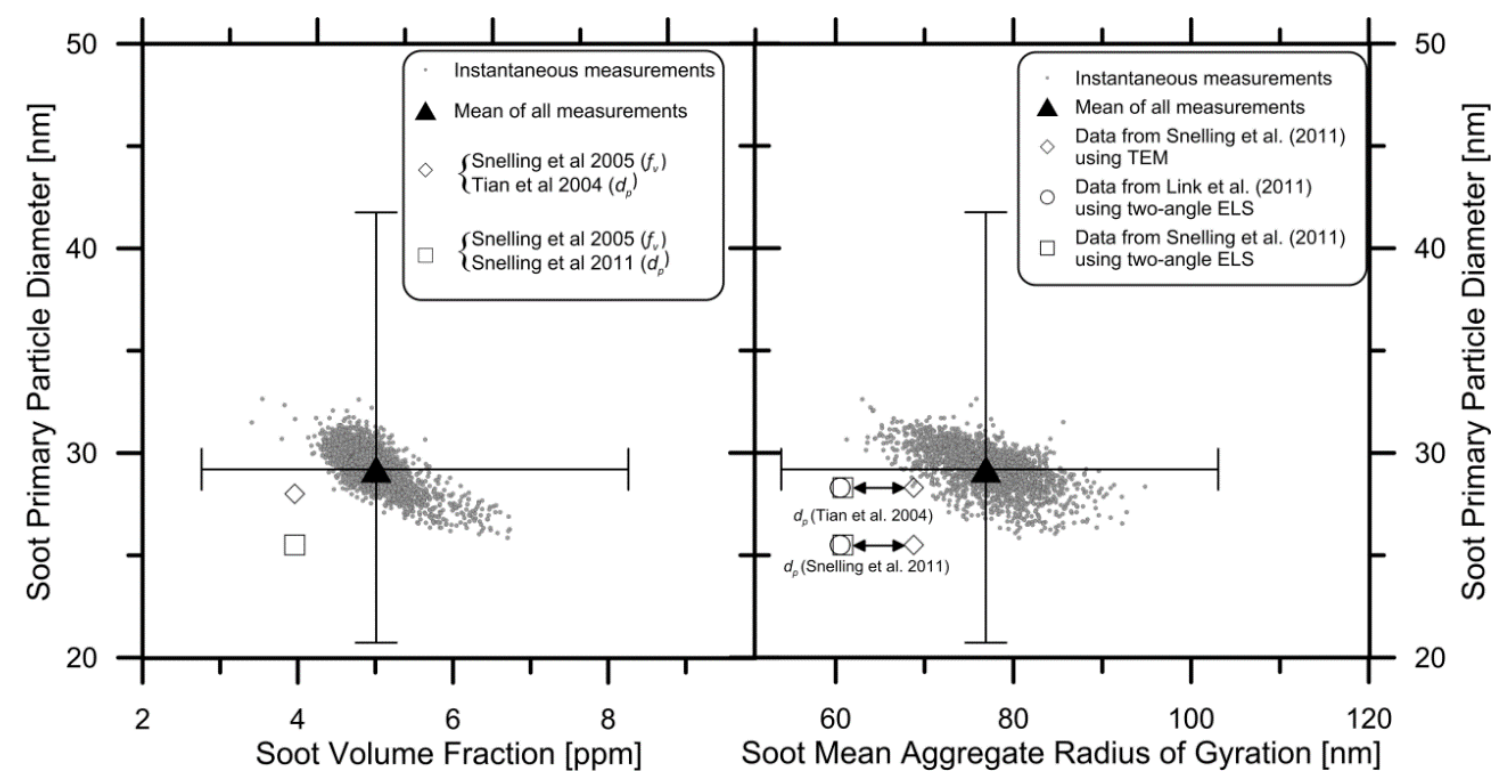

Figure 5.1: (a) Scatter plot of instantaneous measurements of soot volume fraction and soot primary particle diameter with $95 \%$ confidence intervals as compared with data published for soot volume fraction by Snelling et al. (2005) and data published for primary particle diameter by Tian et al. (2004) and calculated from the results presented in Snelling et al. (2011) (Crosland, Thomson, et al., 2013). (b) Scatter plot of instantaneous measurements of soot primary particle diameter and soot mean aggregate radius of gyration with $95 \%$ confidence intervals as compared with data published for radius of gyration by Snelling et al. (2011) using TEM and scattering measurements from Snelling et al. (2011) and Link et al. (2011) plotted against primary particle diameter data by Tian et al. (2004) and Snelling et al. (2011). All measurements are taken at a height of $42 \mathrm{~mm}$ above the burner exit.

The scatter plot shows that a relationship exists between the soot volume fraction measurement and the particle diameter. This is important in the uncertainty analysis (to be discussed later) as it will be shown that uncertainties in the soot volume fraction calculations propagate through and affect the primary particle diameter measurements as well.

The results also indicate that within the $95 \%$ confidence interval on each measurement, the measurements taken agree with the published data for all three measured quantities, i.e. the primary particle diameter, mean aggregate radius of gyration, and the soot volume fraction. The mean measured soot volume fraction of $5.01 \mathrm{ppm}$ 
over-estimates the measured value published by Snelling et al. (2005) by $25 \%$ while the mean primary particle diameter of $29.2 \mathrm{~nm}$ is $4 \%$ higher than the TEM results published in Tian et al. (2004). The published data for the aggregate radius of gyration measurements are based on calculations done by Crosland et al. (2013) by using the results reported in Snelling et al. (2011) and Link et al. (2011). Snelling et al. (2011) provided the data determined by TEM as the geometric mean number of particles in the aggregate size distribution, which was converted into an aggregate radius of gyration of $68.8 \mathrm{~nm}$ using Equation (2.8) by Crosland et al. (2013). A primary particle diameter of $28.3 \mathrm{~nm}$ (Tian et al., 2004) was used along with the soot optical properties that are consistent with the values used in the measurements obtained through this work. The scattering radius of gyration data of $60.8 \mathrm{~nm}$ (Snelling et al., 2011) and $60.5 \mathrm{~nm}$ (Link et al., 2011) were calculated by Crosland et al. (2013) using Equations (2.7) and (2.8) based on the scattering coefficients reported in the respective papers. The radius of gyration of $76.9 \mathrm{~nm}$ measured in the current work is $11 \%$ higher than the TEM results from Snelling et al. (2011) and 26\% higher than the scattering results from Snelling et al. (2011) and Link et al. (2011). Given the unknown measurement uncertainties in the comparison data, and the inherent difficulty of making in-flame measurements of soot, the agreement shown in Figure 5.1 is very encouraging and demonstrates the success of the developed LII/ELS measurement system.

The uncertainty analysis (as described in Section 5.2) provides the basis of comparison to the published data. It is important to note that the LII excitation wavelenght and assumed soot optical properties used in Snelling et al. (2005) are different than the ones employed in this work. Specifically, (different a $E(m)$ ratio of 1 
at the LII wavelengths) and the experimental setup is different (different excitation laser wavelength of $532 \mathrm{~nm}$ ). Hence in the uncertainty analysis, none of the parameters are considered to be common and a comprehensive Monte Carlo simulation where all the parameters are allowed to vary was used.

\subsection{Uncertainty Analysis with $\mathbf{5 0 0} \mu \mathrm{m}$ Pinhole}

To calculate the measurement uncertainties, a Monte Carlo simulation with 10000 draws was used to propagate the uncertainties of each element through the equations to obtain the total uncertainties in the soot volume fraction, primary particle diameter, and mean aggregate radius of gyration measurements. A convergence test was performed to ensure the accuracy of the Monte Carlo analysis while maintaining reasonable processing times.

Table 5.1 below presents all the input parameters to the Monte Carlo simulation along with a description of their distribution and the sources from which the distribution was derived. The optical properties of soot such as $E(m), \sigma, k_{f}$ and $D_{f}$ were all derived from the literature and the individual sources are presented in the table below. Other input parameters that are measured or calculated are also included in the table. Finally, the last column in the table shows the individual effect of each of those input parameters on the $2 \sigma(95 \%$ confidence interval) in the uncertainty of each of the soot volume fraction, primary particle diameter, and radius of gyration measurements that were taken. The individual effect of the parameters was determined by fixing all the other parameters in the study and allowing only the single input parameter that is being studied to be varied. 
Table 5.1: Input parameters to the Monto Carlo Distribution and their relative contribution to the uncertainties on the measured quantities

\begin{tabular}{|c|c|c|c|c|c|c|}
\hline \multicolumn{2}{|c|}{ Input } & Distribution & Source & $\begin{array}{l}\text { Cont. to } \\
2 \sigma \text { of } f_{v}\end{array}$ & $\begin{array}{l}\text { Cont. to } \\
2 \sigma \text { of } d_{p}\end{array}$ & $\begin{array}{c}\text { Cont. to } \\
2 \sigma \text { of } \\
R_{g}\end{array}$ \\
\hline \multicolumn{7}{|c|}{ LII } \\
\hline \multicolumn{2}{|c|}{$\begin{array}{l}\text { Soot refractive index light } \\
\text { absorption function at lower LII } \\
\text { wavelength }\left(E\left(\boldsymbol{m}_{\lambda_{1}}\right)\right)\end{array}$} & $\begin{array}{c}\text { Normal } \\
\mu=0.348 \\
\sigma=0.045\end{array}$ & $\begin{array}{l}\text { (Dobbins } \\
\text { et al., } \\
\text { 1994; } \\
\text { Snelling et } \\
\text { al., 2004; } \\
\text { Yon et al., } \\
\text { 2011; } \\
\text { Köylü and } \\
\text { Faeth, } \\
\text { 1996; } \\
\text { Schnaiter } \\
\text { et al., } \\
\text { 2003; } \\
\text { Bond and } \\
\text { Bergstrom, } \\
\text { 2006) }\end{array}$ & $\begin{array}{c}+31 /- \\
21 \%\end{array}$ & $+8 /-9 \%$ & $0 \%$ \\
\hline \multicolumn{2}{|c|}{$\begin{array}{l}\text { Ratio of soot refractive index } \\
\text { light absorption function at } \\
\text { lower and upper LII } \\
\text { wavelengths }\left(\frac{E\left(m_{\lambda_{1}}\right)}{E\left(m_{\lambda_{2}}\right)}\right)\end{array}$} & $\begin{array}{c}\text { Normal } \\
\mu=1.15 \\
\sigma=0.11\end{array}$ & $\begin{array}{l}\text { (Dobbins } \\
\text { et al., } \\
\text { 1994; } \\
\text { Snelling et } \\
\text { al., 2004; } \\
\text { Yon et al., } \\
2011 ; \\
\text { Coderre et } \\
\text { al., 2011) }\end{array}$ & $\begin{array}{c}+49 /- \\
40 \%\end{array}$ & $\begin{array}{c}+18 /- \\
13 \%\end{array}$ & $0 \%$ \\
\hline \multirow{3}{*}{$\begin{array}{c}\text { Input } \\
\text { Voltages }\end{array}$} & LII at $\lambda_{\text {blue }}$ & $\begin{array}{c}\text { Normal } \\
\mu=9.62 \mathrm{~V} \\
\sigma=0.31 \mathrm{~V}\end{array}$ & Measured & $+11 /-9 \%$ & $+3 /-4 \%$ & $0 \%$ \\
\hline & \multirow[b]{2}{*}{ LII at $\lambda_{\text {red }}$} & \multirow[b]{2}{*}{$\begin{array}{c}\text { Normal } \\
\mu=10.78 \mathrm{~V} \\
\sigma=0.22 \mathrm{~V}\end{array}$} & & \multirow[b]{2}{*}{$\begin{array}{c}+13 /- \\
11 \%\end{array}$} & \multirow[b]{2}{*}{$+4 /-4 \%$} & \multirow[b]{2}{*}{$0 \%$} \\
\hline & & & Measured & & & \\
\hline
\end{tabular}


Table 5.1: Input parameters to the Monto Carlo Distribution and their relative contribution to the uncertainties on the measured quantities (continued)

\begin{tabular}{|c|c|c|c|c|c|c|}
\hline \multicolumn{2}{|c|}{ Input } & Distribution & Source & $\begin{array}{l}\text { Cont. to } \\
2 \sigma \text { of } f_{v}\end{array}$ & $\begin{array}{l}\text { Cont. to } \\
2 \sigma \text { of } d_{p}\end{array}$ & $\begin{array}{c}\text { Cont. to } \\
2 \sigma \text { of } \\
R_{g}\end{array}$ \\
\hline \multirow{2}{*}{ Calibration } & $\eta_{\text {blue }}$ & $\begin{array}{c}\text { Normal } \\
\mu=1.66 \times 10^{-11} \frac{\mathrm{m}^{3}}{A} \\
\sigma=0.018 \times 10^{-11} \frac{\mathrm{m}^{3}}{A}\end{array}$ & Calculated & $+4 /-3 \%$ & $+1 /-1 \%$ & $0 \%$ \\
\hline & $\eta_{\text {red }}$ & $\begin{array}{c}\text { Normal } \\
\mu=1.09 \times 10^{-12} \frac{\mathrm{m}^{3}}{\mathrm{~A}} \\
\sigma=0.009 \times 10^{-12} \frac{\mathrm{m}^{3}}{\mathrm{~A}}\end{array}$ & Calculated & $+3 /-3 \%$ & $+1 /-1 \%$ & $0 \%$ \\
\hline \multicolumn{2}{|c|}{$\begin{array}{l}\text { Equivalent Sheet thickness } \\
\qquad\left(w_{b}\right)\end{array}$} & $\begin{array}{c}\text { Normal } \\
\mu=0.17 \mathrm{~mm} \\
\sigma=0.1 \mathrm{~mm}\end{array}$ & $\begin{array}{c}\text { Calculated } \\
\text { based on } \\
\text { numerical } \\
\text { simulation } \\
s \text { as } \\
\text { described } \\
\text { in Section } \\
2.1 \\
\end{array}$ & $\begin{array}{c}+11 /- \\
12 \%\end{array}$ & $+6 /-6 \%$ & $0 \%$ \\
\hline \multirow{2}{*}{$\begin{array}{l}\text { Background } \\
\text { noise }\end{array}$} & Blue & $\begin{array}{c}\text { Normal } \\
\mu=-0.00028 \mathrm{~V} \\
\sigma=9.3 \times 10^{-4} \mathrm{~V}\end{array}$ & Measured & $<0.5 \%$ & $<0.5 \%$ & $0 \%$ \\
\hline & Red & $\begin{array}{c}\text { Normal } \\
\mu=0.0083 \mathrm{~V} \\
\sigma=6.6 \times 10^{-3} \mathrm{~V}\end{array}$ & Measured & $<0.5 \%$ & $<0.5 \%$ & $0 \%$ \\
\hline \multirow{2}{*}{$\begin{array}{l}\text { Modelling } \\
\text { Errors }\end{array}$} & $\begin{array}{l}\text { Equivalent filter } \\
\text { approximation }\end{array}$ & $\begin{array}{c}\text { Normal } \\
\mu=1 \\
\sigma=0.005\end{array}$ & $\begin{array}{l}\text { Applied to } \\
\text { value of } \\
\quad T_{p e} \\
\text { (Snelling et } \\
\text { al., 2005) }\end{array}$ & $+10 /-9 \%$ & $+3 /-3 \%$ & $0 \%$ \\
\hline & $\begin{array}{l}\text { LII signal } \\
\text { trapping }\end{array}$ & $\begin{array}{c}\text { Normal } \\
\mu=1 \\
\sigma=0.005\end{array}$ & $\begin{array}{l}\text { Applied to } \\
f_{v} \\
\text { (Liu and } \\
\text { Snelling, } \\
\text { 2008) }\end{array}$ & $+5 /-5 \%$ & $+2 /-2 \%$ & $0 \%$ \\
\hline
\end{tabular}


Table 5.1: Input parameters to the Monto Carlo Distribution and their relative contribution to the uncertainties on the measured quantities (continued)

\begin{tabular}{|c|c|c|c|c|c|c|}
\hline \multicolumn{2}{|c|}{ Input } & Distribution & Source & $\begin{array}{l}\text { Cont. to } \\
2 \sigma \text { of } f_{v}\end{array}$ & $\begin{array}{l}\text { Cont. to } \\
2 \sigma \text { of } d_{p}\end{array}$ & $\begin{array}{c}\text { Cont. to } \\
2 \sigma \text { of } \\
R_{g}\end{array}$ \\
\hline \multicolumn{7}{|c|}{ ELS } \\
\hline $\begin{array}{r}\text { Soot refra } \\
\text { scatteri } \\
\text { scatteri } \\
(1\end{array}$ & $\begin{array}{l}\text { fe index light } \\
\text { function at } \\
\text { vavelength } \\
\left(_{\lambda_{s}}\right) \text { ) }\end{array}$ & $\begin{array}{c}\text { Normal } \\
\mu=0.31 \mathrm{~V} \\
\sigma=0.04 \mathrm{~V}\end{array}$ & $\begin{array}{c}\text { (Yon et al., } \\
\text { 2011) }\end{array}$ & $0 \%$ & $+9 /-8 \%$ & $0 \%$ \\
\hline \multicolumn{2}{|c|}{$\begin{array}{l}\text { Width of log-normal } \\
\text { distribution }\left(\sigma_{g}\right)\end{array}$} & $\begin{array}{c}\text { Uniform } \\
\text { Minimum = } 1.7 \\
\text { Maximum = } 2.5\end{array}$ & $\begin{array}{c}\text { (Link et al., } \\
\text { 2011; } \\
\text { Sorensen } \\
\text { et al., } \\
1995)\end{array}$ & $0 \%$ & $+4 /-4 \%$ & $\begin{array}{c}+23 /- \\
21 \%\end{array}$ \\
\hline \multicolumn{2}{|c|}{ Fractal dimension $\left(D_{f}\right)$} & $\begin{array}{c}\text { Normal } \\
\mu=1.7 \\
\sigma=0.15\end{array}$ & $\begin{array}{c}\text { (Köylü, } \\
\text { Faeth, et } \\
\text { al., 1995) }\end{array}$ & $0 \%$ & $\begin{array}{c}+19 /- \\
15 \%\end{array}$ & $+4 /-3 \%$ \\
\hline \multicolumn{2}{|c|}{ Fractal prefactor $\left(\boldsymbol{k}_{f}\right)$} & $\begin{array}{l}\text { Normal } \\
\mu=1.7 \\
\sigma=0.5\end{array}$ & $\begin{array}{c}\text { (Sorensen, } \\
\text { 2001) }\end{array}$ & $0 \%$ & $\begin{array}{c}+34 /- \\
16 \%\end{array}$ & $0 \%$ \\
\hline \multicolumn{2}{|c|}{ Forward detection angle $\left(\theta_{1}\right)$} & $\begin{array}{c}\text { Uniform } \\
\text { Minimum }=28^{\circ} \\
\text { Maximum }=32^{\circ}\end{array}$ & Measured & $0 \%$ & $<0.5 \%$ & $<0.5 \%$ \\
\hline \multicolumn{2}{|c|}{ Backward detection angle $\left(\boldsymbol{\theta}_{2}\right)$} & $\begin{array}{c}\text { Uniform } \\
\text { Minimum }=148^{\circ} \\
\text { Maximum }=152^{\circ}\end{array}$ & Measured & $0 \%$ & $+1 /-1 \%$ & $<0.5 \%$ \\
\hline \multirow{2}{*}{$\begin{array}{l}\text { Input } \\
\text { Voltages }\end{array}$} & Scatt. at $\theta_{1}$ & $\begin{array}{c}\text { Normal } \\
\mu=11.06 \mathrm{~V} \\
\sigma=0.42 \mathrm{~V}\end{array}$ & Measured & $0 \%$ & $+6 /-6 \%$ & $\begin{array}{c}+12 /- \\
11 \%\end{array}$ \\
\hline & Scatt. at $\theta_{2}$ & $\begin{array}{c}\text { Normal } \\
\mu=11.34 \mathrm{~V} \\
\sigma=0.56 \mathrm{~V}\end{array}$ & Measured & $0 \%$ & $+4 /-3 \%$ & $\begin{array}{c}+13 /- \\
15 \%\end{array}$ \\
\hline \multirow{2}{*}{ Calibration } & $\boldsymbol{\eta}_{\theta_{1}}$ & $\begin{array}{c}\text { Normal } \\
\mu=0.415 \mathrm{Vm} \\
\sigma=1.2 \times 10^{-3} \mathrm{Vm}\end{array}$ & Measured & $0 \%$ & $+1 /-1 \%$ & $+1 /-1 \%$ \\
\hline & $\boldsymbol{\eta}_{\boldsymbol{\theta}_{2}}$ & $\begin{array}{c}\text { Normal } \\
\mu=0.25 \mathrm{Vm} \\
\sigma=7.5 \times 10^{-3} \mathrm{Vm}\end{array}$ & Measured & $0 \%$ & $+1 /-1 \%$ & $+3 /-3 \%$ \\
\hline \multirow{2}{*}{$\begin{array}{l}\text { Background } \\
\text { noise }\end{array}$} & $\boldsymbol{\theta}_{1}$ & $\begin{array}{c}\text { Normal } \\
\mu=0.0126 \mathrm{~V} \\
\sigma=0.0041 \mathrm{~V}\end{array}$ & Measured & $0 \%$ & $<0.5 \%$ & $<0.5 \%$ \\
\hline & $\boldsymbol{\theta}_{2}$ & $\begin{array}{c}\text { Normal } \\
\mu=0.0223 \mathrm{~V} \\
\sigma=0.0039 \mathrm{~V}\end{array}$ & Measured & $0 \%$ & $<0.5 \%$ & $<0.5 \%$ \\
\hline
\end{tabular}


Table 5.1: Input parameters to the Monto Carlo Distribution and their relative contribution to the uncertainties on the measured quantities (continued)

\begin{tabular}{|c|c|c|c|c|c|c|}
\hline \multicolumn{2}{|c|}{ Input } & Distribution & Source & $\begin{array}{l}\text { Cont. to } \\
2 \sigma \text { of } f_{v}\end{array}$ & $\begin{array}{l}\text { Cont. to } \\
2 \sigma \text { of } d_{p}\end{array}$ & $\begin{array}{c}\text { Cont. to } \\
2 \sigma \text { of } \\
R_{\alpha}\end{array}$ \\
\hline \multirow{5}{*}{$\begin{array}{l}\text { Modelling } \\
\text { errors }\end{array}$} & $\begin{array}{c}\text { Monodispersity } \\
\text { assumption }\end{array}$ & $\begin{array}{c}\text { Normal } \\
\mu=1 \\
\sigma=0.1\end{array}$ & $\begin{array}{c}\text { Calculated } \\
\text { on } d_{p} \\
\text { (Tian et al., } \\
\text { 2004) }\end{array}$ & $0 \%$ & $\begin{array}{c}+20 /- \\
20 \%\end{array}$ & $0 \%$ \\
\hline & $\begin{array}{l}\text { ELS signal } \\
\text { trapping }\end{array}$ & $\begin{array}{c}\text { Normal } \\
\mu=1 \\
\sigma=0.033\end{array}$ & $\begin{array}{c}\text { Calculated } \\
\text { on } K_{v v} \\
\text { (Snelling et } \\
\text { al., 2005) }\end{array}$ & $0 \%$ & $\begin{array}{c}+1.3 /- \\
1.3 \%\end{array}$ & $+3 /-3 \%$ \\
\hline & $\begin{array}{c}\text { Intra-aggregate } \\
\text { scattering }\end{array}$ & $\begin{array}{c}\text { Normal } \\
\mu=1 \\
\sigma=0.05\end{array}$ & $\begin{array}{l}\text { Calculated } \\
\text { on } K_{v v}\end{array}$ & $0 \%$ & $+1 /-1 \%$ & $0 \%$ \\
\hline & $\begin{array}{c}\text { Choice of } \\
\text { structure factor }\end{array}$ & $\begin{array}{c}\text { Normal } \\
\mu=1 \\
\sigma=0.03\end{array}$ & $\begin{array}{c}\text { Calculated } \\
\text { on } R_{g m 1} \\
\text { (Crosland } \\
\text { et al., } \\
2015 \text { ) }\end{array}$ & $0 \%$ & $+4 /-3 \%$ & $+6 /-6 \%$ \\
\hline & $\begin{array}{l}\text { Choice of } R_{g} \\
\text { distribution }\end{array}$ & $\begin{array}{c}\text { Normal } \\
\mu=1 \\
\sigma=0.02\end{array}$ & $\begin{array}{c}\text { Calculated } \\
\text { on } R_{g m 1} \\
\text { (Crosland } \\
\text { et al., } \\
2015 \text { ) }\end{array}$ & $0 \%$ & $+2 /-2 \%$ & $+4 /-4 \%$ \\
\hline
\end{tabular}

It is apparent from the data that is presented in the above table that the uncertainty in soot optical properties dominates the overall uncertainties in the measurements. In the case of the LII measurements, the ratio of soot refractive index function $\left(E\left(m_{\lambda 1}\right) / E\left(m_{\lambda 2}\right)\right)$ is the main contributor to the uncertainties of the soot volume fraction $(+31 /-21 \%)$, while in the ELS experiment, the width of the log normal distribution $\left(\sigma_{g}\right)$ dominates the uncertainties of the radius of gyration measurements (+49/-40\%); and the fractal dimension $\left(D_{f}\right)$ and the fractal prefactor $\left(k_{f}\right)$ contribute the most to the uncertainties of the primary particle diameter measurements $\left(+19 /-15 \%\right.$ for $D_{f}$ and $+34 /-16 \%$ for $\left.k_{f}\right)$.

Based on the above conclusions, it was then important to evaluate the uncertainties coming from the measurement noise only. Hence, the Monte Carlo 
simulation was run again while keeping assumed soot optical and morphological properties constant and allowing only the measured voltages to vary based on their defined distributions. Table 5.2 presents a comparison between the total uncertainties and the uncertainties from the measurement noise only.

Table 5.2: Comparison of the total uncertainties and the measurement noise uncertainties only

\begin{tabular}{|c|c|c|}
\hline Measured Quantity & Total Uncertainties & Measurement Noise only \\
\hline Soot volume fraction, $\boldsymbol{f}_{v}$ & $4.9\left\{\begin{array}{l|l}8.3 \\
2.6\end{array}\right.$ ppm $\left.\begin{array}{l}69 \% \\
46 \%\end{array}\right\}$ & $4.7\left\{\begin{array}{l|l}5.3 \\
4.1\end{array}\right.$ ppm $\left.\begin{array}{l}12 \% \\
13 \%\end{array}\right\}$ \\
\hline Primary particle diameter, $d_{p}$ & $33\left\{\begin{array}{l|l}46 \\
23\end{array}\right.$ nm $\left.\begin{array}{l}40 \% \\
29 \%\end{array}\right\}$ & $32\left\{\begin{array}{l|l}35 & n m \\
30 & \begin{array}{c}9 \% \\
7 \%\end{array}\end{array}\right\}$ \\
\hline $\begin{array}{l}\text { Soot aggregate radius of } \\
\text { gyration, } R_{g m 1}\end{array}$ & $73\left\{\begin{array}{l|l}98 \\
52\end{array} n \mathrm{l} \mid \begin{array}{l}34 \% \\
29 \%\end{array}\right\}$ & $73\left\{\begin{array}{l|l}84 & n m \\
61 & \begin{array}{l}16 \% \\
16 \%\end{array}\end{array}\right\}$ \\
\hline
\end{tabular}

While the total uncertainties of $69 \%$ might seem to be high, a closer look at the individual contributions show that it is in fact dominated by the uncertainties in the optical properties of soot which is a common factor in all optical soot measurement techniques albeit with different effects. The results in Table 5.2 suggest that for the case of relative measurements within or among flames for which the optical and fractal properties could be assumed similar, the relative uncertainties that arise from the measurement noise are low. This is an important achievement that demonstrates the utility of this system in the proposed target application of investigating soot formation processes within turbulent flames representative of industrial flares. It is also worth noting that measurement uncertainties attributable to uncertainties in optical and morphological properties of soot might plague all optical measurement techniques and may often be considered as a common bias error. 


\subsection{Measurement Uncertainty with Varying the Pinhole Size}

Building on the results presented above, and working towards the future development of the combined LII/ELS techniques where application in turbulent flames is desirable, it was important to reduce the measurement volume inside the flame as much as possible. A smaller measurement volume permits a better spatial resolution which is highly advantageous in turbulent flames where mixing effects are prevalent. The measurement volume should be smaller than the smallest turbulence scale that is found in the flame in order to overcome the effects of mixing. Coppalle and Joyeux (1994) reported an integral turbulence length scale $\left(\ell_{0}\right)$ of approximately $15 \mathrm{~mm}$ for a turbulent nonpremixed turbulent flame from a $9 \mathrm{~mm}$ diameter burner with a fuel exit velocity of $6.3 \mathrm{~m} / \mathrm{s}$ and Reynolds number of 5800. Although Coppalle and Joyeux (1994) did not report r.m.s velocity fluctuations, a value of $\sim 5 \%$ may be assumed from measurements by Crosland et al. (2015) on a turbulent flame with comparable Reynolds number of 4800 that closely matches the target application. Assuming a kinematic viscosity of $32 \times 10^{-}$ ${ }^{5} \mathrm{~m}^{2} / \mathrm{s}$ in the flame equivalent to that of air at $2000 \mathrm{~K}$, a turbulence Reynolds number $\left(R e_{\ell_{0}}\right)$ of 11 can be estimated. Finally, a Kolmogorov turbulence length scale $\left(\ell_{K}\right)$ of $\sim 2.4 \mathrm{~mm}$ can then be approximated assuming $\ell_{0} / \ell_{K}=R e_{\ell_{0}}^{3 / 4}$.

In the present system, the measurement volume is defined mainly by the image of the pinhole on the laser sheet. Varying the size of the pinhole allowed varied the size of the measurement volume. However, reducing the pinhole size also reduced the amount of light reaching the detectors, which could adversely affect measurement uncertainties. The measurement volumes of 0.709 to $0.064 \mathrm{~mm}^{3}$ (maximum dimensions of 3 to $0.9 \mathrm{~mm}$, 
see Section 3.3.1) studied in this research have dimensions that are smaller than the estimated Kolmogorov scale. However based on (Hu et al., 2003), soot streaks of less than $1 \mathrm{~mm}$ may be expected in turbulent flames. Thus, the measurement volumes studied in this experiment provide a range of options that that could be smaller than the estimated Kolmogorov scale, and either bigger of smaller than the smallest anticipated soot streaks.

For each tested pinhole size (i.e. base case of $500 \mu \mathrm{m}$, as well as $300 \mu \mathrm{m}, 200 \mu \mathrm{m}$, and $150 \mu \mathrm{m}$ ), the entire optical system was realigned and new calibration constants were found. A new set of measurements with each pinhole size was then taken and a detailed uncertainty study similar to the one presented above was conducted to evaluate the uncertainties associated with each pinhole size. Figure 5.2 - Figure 5.4 show the plots obtained for the soot volume fraction, primary particle diameter, and mean aggregate radius of gyration obtained from each measurement along with the $95 \%$ confidence interval evaluated from the total uncertainties (dotted line) and evaluated from the measurement noise only (bold lines). Published data (Snelling et al., 2005; Tian et al., 2004; Snelling et al., 2011; Link et al., 2011) are also plotted for comparison. 


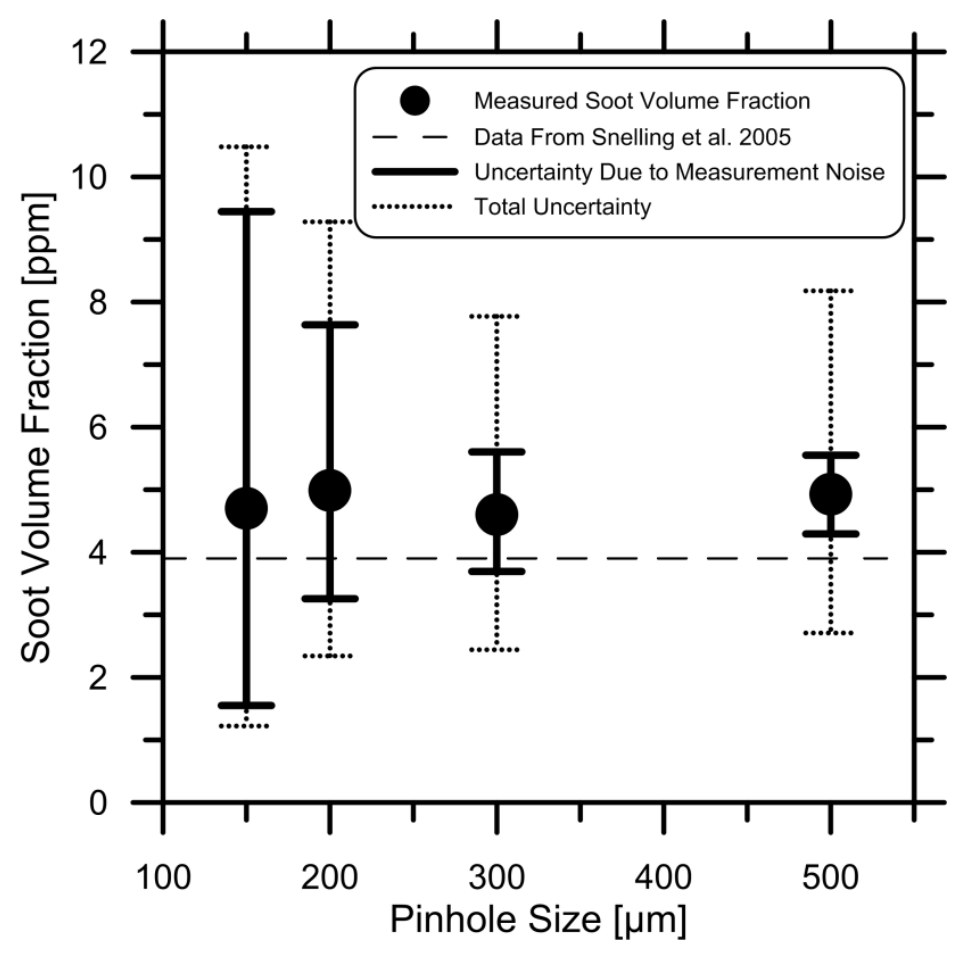

Figure 5.2: Effect of varying the measurement volume on the uncertainty in the soot volume fraction measurement. $95 \%$ confidence intervals are plotted for both the total uncertainties (dotted lines) and measurement noise (bold lines)

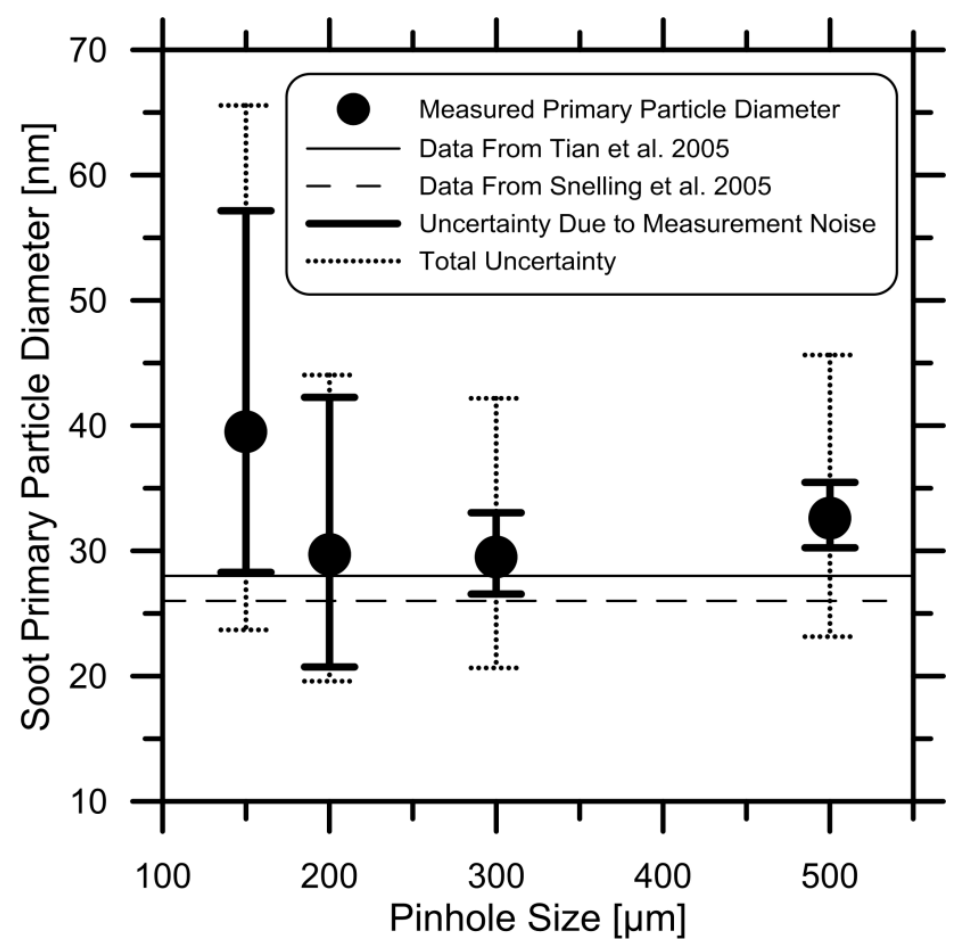

Figure 5.3: Effect of varying the measurement volume on the uncertainty in the primary particle diameter measurement. $95 \%$ confidence intervals are plotted for both the total uncertainties (dotted lines) and measurement noise (bold lines) 


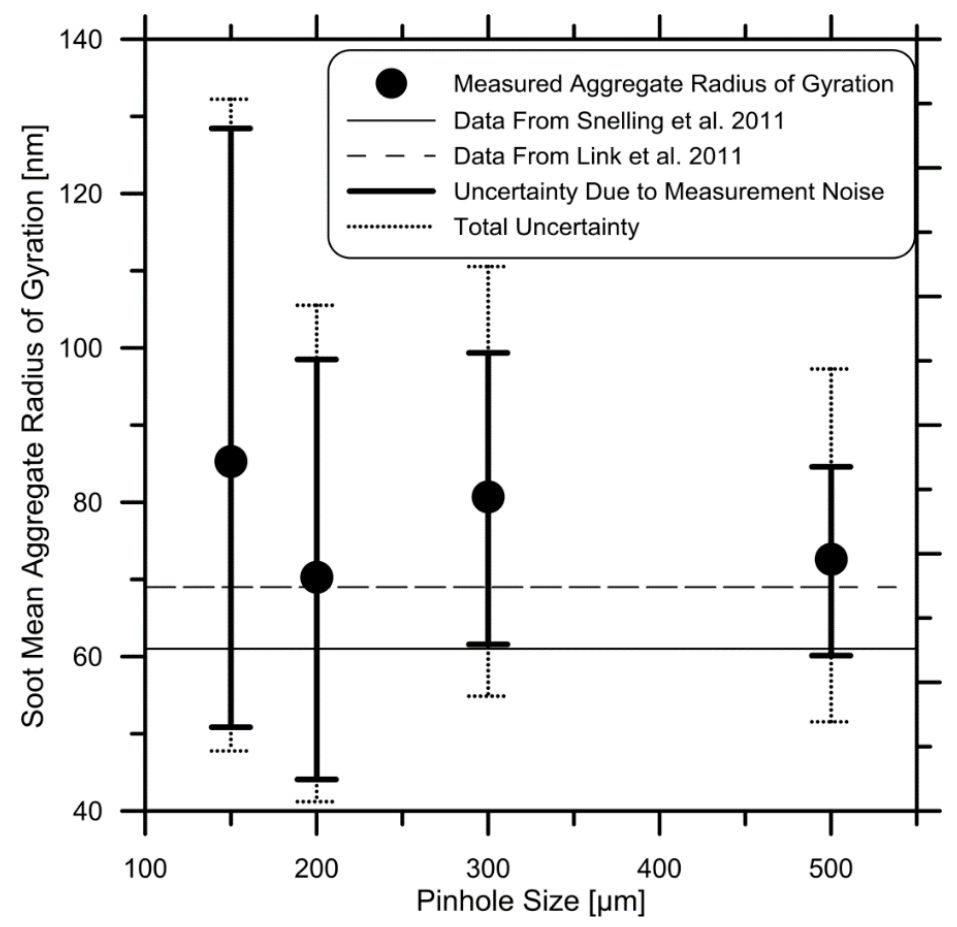

Figure 5.4: Effect of varying the measurement volume on the uncertainty in the mean aggregate radius of gyration measurement. $95 \%$ confidence intervals are plotted for both the total uncertainties (dotted lines) and measurement noise (bold lines)

As demonstrated in the plots, the measured results across all sizes of the measurement volumes studied (i.e. pinhole sizes) agree with available published results in the literature. As presented in the detailed uncertainty analysis for the $500 \mu \mathrm{m}$ case, the uncertainties in the measurements are dominated by the soot optical properties and not the measurement noise. However, as the pinhole size drops, the signal drops and hence the noise to signal ratio goes up and the uncertainties in the measurements become predominantly reliant on the measurement noise. As the measurement volume goes down, the total uncertainties increase from $69 \%$ to $123 \%$ in the soot volume fraction measurement, from $40 \%$ to $66 \%$ on the particle diameter measurement, and from $34 \%$ to $55 \%$ in the radius of gyration measurement. 
As for when the soot properties are assumed to be constant and the uncertainties are evaluated only based on the noise in the signal, the uncertainties increase from $12 \%$ to $101 \%$ in the soot volume fraction measurement, from $9 \%$ to $45 \%$ on the primary particle diameter measurement, and from $17 \%$ to $51 \%$ in the radius of gyration measurement. It is interesting to note that the biggest jump in the uncertainties happens between the $300 \mu \mathrm{m}$ pinhole and the $200 \mu \mathrm{m}$ pinhole, where the measurement noise uncertainties rise from $22 \%$ to $54 \%$ on the soot volume fraction measurement, from $12 \%$ to $42 \%$ on the particle diameter measurement, and from $23 \%$ to $40 \%$ on the radius of gyration measurement.

This parametric study of the effect of decreasing the measurement volume on the uncertainties in the measurements provides an important guideline for further measurements and developments of the optical system that is presented here. The future plan is to conduct tests in turbulent flames where the uncertainties are inherently higher but a finer spatial resolution would also be desirable. It can be seen that there is a tradeoff between the uncertainties and the size of the measurement volume and a design decision would need to be made when using this apparatus for future measurements.

\subsection{Repeatability and Precision}

The experiment was repeated on two separate days providing 8 data sets to assess the precision and repeatability of the setup. For this test, the case with the maximum uncertainties was chosen $(150 \mu \mathrm{m})$. Because the precision error scales with the measurement noise, the precision results for the smallest measurement volume would present the worst possible precision error for the setup. At each measurement set, the 
entire system was shut down and repowered again and the measurement channels were zeroed. The flame was also turned off and on again before the data set was collected. Figure 5.5 shows the box and whisker plot of the mean measurements collected for each set.

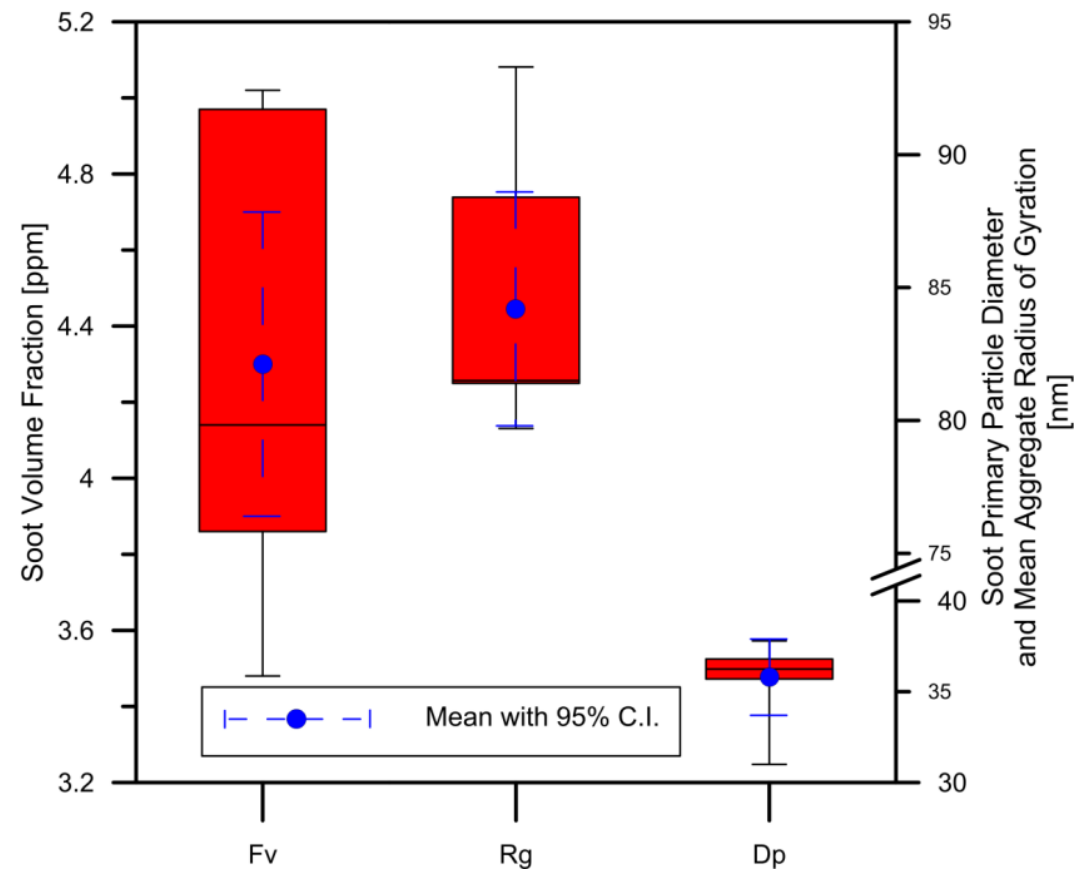

Figure 5.5: Box and whisker plot showing the spread of the means for 8 different sets of measurements. The mean and $95 \%$ confidence intervals obtined through a t-test are also plotted (blue dashed).

The mean (and 95\% confidence intervals) for the three sets of measurements were $4.3(0.3) \mathrm{ppm}$ for the soot volume fraction, $84.2(3.7) \mathrm{nm}$ for the aggregate radius of gyration and $35.8(1.8) \mathrm{nm}$ for the primary particle diameter. This shows that for the case with the highest uncertainties due to the low signal to noise ratio, the results are repeatable within $7 \%$ for the soot volume fraction measurement and within $5 \%$ for the radius of gyration and primary particle diameter measurements at $95 \%$ confidence. 


\section{Chapter 6}

\section{Conclusion}

This thesis presented a detailed description and validation of an optical measurement technique capabale of making simultaneous, instantaneous measurements of the soot volume fraction, soot primary particle diameter and soot mean aggregate radius of gyration in large, turbulent non-premixed flames. A combined laser induced incandescence and elastic light scattering technique was employed using a $1064 \mathrm{~nm}$ laser firing at a rate of $15 \mathrm{~Hz}$. The geometric dimensions of the apparatus allow for measurements on large-scale flares which will be particularly useful when making measurements on replicated industrial flares at the Carleton University flaring facility.

The measurement technique was validated by making measurements inside a well-studied co-annular laminar diffusion flame and comparing the results to published data. The system produced comparable results with total uncertainties of $(+69 /-46) \%$ on the soot volume fraction measurement, $(+40 /-29) \%$ on the primary particle diameter measurement and $(+34 /-29) \%$ on the mean aggregate radius of gyration measurement with the largest optical probe volume of $0.71 \mathrm{~mm}^{3}$. These uncertainties are dominated by uncertainties in the optical and fractal properties of soot, which are a common limit to most optical measurements with a varying degree depending on the technique. For the case of relative measurements with a flame or similar flames (for which optical and fractal properties could be assumed to be similar), relative uncertainties arising from measurement noise only were much lower. In this latter case, relative uncertainties of 
$(+12 /-13) \%$ on the soot volume fraction measurement, $(+9 /-7) \%$ on the primary particle diameter measurement, and $(+16 /-16) \%$ on the soot mean aggregate radius of gyration were possible. Given the inherent difficulties in making measurements of soot within turbulent flames, these results are considered quite encouraging and bode well for planned future work applying this technique to the study of replicated industrial flares in controlled laboratory conditions.

A study on the effect of varying the size of the measurement volume was also conducted. It was found that at smaller measurement volumes the measurement noise starts to dominate the total uncertainties with the uncertainties growing exponentially to as much as $123 \%$ for the smallest tested measurement volume of $0.064 \mathrm{~mm}^{3}$. The trends also suggest that a measurement volume of $0.254 \mathrm{~mm}^{3}$ provides a balance between the small measurement volume that is desirable for turbulent flames and the measurement noise that adversely affects the total uncertainties of the system, however this optimum might still be bigger than the $0.1 \mathrm{~mm}$ corresponding to the smallest anticipated soot streaks in the target flame. Finally, the repeatability of the system was examined by repeating the measurement multiple times and assessing the spread of the results. It was found that for the case with the worst uncertainties, the measurements were repeatable within $7 \%$ at a $95 \%$ confidence interval.

The aforementioned results demonstrate that the developed measurement system is ready to be implemented in subsequent experiments. The large scale of the apparatus provides an exploitable avenue into understanding the fundamental concepts of soot formation and residence times inside large turbulent flames. This will add to the very 
limited data available for modelling of soot formation within turbulent flames and will provide invaluable results which will be used to develop emissions models for flaring.

\subsection{Future Improvements}

Stemming directly from the presented results, this section considers potential enhancements to the measurement system and the predicted effect on the results.

\subsubsection{Varying the size of the measurement optics}

It is evident that the size of the measurement volume is the major hindrance when trying to achieve better spatial resolution. This was because in the analysis that was conducted above, when the size of pinhole aperture was decreased the noise to signal ratio significantly increased. However, if the measured signal could be better maximized, improved uncertainties could be obtained with a higher spatial resolution. One way of achieving this is to increase the size of the collection optics. By doing so, the solid angle of the collection optics would increase and result in more signal being captured. This would happen while the size of the measurement volume remained unaltered.

In the current setup the collection lenses had a diameter of $75 \mathrm{~mm}$ ( $3 \mathrm{in})$. Analysis of the size of the lens versus the solid angle that formed at the measurement volume shows that the solid angle increases with the square of the diameter of the collection lens. The intensity of the measured detector signal varies linearly with the solid angle of the collection optics (Crosland et al., 2011) and hence the captured signal increases with the square of the diameter of the collection optics. Quantitatively, this means that doubling the size of the collection optics will result in an increase in the signal to noise ratio by a factor of four, resulting in a notable decrease in the total uncertainties. 
In practice, based on the results presented in Section 5.3, uncertainties comparable to the results obtained for the $300 \mu \mathrm{m}$ pinhole should be achievable for the smaller measurement volumes by doubling the size of the collection optics while keeping the total magnification constant. This could be an important consideration when attempting to obtain finely resolved data inside turbulent flames while maintaining reasonable accuracies.

\subsubsection{Choice of wavelength}

The choice of wavelength used to run the experiment also provides an important design decision. Higher wavelengths are more favorable in the incandescence experiment as it minimizes the occurrence of florescence (Snelling et al., 2011). However, the scattering signal at the higher wavelengths is weaker and hence, a smaller wavelength would be desirable for the scattering experiment. This provides a design decision as the choice of wavelength would affect the signal strength and by association the measurement uncertainties. In addition to this, the use of shorter wavelengths for scattering would decrease the measureable range of particle diameters. The current setup allows for measuring aggregates with radii of gyration up to $300 \mathrm{~nm}$ while the use of a $532 \mathrm{~nm}$ laser would only allow for measurements of up to $200 \mathrm{~nm}$ (Crosland, Thomson, et al., 2013). This shows that within the scattering experiment there exists a tradeoff of signal strength versus detectable range based on the choice of wavelength.

In the presented experiment, the same $1064 \mathrm{~nm}$ laser was used for both the scattering and the LII experiment. This allowed for maintaining the same measurement volume across both measurements which is an important criterion for making 
simultaneous measurements. However, based on this discussion, it can be seen that the choice of a smaller wavelength might result in a reduction of uncertainties for the scattering measurements of $R_{g m l}$ and $d_{p}$ while decreasing the detection range of the particles. Within the limits noted here, this might provide an exploitable method of reducing uncertainties on the scattering measurements. 


\section{References}

Arana, C., Pontoni, M., Sen, S., and Puri, I., (2004). Field measurements of soot volume fractions in laminar partially premixed coflow ethylene/air flames. Combust. Flame. 138:362-372.

Bladh, H., Johnsson, J., Olofsson, N.E., Bohlin, A., and Bengtsson, P.E., (2011). Optical soot characterization using two-color laser-induced incandescence (2C-LII) in the soot growth region of a premixed flat flame. Proc. Combust. Inst.. 33:641-648.

Bond, T.C. and Bergstrom, R.W., (2006). Light Absorption by Carbonaceous Particles: An Investigative Review. Aerosol Sci. Technol.. 40:27-67.

Bond, T.C., Doherty, S.J., Fahey, D.W., Forster, P.M., Berntsen, T., DeAngelo, B.J., Flanner, M.G., Ghan, S., Kärcher, B., Koch, D., et al., (2013). Bounding the role of black carbon in the climate system: A scientific assessment. J. Geophys. Res. Atmos.. 118:5380-5552.

Bond, T.C., Habib, G., and Bergstrom, R.W., (2006). Limitations in the enhancement of visible light absorption due to mixing state. J. Geophys. Res.. 111:D20211.

Cenker, E., Bruneaux, G., Dreier, T., and Schulz, C., (2014). Sensitivity analysis for incylinder soot-particle size imaging with laser-induced incandescence. Appl. Phys. B. (submitted:745-763.

Charwath, M., Suntz, R., and Bockhorn, H., (2011). Constraints of two-colour TiRe-LII at elevated pressures. Appl. Phys. B. 104:427-438.

Coderre, A.R., Thomson, K.A., Snelling, D.R., and Johnson, M.R., (2011). SpectrallyResolved Light Absorption Properties of Cooled Soot from a Methane Flame. Appl. Phys. B. 104:175-188.

Conrad, B.M. and Johnson, M.R., (2017). Field Measurements of Black Carbon Yields from Gas Flaring. Environ. Sci. Technol. in press.

Coppalle, A. and Joyeux, D., (1994). An optical technique for measuring mean and fluctuating values of particle concentrations in round jets. Exp. Fluids. 16:285-288.

Crosland, B.M., Johnson, M.R., and Thomson, K.A., (2011). Analysis of uncertainties in instantaneous soot volume fraction measurements using two-dimensional, autocompensating, laser-induced incandescence (2D-AC-LII). Appl. Phys. B. 102:173183.

Crosland, B.M., Johnson, M.R., and Thomson, K.A., (2013). Diffuse Surface Calibration Method to Improve Accuracy and Dynamic Range of Aerosol Elastic Light Scattering Measurements. Appl. Phys. B. 110:315-320. 
Crosland, B.M., Thomson, K.A., and Johnson, M.R., (2013). Instantaneous in-flame measurement of soot volume fraction, primary particle diameter, and aggregate radius of gyration via auto-compensating laser-induced incandescence and twoangle elastic light scattering. Appl. Phys. B. 112:381-393.

Crosland, B.M., Thomson, K.A., and Johnson, M.R., (2015). Simultaneous instantaneous measurements of soot volume fraction, primary particle diameter, and aggregate size in turbulent buoyant diffusion flames. Proc. Combust. Inst. . 35:1851-1859.

Dasch, C.J., (1992). One-dimensional tomography: a comparison of Abel, onion-peeling, and filtered backprojection methods. Appl. Opt.. 31:1146-1152.

De Iuliis, S., Cignoli, F., Benecchi, S., and Zizak, G., (1998). Determination of soot parameters by a two-angle scattering-extinction technique in an ethylene diffusion flame. Appl. Opt.. 37:7865-74.

Dobbins, R.A. and Megaridis, C.M., (1991). Absorption and scattering of light by polydisperse aggregates. Appl. Opt.. 30:4747-4754.

Dobbins, R.A., Mulholland, G.W., and Bryner, N.P., (1994). Comparison of a fractal smoke optics model with light extinction measurements. Atmos. Environ.. 28:889897.

Eklund, A.G., Chow, J.C., Greenbaum, D.S., Hidy, G.M., Kleinman, M.T., Watson, J.G., and Wyzga, R.E., (2014). Public health and components of particulate matter: The changing assessment of black carbon. J. Air Waste Manage. Assoc.. 64:1221-1231.

Elvidge, C.D., Ziskin, D., Baugh, K.E., Tuttle, B.T., Ghosh, T., Pack, D.W., Erwin, E.H., and Zhizhin, M., (2009). A Fifteen Year Record of Global Natural Gas Flaring Derived from Satellite Data. Energies. 2:595-622.

Erik, N., Johan, O., Sandra, S., Bladh, H., and Erik, P., (2015). Evolution of properties for aging soot in premixed flat flames studied by laser - induced incandescence and elastic light scattering. Appl. Phys. B. 669-683.

Grahame, T.J., Klemm, R., and Schlesinger, R.B., (2014). Public health and components of particulate matter: The changing assessment of black carbon. J. Air Waste Manage. Assoc. . 64:620-660.

Greenberg, P.S. and Ku, J.C., (1997). Soot volume fraction imaging. Appl. Opt.. 36:5514-5522.

Gülder, Ö.L. and Snelling, D.R., (1993). Influence of nitrogen dilution and flame temperature on soot formation in diffusion flames. Combust. Flame. 92:115-124.

Hadef, R., Geigle, K.P., Zerbs, J., Sawchuk, R. a., and Snelling, D.R., (2013). The concept of 2D gated imaging for particle sizing in a laminar diffusion flame. Appl. Phys. B. 112:395-408.

Hu, B., Yang, K., and Köylü, Ü.Ö., (2003). Soot measurements at the axis of an 
ethylene/air non-premixed turbulent jet flame. Combust. Flame. 134:93-106.

Huber, F.J.T., Altenhoff, M., and Will, S., (2016). A mobile system for a comprehensive online-characterization of nanoparticle aggregates based on wide-angle light scattering and laser-induced incandescence. Rev. Sci. Instrum.. 87:53102.

Jacobson, M.Z., (2010). Short-term effects of controlling fossil-fuel soot, biofuel soot and gases, and methane on climate, Arctic ice, and air pollution health. J. Geophys. Res. . 115:1-24.

Johnsson, J., Bladh, H., Olofsson, N.-E., and Bengtsson, P.-E., (2013). Influence of soot aggregate structure on particle sizing using laser-induced incandescence: importance of bridging between primary particles. Appl. Phys. B. 112:321-332.

Julien, R. and Botet, R., (1987). Aggregation and Fractal Aggregates. World Scientific.

Kempema, N.J. and Long, M.B., (2016). Combined optical and TEM investigations for a detailed characterization of soot aggregate properties in a laminar coflow diffusion flame. Combust. Flame. 164:373-385.

Köhler, M., Boxx, I., Geigle, K.P., and Meier, W., (2011). Simultaneous planar measurements of soot structure and velocity fields in a turbulent lifted jet flame at 3 kHz. Appl. Phys. B. 103:271-279.

Köhler, M., Geigle, K.-P., Meier, W., Crosland, B.M., Thomson, K.A., and Smallwood, G.J., (2011). Sooting turbulent jet flame: characterization and quantitative soot measurements. Appl. Phys. B. 104:409-425.

Köylü, Ü.Ö. and Faeth, G.M., (1996). Spectral extinction coefficients of soot aggregates from turbulent diffusion flames. J. Heat Transfer. 118:415-421.

Köylü, Ü.Ö., Faeth, G.M., Farias, T.L., and Carvalho, M.G., (1995). Fractal and projected structure properties of soot aggregates. Combust. Flame. 100:621-633.

Köylü, Ü.Ö., Xing, Y., and Rosner, D.E., (1995). Fractal Morphology Analysis of Combustion-Generated Aggregates Using Angular Light Scattering and Electron Microscope Images. Langmuir. 11:4848-4854.

Krishnan, S.S., Lin, K.-C., and Faeth, G.M., (2000). Optical Properties in the Visible of Overfire Soot in Large Buoyant Turbulent Diffusion Flames. J. Heat Transfer. 122:517-524.

Lee, S.-Y., Turns, S.R., and Santoro, R.J., (2009). Measurements of soot, OH, and PAH concentrations in turbulent ethylene/air jet flames. Combust. Flame. 156:2264-2275.

Leschowski, M., Thomson, K.A., Snelling, D.R., Schulz, C., and Smallwood, G.J., (2015). Combination of LII and extinction measurements for determination of soot volume fraction and estimation of soot maturity in non-premixed laminar flames. Appl. Phys. B Lasers Opt.. 119:685-696. 
Lin, M.Y., Lindsay, H.M., Weitz, D.A., Klein, R., Ball, R.C., and Meakin, P., (1990). Universal diffusion-limited colloid aggregation. J. Phys. Condens. Matter. 2:30933113 .

Link, O., Snelling, D.R., Thomson, K.A., and Smallwood, G.J., (2011). Development of absolute intensity multi-angle light scattering for the determination of polydisperse soot aggregate properties. Proc. Combust. Inst. 33:847-854.

Liu, F. and Snelling, D.R., (2008). Evaluation of the Accuracy of the RDG Approximation for the Absorption and Scattering Properties of Fractal Aggregates of FlameGenerated Soot. In 40th Thermophysics Conference. Seattle, American Institute for Aeronautics and Astronautics, pp.1-13.

Ma, B. and Long, M.B., (2014). Combined soot optical characterization using 2-D multiangle light scattering and spectrally resolved line-of-sight attenuation and its implication on soot color-ratio pyrometry. Appl. Phys. B Lasers Opt.. 117:287-303.

Mahmoud, S.M., Nathan, G.J., Medwell, P.R., Dally, B.B., and Alwahabi, Z.T., (2015). Simultaneous planar measurements of temperature and soot volume fraction in a turbulent non-premixed jet flame. Proc. Combust. Inst. 35:1931-1938.

Martin, J.E. and Hurd, J.A., (1987). Scattering From Fractals. J. Appl. Crystallogr. . 20:61-78.

McEwen, J.D.N. and Johnson, M.R., (2012). Black Carbon Particulate Matter Emission Factors for Buoyancy Driven Associated Gas Flares. J. Air Waste Manage. Assoc. . 62:307-321.

Narayanan, P. and Trouvé, A., (2009). Radiation-driven flame weakening effects in sooting turbulent diffusion flames. Proc. Combust. Inst. 32:1481-1489.

Olofsson, N.-E., Johnsson, J., Bladh, H., and Bengtsson, P.-E., (2013). Soot sublimation studies in a premixed flat flame using laser-induced incandescence (LII) and elastic light scattering (ELS). Appl. Phys. B. 112:333-342.

Oltmann, H., Reimann, J., and Will, S., (2010). Wide-angle light scattering (WALS) for soot aggregate characterization. Combust. Flame. 157:516-522.

Oltmann, H., Reimann, J., and Will, S., (2012). Single-shot measurement of soot aggregate sizes by wide-angle light scattering (WALS). Appl. Phys. B Lasers Opt.. 106:171-183.

Qamar, N.H., (2009). Sooting Behaviour of Turbulent Non-Premixed Jet Flames. University of Adelaide.

Qamar, N.H., Alwahabi, Z.T., Chan, Q.N., Nathan, G.J., Roekaerts, D., and King, K.D., (2009). Soot volume fraction in a piloted turbulent jet non-premixed flame of natural gas. Combust. Flame. 156:1339-1347.

Quay, B., Lee, T.W., Ni, T., and Santoro, R.J., (1994). Spatially resolved measurements 
of soot volume fraction using laser-induced incandescence. Combust. Flame. 97:384-392.

Ramanathan, V. and Carmichael, G., (2008). Global and regional climate changes due to black carbon. Nat. Geosci.. 1:221-227.

Reimann, J., Kuhlmann, S.-A., and Will, S., (2009). 2D aggregate sizing by combining laser-induced incandescence (LII) and elastic light scattering (ELS). Appl. Phys. B. 96:583-592.

Santoro, R. and Miller, J., (1987). Soot Particle Formation in Laminar Diffusion Flames. Langmuir. 3:244-254.

Schnaiter, M., Horvath, H., Mohler, O., Naumann, K., Saathoff, H., and Schock, O., (2003). UV-VIS-NIR spectral optical properties of soot and soot-containing aerosols. J. Aerosol Sci.. 34:1421-1444.

Snelling, D.R., Link, O., Thomson, K.A., and Smallwood, G.J., (2011). Measurement of soot morphology by integrated LII and elastic light scattering. Appl. Phys. B. 104:385-397.

Snelling, D.R., Liu, F., Smallwood, G.J., and Gülder, Ö.L., (2004). Determination of the soot absorption function and thermal accommodation coefficient using low-fluence LII in a laminar coflow ethylene diffusion flame. Combust. Flame. 136:180-190.

Snelling, D.R., Smallwood, G.J., Liu, F., Gülder, Ö.L., and Bachalo, W.D., (2005). A calibration-independent laser-induced incandescence technique for soot measurement by detecting absolute light intensity. Appl. Opt.. 44:6773-6785.

Snelling, D.R., Thomson, K.A., Smallwood, G.J., and Gülder, Ö.L., (1999). Twodimensional imaging of soot volume fraction in laminar diffusion flames. Appl. Opt. . 38:2478-2485.

Sorensen, C.M., (2001). Light Scattering by Fractal Aggregates: A Review. Aerosol Sci. Technol.. 35:648-687.

Sorensen, C.M., (2011). The Mobility of Fractal Aggregates: A Review. Aerosol Sci. Technol.. 45:765-779.

Sorensen, C.M., Cai, J., and Lu, N., (1992). Light-scattering measurements of monomer size, monomers per aggregate, and fractal dimension for soot aggregates in flames. Appl. Opt. 31:6547-6557.

Sorensen, C.M., Lu, N., and Cai, J., (1995). Fractal Cluster Size Distribution Measurement Using Static Light Scattering. J. Colloid Interface Sci.. 174:456-460.

Stohl, A., Klimont, Z., Eckhardt, S., Kupiainen, K., Shevchenko, V.P., Kopeikin, V.M., and Novigatsky, A.N., (2013). Black carbon in the Arctic: the underestimated role of gas flaring and residential combustion emissions. Atmos. Chem. Phys.. 13:88338855 . 
Teng, Y. and Köylü, Ü.Ö., (2006). Optical sizing of aggregated combustion particles: computational development of a two-angle laser scattering technique. Appl. Opt.. 45:4396-403.

Thomson, K.A., Johnson, M.R., Snelling, D.R., and Smallwood, G.J., (2008). Diffuselight two-dimensional line-of-sight attenuation for soot concentration measurements. Appl. Opt. 47:694-703.

Tian, K., Liu, F., Thomson, K., Snelling, D.R., Smallwood, G.J., and Wang, D., (2004). Distribution of the number of primary particles of soot aggregates in a nonpremixed laminar flame. Combust. Flame. 138:195-198.

U.S. EPA, (2010). Integrated Science Assessment for Particulate Matter. EPA/600/R08/139F, Research Triangle Park, NC, National Center for Environmental Assessmement-RTP Division, U.S. Environmental Protection Agency.

U.S. EPA, (2012). Report to Congress on Black Carbon. EPA-450/R-12-001, Research Triangle Park, NC, United States Environmental Protection Agency (U.S. EPA).

Xin, Y. and Gore, J.P., (2005). Two-dimensional soot distributions in buoyant turbulent fires. Proc. Combust. Inst. 30:719-726.

Yang, B. and Köylü, Ü.Ö., (2005a). Detailed soot field in a turbulent non-premixed ethylene/air flame from laser scattering and extinction experiments. Combust. Flame. 141:55-65.

Yang, B. and Köylü, Ü.Ö., (2005b). Soot processes in a strongly radiating turbulent flame from laser scattering/extinction experiments. J. Quant. Spectrosc. Radiat. Transf.. 93:289-299.

Yon, J., Lemaire, R., Therssen, E., Desgroux, P., Coppalle, A., and Ren, K.F., (2011). Examination of wavelength dependent soot optical properties of diesel and diesel/rapeseed methyl ester mixture by extinction spectra analysis and LII measurements. Appl. Phys. B. 104:253-271. 


\section{Appendix A: INVAR Hoop Details}

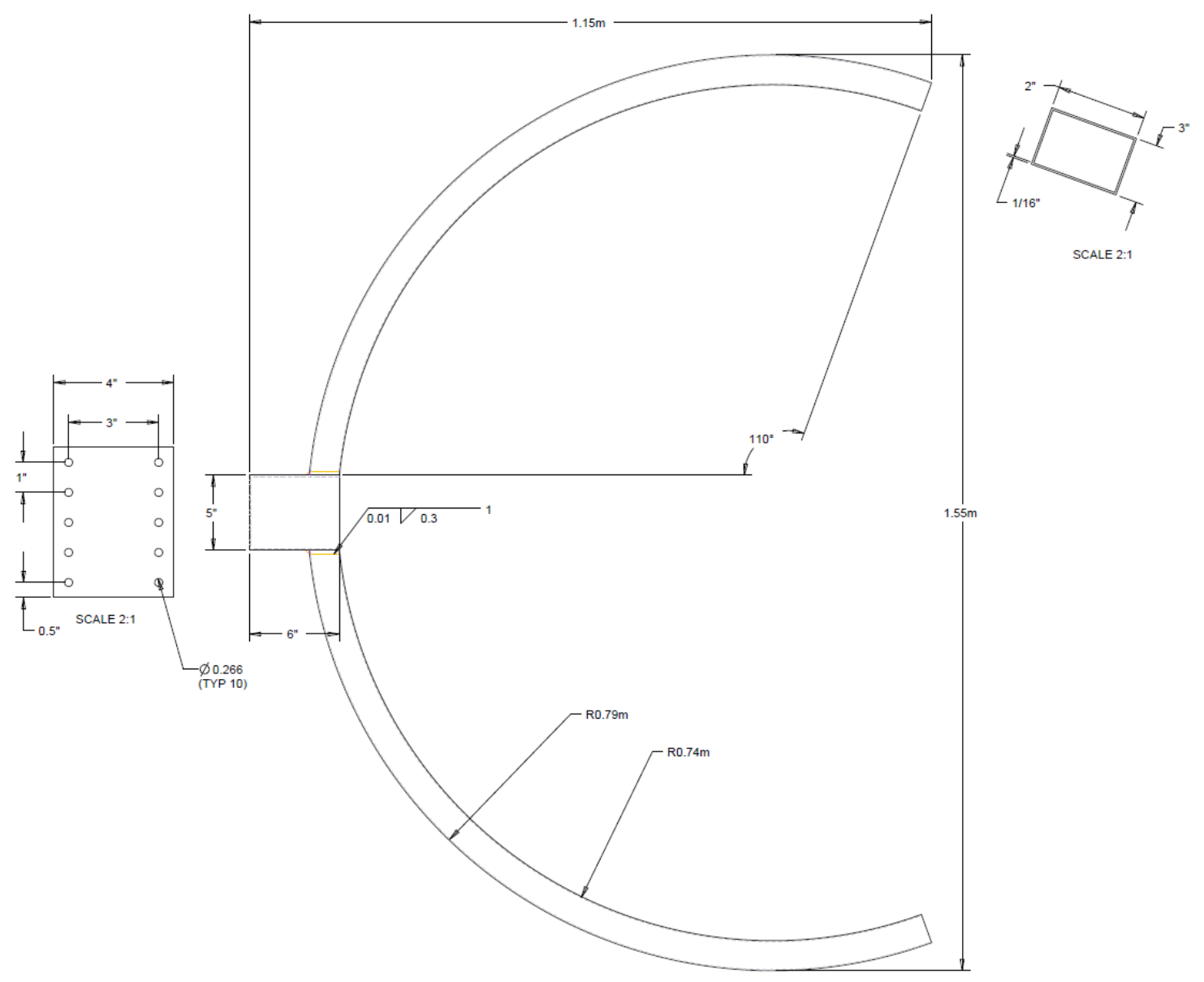

Figure A.1: INVAR hoop engineering drawing 